Portland State University

PDXScholar

$1-1-1981$

\title{
An analysis of environmental, social and personal dimensions and their relationship to psychological well-being in late life
}

Renee Tissue

Portland State University

Follow this and additional works at: https://pdxscholar.library.pdx.edu/open_access_etds Let us know how access to this document benefits you.

\section{Recommended Citation}

Tissue, Renee, "An analysis of environmental, social and personal dimensions and their relationship to psychological well-being in late life" (1981). Dissertations and Theses. Paper 876.

https://doi.org/10.15760/etd.876

This Dissertation is brought to you for free and open access. It has been accepted for inclusion in Dissertations and Theses by an authorized administrator of PDXScholar. Please contact us if we can make this document more accessible: pdxscholar@pdx.edu. 
AN ANALYSIS OF ENVIRONMENTAL, SOCIAL AND PERSONAL DIMENSIONS AND THEIR RELATIONSHIP TO PSYCHOLOGICAL WELL-BEIING

IN I.ATE LIFE

by

RENEE TISSUE

A dissertation submitted in partial fulfillment of the requirements for the degree of

\section{DOCTOR OF PHILOSOPHY}

in

URBAN STUDIES

Portland State University

1981 
TO THE OFFICE OF GRADUATE STUDIES AND RESEARCY:

The members of the Committee approve the dissertation of Renee Tissue presented April 6, 1981.
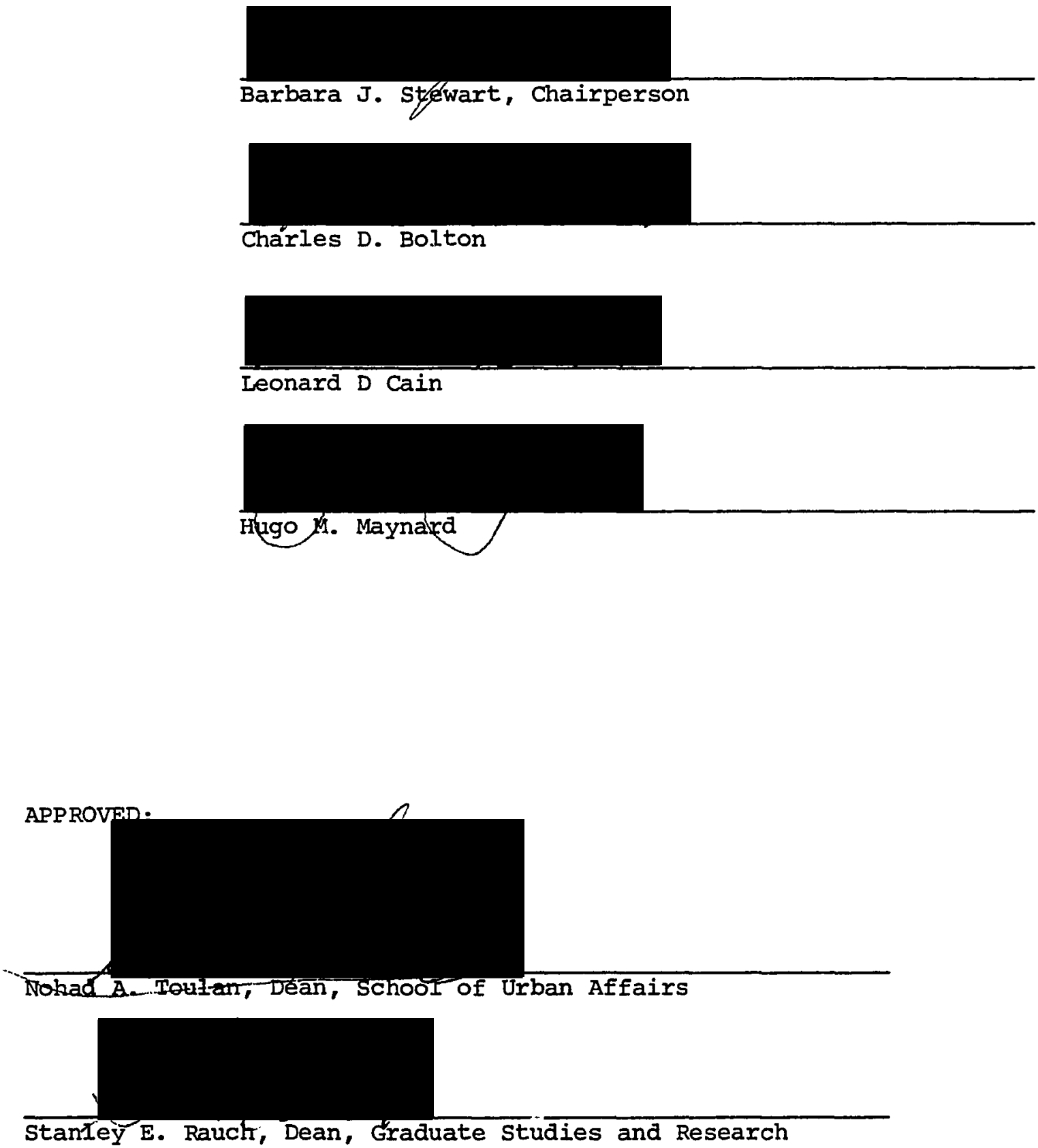
AN ABSTRACT OF THE DISSERTATION OF Renee Alexander Tissue for the Doctor of Philosophy in Urban Studies presented April 6, 1981.

Title: An Analysis of Environmental, Social and Personal Dimensions and Their Relationship to Psychological Well-Being in Late Life. APPROVED BY MEMBERS OF THE DISSERTATION COMMITTEE:
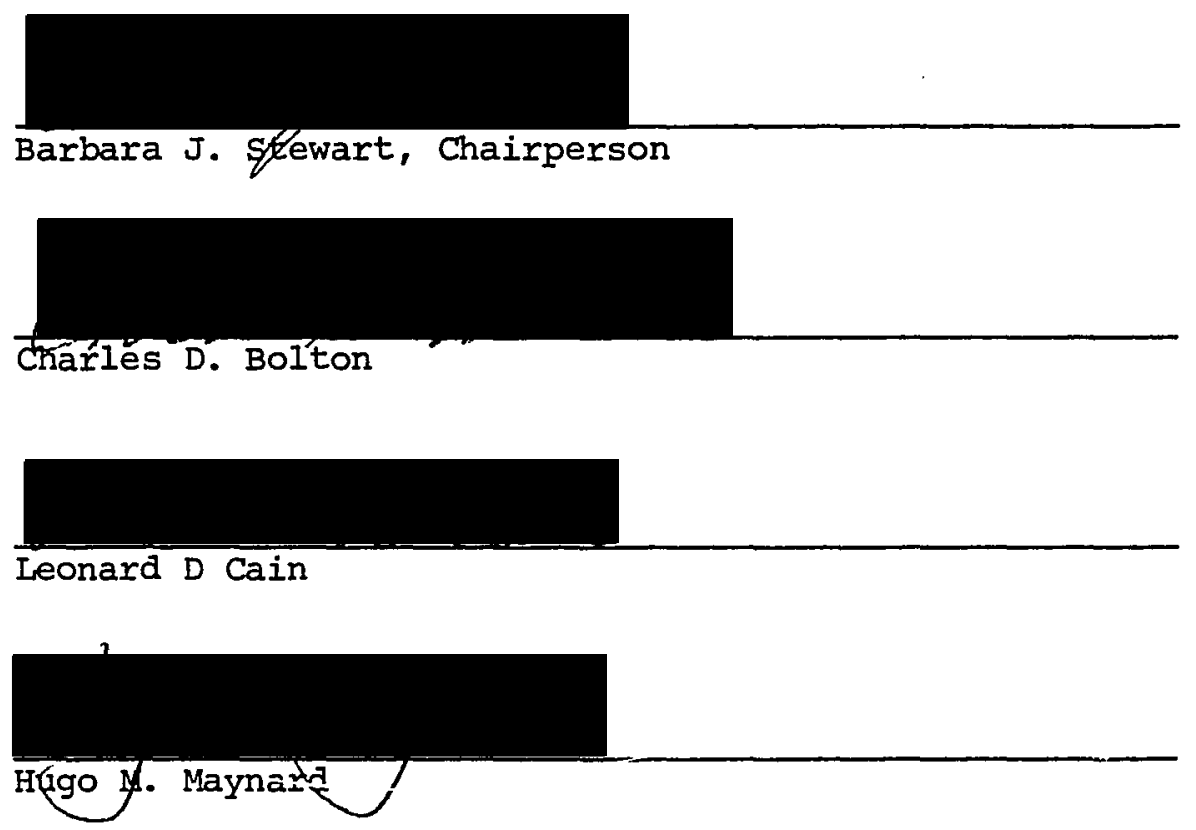

This dissertation focused on the relationship between psychological well-being and life situations of older persons. Specifically, this study examined whether life situations were different for persons whose Life Satisfaction Index scores changed over a two-year period compared to those whose scores were stable.

The sample included 215 older persons living in reduced circumstances. These persons were interviewed on three occasions separated 
by one-year intervals. Pearson correlations, analysis of variance, and multiple regression procedures were employed to test five hypotheses. Fourteen case studies were selected to illustrate statistical findings. When the dissertation data were analyzed for each occasion separately, findings from this study regarding correlates of psychological well-being were similar to findings from past studies. However, a different pattern of results emerged from the longitudinal analyses. For the group of persons having stable life satisfaction scores across occasions, life satisfaction was not significantly correlated with health, lack of impairment, or activities. In contrast, change in psychological well-being was significantly related to changes in these life situations. Practical and theoretical implication of the findings as well as directions for future research are discussed. 


\section{ACKNOWLEDGMENTS}

My sincere thanks to the following people for their support and direction in my professional and personal life: Dr. Barbara Stewart, Dr. Leonard Cain, Dr. Charles Bolton, Dr. Hugo Maynard, Marie BeaudetWalters, Gerald Winn, Kenneth, Kevin, Jene, Jerry and Sean Giles, and Thomas Tissue. 
TABLE OF CONTENTS

\section{PAGE}

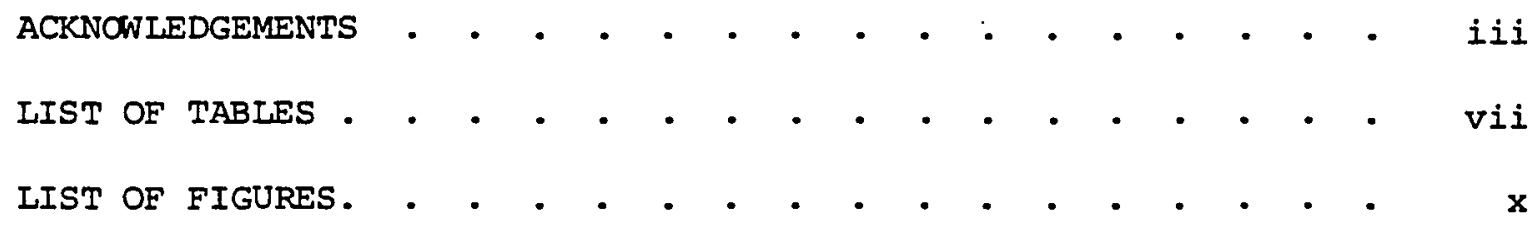

CHAPTER

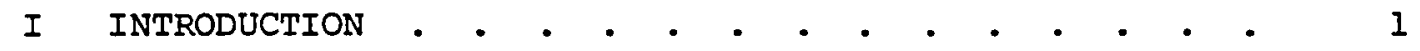

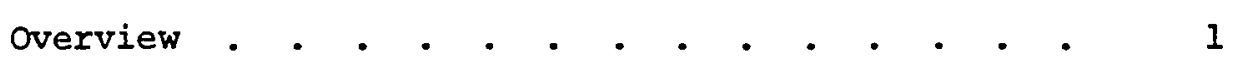

Identification of the Research Problem . . . . 2

Theoretical Issues • • • • • • • • • • • 7

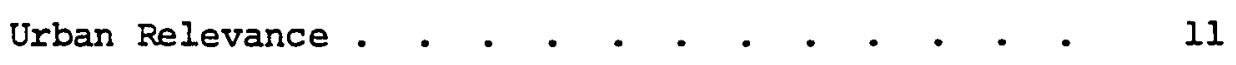

II REVIEW AND CRITIQUE OF THE IITERATURE • • • • • • • • $\quad 15$

Psychological Well-Being • • • • • . • • • 15

The Life Satisfaction Index . • • . . . . . 21

Stability of Psychological Well-Being. . . . . 25

Correlates of Psychological Well-Being . . . . 27

Health. • • • • . • • • • • • • 27

Socioeconomic Status . • . . . . . . . 29

Activity Patterns and Social Interaction . . 30

Housing and Transportation . . - . . - . 32

Other Variables. . • • . . • • . • . 33

Summary and Interpretation - . - . . - . . 34

II HYPOTHESES • 
The Study Population . . . . . . . . . 46

SSI Sample Selection . . . . . . . . . 47

Sample Selection for the Dissertation Research. 51

Dependent and Independent Variables. . . . . . 53

Methodological Issues in Scale Construction . . . 54

Formation of Iife Satisfaction Groups . • . • . 56

Stable IS Groups. . . . . . . . . . . 63

Change IS Groups. . . . . . . . . . 64

Formation of Iife Satisfaction Groups . . . . . 66

Well-Being Indicators at Time 1. . . . . . 68

Well-Being Indicators at Time 2. . . . . . 70

Well-Being Indicators at Time 3. . . . . . 71

Measures of Time 1 to Time 3 Change on the

Well-Being Indicators. . . . . . . . 73

Reliability, stability, and Validity

Measures of Well-Being Indicators. . . . 73

Statistical Methods • . . . . . . . . . 79

Frequency Distributions . • . • . • . 79

Scale Building . . . . . . . . . . . 79

Internal Consistency Reliability . . . . . 80

Pearson Correlations . . . . . . . . 80

Multiple Regression . . . . . . . . . 80

Analysis of Variance . . . . . . . . . 81

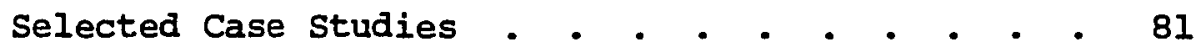




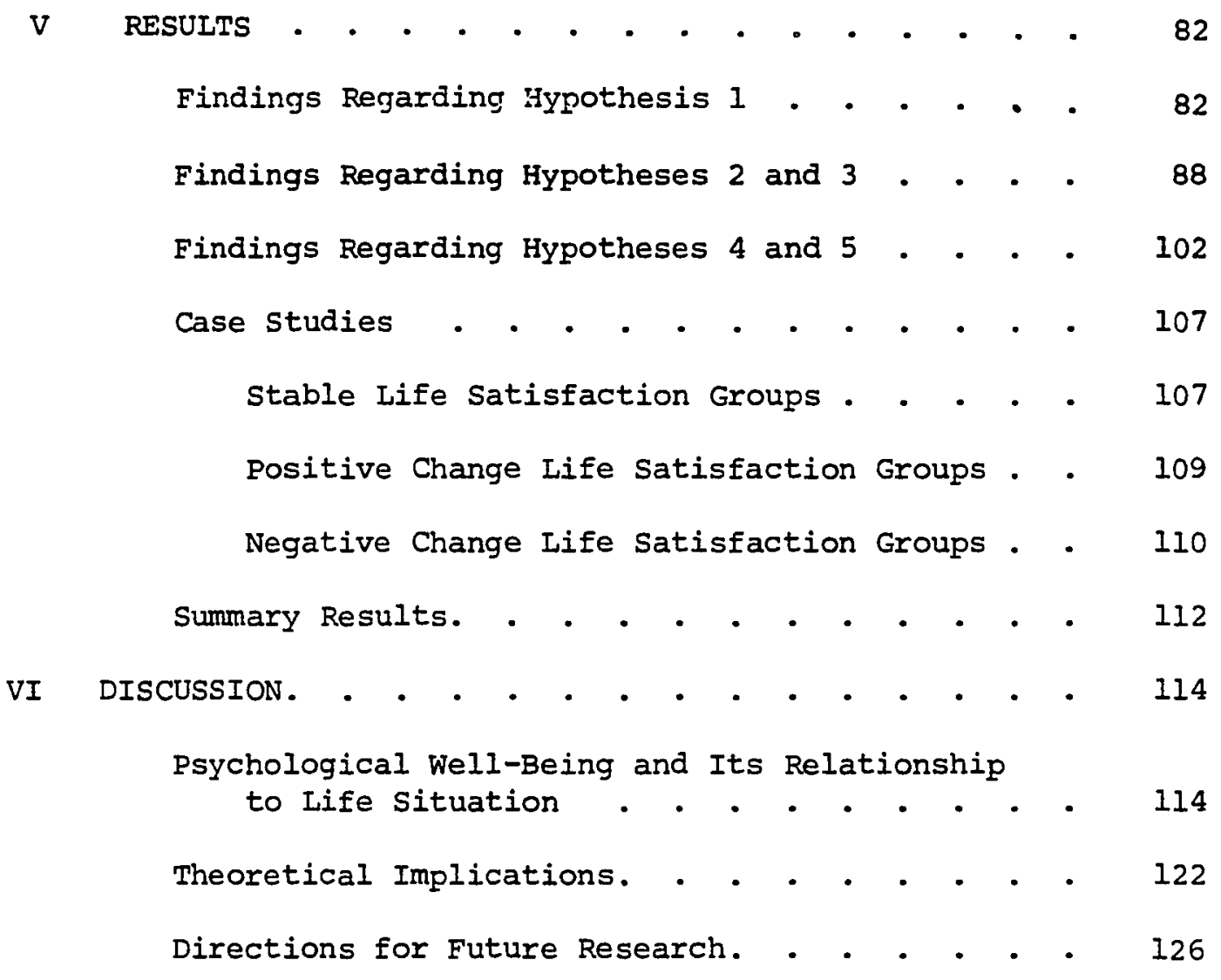

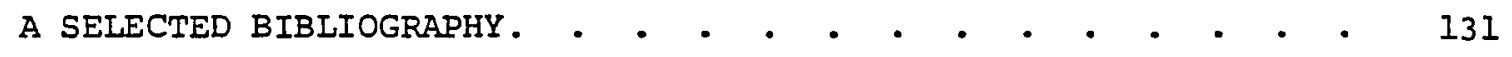

APPENDICES

A LIFE SATISFACTION INSTRUMENT. • • • • • • • • 144

B A COMPARISON OF MEANS ON INDICATORS OF WELL-BEING FOR SEVEN LIFE SATISFACTION GROUPS . • • • • I

C RELIABILITY, STABILITY, AND VALIDITY OF THE WBIS

AT TIMES 1, 2, AND 3 • • • • • • • • • • • 151

D CASE Studies • • • • • • • • • • • • • • 155 
I Measures of Subjective Well-Being of older Persons . . . . . . . . . . . . . . .

II The Modified Iife Satisfaction Index . . . . . .

III Summary Table of Correlations of Major Life

Situation Variables with Subjective Well-Being

for the Population of Americans over 60 . . .

IV Personal, Social and Environmental Well-Being

Indicators Describing the Life situations of

the Elderly . . . . . . . . . . . . . .

V Sampling Stratification Definition . . . . . . . .

VI Characteristics of Population Aged 65 and over

for the United states, Multnomah County, the

Study Population and the SSI Study Sample . . . 50

VII Median Income for Single and Two Person Units . • • 52

VIII Factor Analysis of the Life Satisfaction Index

Administered at Time 3 . . . . . . . . . 59

IX Life Satisfaction Group Formation and Sumary.

Statistics on the ISI at Time 1 and Time 3 ...

$\mathrm{X}$ Correlations Between WBIs and ISI Scores and 
XI Correlations Between WEI and LSI Scores Using Total, Stable and Change LS Groups ............

XII Number of Significant Correlations by Total, Stable, and Change ISI Scores . . . . . . . . . .

XIII Multiple Linear Regression Analyses for Predicting

Time 3 LSI from Time 1 LSI and WBIs

At Times 1, 2, and 3............. 90

XIV Comparison of Means for Stable-High and Stable-Iow

IS Groups on Eight Indicators of Well-Being . . . . 96

XV Comparison of Means for Positive and Negative Change

LS Groups on Eight Indicators of Well-Being . ...

XVI Comparison of Means Within the Positive and Negative

Change LS Groups on Eight Indicators of Well-Being. 100

XVII Comparison of Means for Stable and Change LS Groups on

Eight Indicators of Well-Being . . . . . . . 101

XVIII Multiple Linear Regression Analyses for Preáicting

Time 1 to Time 3 Change in LSI from Time 1 to

Time 3 Change in WBIs ............. 103

XIX Comparison of Means on Stable and Change ISI Groups

Using WBI Residualized Change Scores. . . . . . 104

XX The Form of the Modified Life Satisfaction Index Used

in the SSI Study and for This Dissertation.....

XXI A Comparison of Means on Time 1 Indicators of Well-Being for Seven Life Satisfaction Groups . . . . . . 147

XXII A Comparison of Means on Time 2 Indicators of Well-Being for Seven Life Satisfaction Groups . . . . . . 
XXIII A Comparison of Means on Time 3 Indicators of Well-Being for Seven Life Satisfaction Groups . . . . . . . 149

XXIV A Comparison of Means on Indicators of Well-Being Using Residualized Change Scores for Seven Life Satisfaction Groups . . . . . . . . . 150

XXV Internal Consistency Reliability (Coefficient Alpha)

for the Eight WBIs ............. . . 152

XXVI Stability Coefficients for the Eight well-Being

Indicators Across Time 1, Time 2, and Time $3 . .$.

XXVII Intercorrelation Matrix for Eight Well-Being Indicators for Time 1, Time 2, and Time $3 . . . . . . .$. 


\section{LIST OF FIGURES}

FIGURE

PAGE

1. Illustration of overall Sampling Plan and Interview Attrition . . . . . . . . . . . .

2. A Comparison of the IS Group Means on the Eight Time 1 Well-being Indicators . . . . . . . . . . .

3. A Comparison of the IS Group Means on the Eight Time 2 Well-Being Indicators . . . . . . . . . .

4. A Comparison of the IS Group Means on the Eight Time 3 Well-Being Indicators . . . . . . . . . .

5. A Comparison of the LS Group Means on Eight Residualized Change Measures . . . . . . . . . . . . 
CHAPTER I

INTRODUCTION

Overview

Psychological well-being during old age has long been a central research interest of social gerontologists both from a theoretical and methodological viewpoint. The purpose of this dissertation is to examine the theoretical construct of psychological well-being with special emphasis on the problem of its meaning over time. Specifically, psychological well-being is examined to determine in what ways it is stable, in what ways it changes, and in what ways the construct might be related to changes in the life situations of the elderly. The general framework of the dissertation is multidisciplinary in its approach, the disciplinary perspectives coming predominantly from psychology and sociology. It is well recognized that the adjustments to old age involve accommodating to changes in almost every life situation. Role loss from retirement and widowhood, reduced incomes, increased health problems - all bring about changes in the life situations of the elderly. Understanding these changes requires a cumulative body of knowledge from various disciplines which include economics, health, and demography in addition to psychology and sociology.

Current demographic data offer clear evidence of the increased numbers of older persons in urban areas. Size, density and distribution of the elderly, both now and by future projections, 
indicate that cities and their surrounding urban areas will be the places where large numbers of older people will reside. The quality of life of this aging population will be determined in part by the cities in which they live.

In conclusion, the problem with which this dissertation is concerned is the meaning of psychological well-being over time. Examination of this problem requires a multidisciplinary perspective and consideration of the urban environment in which the older population of interest lives. Following is a description of how the research problem was identified.

\section{Identification of the Research Problem}

The initial promptings for this study resulted from several observations by the author during her work on a larger longitudinal research project. ${ }^{1}$ The dissertation sample was selected from this larger project. The first observation concerned the ability of the dissertation sample members to maintain themselves under marginal circumstances. The second observation clearly showed that life changes were occuring for certain members of the longitudinal sample while other sample members were remaining relatively stable over time. An examination of relevant literature followed as well as further prelimimary data analysis. These efforts resulted in the identification of the research problem for this dissertation. Following is an elaboration of these observations.

First, the respondents in the dissertation sample are persons for

$1_{\text {The author was the project manager for a longitudinal research }}$ project, "Impact Research on Supplemental Security Income" funded by the Social security Administration. (SSA-PMB-74-275). 
whom psychological well-being, its stability and its relationship to life situations, are of particular interest and concern. They were selected for the study because they were older, poorer, and more debilitated than the total United States population of older adults. They represent the types of persons who are targets for national and local intervention programs, who are residents of middle sized cities, and who are considered to be at high risk of institutionalization (Federal Council on Aging, 1978). Persons in this high risk group are frequently socially isolated and in need of a number of supportive services if they are to remain in their own homes.

one question repeatedly arose regarding the sample. Given their reduced circumstances, how did these persons continue to maintain themselves, coping with their marginal physical, social and environmental circumstances and what was the effect of their reduced circumstances on psychological well-being? The intuitive conclusion was that, in the aggregate, these older persons must be able to draw upon a number of environmental, personal and social resources to assist them in their daily survival.

Aside from their marginal circumstances, they share, with other members of the older population, certain similarities. Born near the turn of the century, these people have experienced cultural, economic and technological change. They have progressed, with the country as a whole, from a predominantly rural background to one that is urban. They have grown old in a youth oriented society and many are poor in a culture where yearly inflation rates have placed extreme burdens on persons living on fixed incomes.

With rising inflation and comparatively low incomes, the elderly 
are forced to spend greater portions of their incomes on shelter, food and utilities with little or nothing remaining for clothing, transportation, socializing or participation in social diversion. Access to the amenities that many people in the United States take for granted is frequently out of reach for the low and middle income old, the bulk of their financing going to provide for only the most basic needs.

In addition to income constraints, the old are frequently pictured as experiencing decline in social roles and control that comes with adult status. They no longer control the rewards of their society and power is given over to those who are younger (Atchley, 1977; Rosow, 1963). Loss of spouse, retirement from the work force, increasing health problems, all make it necessary to confront a decreasing ability to remain independent. It seems very likely that these changing life situations would have a measurable impact upon psychological well-being. At the same time, one's psychological well-being may affect how one responds to these life situations.

The second observation leading to identification of the research problem was based on an examination of data from selected personal interviews for the sample. These personal interviews revealed that marked changes occurred in life situations for some persons while for others there was considerable stability. The interviews took place in the homes of these people during the summers of 1975, 1976 and 1977. It was apparent from the data that a number of people interviewed expressed a change in psychological well-being as well as changes in living arrangements, health, mobility, in other words in many of their Iife situations. These changes were not always in a negative direction. As a result of the above observations, the theoretical and 
research literature was examined with respect to overall well-being of the elderly and with special emphasis on those elderly living in marginal circumstances. Gerontological literature has consistently pointed to the lack of longitudinal measures assessing the overall well-being of the elderly, both their psychological well-being and well-being in other areas of their lives, as well as lack of data on the marginally subsisting elderly. It was concluded that the available data held information permitting longitudinal assessment of psychological well-being which could be related to life situations measured at three points in time. Furthermore these data were gathered from a population of older persons previously uninvestigated. The data would provide assessment of a holistic nature not done in previous research.

The literature has consistently advanced the notion of the stability of psychological well-being and yet the empirical investigation of this position has seldom been attempted. Several problems are inherent in the assumption that psychological well-being is stable over time. First, psychological well-being is frequently used as a criterion measure, in studies of the elderly, to determine what aspects of their lives are satisfactory for them. The use of this construct as a criterion or outcome measure assumes that it is something that follows as a result or consequence of other events; that is, it may change as a result of the manipulation of other events. Much of the theoretical work has focused upon psychological well-being conceptually as a stable characteristic. Yet the underlying assumption is that, as an outcome measure, it is in fact not stable, but rather, subject to change with manipulation of life situation variables. An illustration 
of this is in the examination of the relationship between health and psychological well-being. A one-time measure of health correlated with a one-time measure of psychological well-being takes into account neither changes in health frequently occuring with advanced age, nor the possibility that psychological well-being may vary with changes in health.

The problem of assuming that psychological well-being is stable is further illustrated by the preliminary review of personal interviews mentioned earlier. These case studies on some members of the sample indicated that certain changes in life situations were accompanied by changes in psychological well-being. An examination of data scatterplots taken from the first and last interviews also gave evidence of changes in psychological well-being. Further statistical investigation indicated that, indeed, for some of the sample there were measurable changes. For some of the sample, psychological well-being remained stable over time, some having low scores, some in the middle range, and some remaining high. However, for others in the sample, psychological well-being changed either in a positive or negative direction.

Correlational data offered further evidence for questioning the stability of psychological well-being. When the measure of psychological well-being was correlated for two interview times, the correlation coefficient was .50 . It could be said therefore that only approximately $25 \%$ of the variance in psychological well-being scores at the last interview could be accounted for by the variance in scores at the first interview. Seventy-five percent (75\%) of the variance remained unaccounted for. While it is true that some of the unaccounted for variance could be due to measurement error, it could 
also be due, in part, to real change.

Thus, the preceding observations led to the research problem which involved questioning the assumption of stability of the construct, psychological well-being. The theoretical emphasis of this dissertation is not to develop a new theory of aging, but rather to examine some of the assumptions of existing theories for clarification of concepts and testing of existing assumptions.

\section{Theoretical Issues}

Theoretical bases for the concept, psychological well-being, have attempted to expand upon activity and disengagement theories, placing emphasis upon social participation and activities. Other research has advanced the position that psychological well-being is an internal construct to be evaluated by the individual's own assessment of past or present life, satisfaction or happiness. Psychological well-being has been assumed to be stable over time; however, little research of a longitudinal nature has been done to test this assumption (George, 1978).

The examination of psychological well-being has largely been of a cross-sectional nature. These studies have typically focused on the single item correlates of psychological well-being, such as health, income, sex, marital status and the like. Changes in psychological well-being have seldom been measured nor have attempts been made to relate changing health conditions, reduced incomes or role status changes to changes in psychological well-being. The inattention to measures of change is remissible given the difficulties of longitudinal research in general which may become even more problematic when 
attempting to take time-change measures on elderly populations. However, since the elderly are experiencing changes in many areas of their lives, the benefits of longitudinal measures may far outweigh the disadvantages.

A number of approaches have been used to assess psychological well-being of older persons and to incorporate this construct into the cumulative knowledge that constitutes a comprehensive theory of aging. It is now widely acknowledge that the argument of disengagement versus activity theory is a specious one (George, 1978). Both perspectives have focused upon the relationship between activity levels and psychological well-being and viewed that relationship as the criterion for a theory of optimal aging.

Activity theory suggests that maintaining high activity levels is the basis for a continuing sense of well-being whereas disengagement theory postulates a mutual withdrawal of the individual and society. Both theoretical orientations use activity level as a predictor of optimal aging. Subsequent empirical evidence precluded the conclusion that this simple and straightforward relationship existed between activity levels and psychological well-being (Atchley, 1977; Back, 1976; Butler, 1975).

A third theoretical perspective, continuity theory, suggests that continued well-being is contingent upon maintaining a continuity of lifestyle (Maddox, 1968; Williams and Wirths, 1965).

Each of the aforementioned ways of viewing psychological wellbeing contains within it certain societal values that tend to preclude a high level of well-being on social participation, activity level or continuity of lifestyle is strongly biased against those who become 
chronically ill, are homebound and may have drastically reduced incomes. The implicit assumption in such a measure is that a positive affective response to well-being is limited only to those older persons who are able to maintain the positive characteristics of the middle years.

In view of the foregoing, subsequent measures have tended to define well-being as an internal construct with only secondary attention given to the level of social participation, activity and the like (Neugarten, Havighurst and Tobin, 1961). The variables measured using this approach have included the individual's evaluation of his present or past life, his satisfaction or happiness. The assumptions are that the individual is the proper judge of his or her well-being, that the value judgments of the investigator can thus be minimized, and that it is not appropriate to measure well-being in old age by the same standards that apply to middle age, namely, standards based upon activity or social involvement (Neugarten et al., 1961).

Initial attempts to measure psychological well-being used the construct as a unidimensional one. Further research confirmed its multidimensional nature which led to the development of a number of multidimensional scales which were given an assortment of names including contentment, adjustment to aging, morale and life satisfaction. Despite the complexity of the concept of well-being, continued effort has allowed considerable progress in isolating its components and there is little doubt that within these multiple measures there exists a shared core of something that can be considered well-being (Larson, 1978). Some interesting and 
significant questions remain virtually uninvestigated, however, and the gerontological literature consistently points to the need for research to resolve these questions.

One such pertinent question is related to the stability of psychological well-being which, in addition to being paired with levels of activity, has historically been looked upon as a stable characteristic (George, 1978). Theoretical perspectives must be able to account for individual stability in behavior over time in order to be usefully applied to the issue of psychological wellbeing (Hall and Lindzey, 1970). The assumption of stability has had very little empirical testing through longitudinal research. Individual differences in psychological well-being and its stability over time are salient issues, the exploration of which will contribute significantly to a more complete and comprehersive theory of aging.

From a psychological perspective, personality has been suggested as the major explanatory factor accounting for individual differences in psychological well-being and behavioral continuity over time (George, 1978). Mischel (1969) describes personality as a stable configuration of cognitive-emotional characteristics that operate to produce consistent behavioral outcomes. The implication is that psychological well-being, as a component of personality, is stable. Using an approach that is more sociological in nature, other theorists have suggested that individual differences in psychological well-being and individual stability in these behaviors primarily reflect the impact of social status variables. Most social status variables (sex, race, social class) are relatively enduring individual characteristics, providing a stable context for social interaction and 
fostering behavioral continuity (George, 1978). According to this approach, individual differences in behavior reflect individual differences in relevant social status factors. However, changes or shifts in these social status variables would be expected to generate changes in relevant behavioral outcomes such as psychological wellbeing.

For older persons, many social status variables are vulnerable to change as are other variables that are not necessarily related to social status. It follows from the above perspective that older persons experiencing altered social status will experience an accompanying change in psychological well-being which may be exacerbated by changes in health, restricted social interactions and decreased personal mobility. It might also be expected that, since psychological well-being may be part of a more stable personality trait, fluctuations in psychological well-being would be relatively small. These assumptions are virtually untested even though much of the literature substantiates the need for such empirical validation (George, 1978; Bell, 1975; Bull and Aucoin, 1975; Maddox, 1968).

\section{Urban Relevance}

There are three major points at issue when considering the urban relevance of this study. The first is a demographic one and depends largely on present and future migration trends. Elderly persons are most numerous in highly urban places (McCoy and Brown, 1978), even though the proportion of persons aged 65 and over is higher in less urbanized settings. In 1974, the highest proportion of elderly 
pèrsons (13 percent) was found in totally rural nonmetropolitan counties of standard metropolitan statistical areas (SMSA, Bureau of Census, 1974, 1970). Beale (1975) reported an increasing number of urban elderly migrating to rural areas; however the most recent Bureau of Census data available (1976) indicate that this trend does not exist and indeed, persons in both age groups 65 to 74 and 75 and over, are moving very little at all, with those who do move, doing so within their own residential areas. The transmigration (rural to suburb to city or vice versa) is almost nonexistent and the rates shown are small enough to be attributable to sampling error (Bureau of Census, 1976). This was also true for the period of 1970 to 1975 when the elderly were the least migratory of any age group in the total U.S. population (Public Policy and the Frail Elderly, Staff Report, 1978). Future migration trends are expected to remain constant for the elderly who will continue to remain significantly less migratory than the population as a whole. Consequently, as the United states population ages, greater numbers of older persons will continue to live in urban places including cities and their SMSAs (McCoy and Brown, 1978).

The second issue to be considered is federal policy regarding the aging. The Administration on Aging and the Federal Council on Aging, both have as part of their mandates, the goals of assisting the elderly to "pursue reasonably independent and satisfying lives in their own place of residence" and to facilitate the provision of "goods and services to assist older Americans to remain in the least restrictive setting" (Guidelines, Administration on Aging, 1978, 1979). Federal dollars go to furthering research efforts facilitating 
implementation of these goals.

With the increased life expectancies of older persons, longer retirements and relative geographic stability, cities and their surrounding metropolitan areas will be faced with the necessities of meeting the diverse needs of increased numbers of older persons and assisting them in maintaining an acceptable quality of life in a community setting.

Because many areas in the life situations of the aging are in a state of change, their needs for supplemental services also change both in numbers of services needed and extent to which the service is needed. Too often the old are placed in total care environments when it is neither necessary nor appropriate (Kistin and Morris, 1972). Careful assessment of the life situations of these persons will indicate where a particular service is needed to supplement and strengthen a situation that may be weakening or breaking down. Examples of such intervention would be providing supplemental income when the person can no longer afford to maintain a private residence, or providing homemaker service to a person who can no longer perform those tasks, or providing supplemental support to family support systems when needed, thus asssiting in keeping the elderly in as independent a situation as is possible.

The final issue to consider is the sample itself. A composite picture of the sample indicates that they were born at about the turn of the century, migrated to the Pacific Northwest and have lived most of their adult lives in the Portland area. City dwellers, for the most part, they express a desire to remain in their own homes and are satisfied with their neighborhoods ( $83 \%$ ) and their living 
arrangements (898). They have accommodated to growth and change in the city, technological expansion, and economic change. It is of real social gerontological interest to study this population now in the last quarter of their lives, to understand the ways in which they have been able to continue to draw upon resources within the city of both a formal and informal nature, to assist them to survive in what appear to be highly marginal circumstances. 
CHAPTER II

REVIEW AND CRITIQUE OF THE LITERATURE

Since 1949, with the pioneering study of Cavan, Burgess, Havighurst, and Goldhamer, the concept of psychological well-being among the elderly has inspired a considerable literature. There follows a critical review of that literature, including such closely related concepts as life satisfaction and morale, as well as a review of the variables which have been found to correlate with psychological well-being.

\section{Psychological Well-Being}

Interest in the psychological well-being of the elderly has stimulated a great deal of research and considerable effort has been devoted to the definition and measurement of the concept. Psychological well-being has variously been referred to as contentment, adjustment to aging, morale, and life satisfaction by researchers whose studies have in common the objective of assessing the general affective experience of older persons on a positive-negative continuum. Initially, research attempted to assess the older person's subjective well-being through measures of adjustment vithin certain dimensions of his or her daily life, such as family, health, religion, and work (Havighurst, 1957; Cavan, Burgess, Havighurst and Goldhamer, 1949). Neugarten, Havighurst and Tobin (1961) discuss the perspective of this research: 
... the level and range of activities and extent of social participation are the variables to be measured. The assumption is made, implicitly or explicitly, that the greater the extent of social participation, and the less the individual varies from the pattern of activity that characterized him in middle age, the greater is his well-being (p. 134).

Theoretical approaches guiding much of the past research in psychological well-being of the aged continue to accept this perspective. Activity theory, for example, suggests that maintaining higher activity level similar to that of middle age is the basis for a continued sense of well-being during old age (Butler and Lewis, 1973). Activity theory evolved as the result of a number of studies investigating the theory of disengagement which postulates a mutual withdrawal of the individual and society (Cuming and Henry, 1961), as part of normal aging. This mutual withdrawal is characterized by psychological wellbeing on the part of the older person (Butler and Lewis, 1973). Continuity theory suggests that continued well-being is contingent upon maintaining a continuity of lifestyle (Atchley, 1977).

Each of these theoretical perspectives of psychological well-being for the elderly contains within it certain societal values that tend to preclude a high level of well-being for many older individuals. For example, to base measurement of well-being on social participation, activity level or continuity of lifestyle is strongly biased against those who become chronically ill, are homebound and may have drastically reduced incomes. The implicit assumption in such a measure is that a positive affective response to well-being is limited only to those older persons who are able to maintain the positive characteristics of midale years.

Measures developed subsequently have tended to define well-being 
as in internal construct with only secondary attention given to the level of social participation, activity and the like. Variables measured using this approach have included the individual's evaluation of his present or past life, his satisfaction or happiness. The assumptions are that the individual is the proper judge of his or her well-being, that the value judgments of the investigator can thus be minimized, and that it is not appropriate to measure well-being in old age by the same standards that apply to midale age, namely, standards based upon activity or social involvement (Neugarten et al., 1961). In developing a measure of subjective well-being, some have defined a multidimensional construct (Bradburn, 1969; Neugarten et al., 1961; Cavan et al., 1949) while still others have conceptualized wellbeing as a unidimensional construct (Rivett, 1976; Thompson, Streib and Kosa, 1960; Kutner, Fanshel, Togo and Langner, 1956; Havighurst and Albrecht, 1953).

One of the earliest examples of measurement of successful aging using the unidimensional, inner definition is Kutner's Morale Scale, developed during the Elmira study at Cornell University. According to Kutner, morale, as used in that scale, refered to a mental state or a set of dispositions, while adjustment refered to behaviors stemming from these dispositions. Hence, he assumed that an attitude or evaluation scale of morale could be used to measure life adjustment (Kutner et al., 1956). Several deficiencies emerged in the use of the Morale scale, one of the more serious being the treatment of successful aging as an unidimensional construct, when analysis of the scale data suggested the emergence of several dimensions. Measurement of a multidimensional construct as though it were unidimensional, violated 
certain prerequisites of scaling techniques and disrupted reliability and consistency measures of the scales (Coombs, 1964, 1950). In an attempt to remedy these deficiencies and, of equal importance, to capture the full content of the meaning and complexity of the construct, researchers began developing multidimensional measures of successful aging. For example, in developing a measure of life satisfaction, Neugarten et al. (1961) isolated five dimensions of psychological wellbeing: zest, congruence of goals, resolution and fortitude, positive self-concept, and mood tone. Drawing heavily on earlier work, they began developing several new measures of successful aging. Their work led to the development of the multidimensional Iife Satisfaction Index, which incorporated the five dimensions listed above. Neugarten et al. (1961) defined successful aging as a feeling of satisfaction with one's present and past life.

Despite the complexity of the concept of well-being, progress has been made in research efforts to isolate empirically the components of well-being. The evidence suggests that within these multiple measures, ther exists "a shared core of something that can be called subjective well-being" (Larson, 1978). This shared core is evident in the high correlation among measures of psychological well-being, as well as in relationships among the measures of psychological well-being and other life situation variables. Similarities between measures appear to be more significant than the differences (Larson, 1978). Table I presents a summary of some frequently used measures of well-being. Reliability and validity statistics of the instrument are also presented in Table I. Iohmann (1977) also found evidence suggesting that these measures were directed toward a common underlying construct. Her data indicated 
that there was a high correlation among several measures of life satisfaction, adjustment, and morale and that, in addition, there were high levels of correlation among the original measures of life satisfaction developed by Neugarten et al. (1961) and modified versions of the original test instrument. Selected correlations from Lohmann's study (1977) are presented in Table I.

The data clearly suggest the presence of an underlying concept of well-being; however there are 1 imitations on the interpretation of these measurements of subjective well-being. The first limitation regards the restricted range of generalizations that can be made from survey measures. Larson (1978) cautions in this regard:

Such measures can tell us little about individual informants. The responses of single persons are likely to be shrouded by unique shades of meaning, ephemeral factors such as moods, and individual response styles. For aggregates of people most of this "noise" can be presumed to cancel out. What does not cancel out is the fact that all responses were quick assessments given in a social situation. Hence, survey measures of well-being should not be interpreted as revealing "deep" psychological factors (pp. 111-112).

Researchers have cautioned that these measures of psychological well-being, as measures of group mental health, are questionable (Gurin, Veroff and Feld, 1960). Rather, the measures do represent statements about

affective experience as it might be expressed in day to day conversation with a friend. They provide important information at the social-psychological level of people's daily verbal behavior (Larson, 1978, p. 112).

Another important caution regarding measures of well-being is the extent to which interpretations are generalizable to differing populations. Larson (1978) states,

The first regards the extent to which it can be assumed that instruments (sic measuring psychological well-being) measure 
MEASURES OP SURJECTIVE WELL-BEING OP OLDER PERSONS

\begin{tabular}{|c|c|c|c|c|c|c|c|c|c|}
\hline \multirow[t]{2}{*}{ MEASURE } & \multirow[t]{2}{*}{ DESCRIPTION OF THE CONSTRUCT } & \multirow{2}{*}{$\begin{array}{l}\text { RRLIABILITY } \\
\text { STATISTIC }\end{array}$} & \multirow{2}{*}{$\begin{array}{l}\text { VALIDITY } \\
\text { STATISTIC }\end{array}$} & \multicolumn{3}{|c|}{ CORREIATIONS WITH } & \multirow{2}{*}{$\begin{array}{l}\text { OTHER } \\
\text { ISI }\end{array}$} & \multicolumn{2}{|c|}{ MEASURES* } \\
\hline & & & & KMS & SR & ISIA & & PCG & AI \\
\hline \multicolumn{10}{|l|}{$\begin{array}{l}\text { Unidimensional } \\
\text { Measures: }\end{array}$} \\
\hline $\begin{array}{l}\text { Kutner Morale scale } \\
\text { (KOS) }\end{array}$ & $\begin{array}{l}7 \text { items, morale defined as } \\
\text { set of dispositions or } \\
\text { mental state }\end{array}$ & $\begin{array}{l}908 \text { reproduc- } \\
\text { lbility of } \\
\text { Guttman ordering }\end{array}$ & & & .397 & .648 & .651 & .736 & .584 \\
\hline $\begin{array}{l}\text { Satisfaction } \\
\text { Rating (SR) }\end{array}$ & $\begin{array}{l}\text { Global Item, "taking all } \\
\text { things together, how would } \\
\text { you say things are these } \\
\text { days?" }\end{array}$ & & & & & .411 & .427 & .468 & .453 \\
\hline \multicolumn{10}{|l|}{$\begin{array}{l}\text { Multidimensional } \\
\text { Measures: }\end{array}$} \\
\hline $\begin{array}{l}\text { Life satisfaction } \\
\text { Index A (LSIA) }\end{array}$ & $\begin{array}{l}20 \text { items, a) zest vs apathy } \\
\text { b) resolution and fortitude } \\
\text { c) congruence between } \\
\text { desired and achieved gools } \\
\text { d) self concept e) mood tone }\end{array}$ & $\begin{array}{l}\text { Spearman-Brown } \\
\text { correlation of } \\
\text { attenuation }=.87\end{array}$ & $\begin{array}{l}x=.55 \\
\text { correlation with } \\
\text { interviewers LSR } \\
\text { ratings }\end{array}$ & & & & .989 & .762 & .792 \\
\hline $\begin{array}{l}\text { Modified Ldfe } \\
\text { Satisfaction Index } \\
\text { (LSI) }\end{array}$ & 13 items & $\begin{array}{l}K R \quad 20=.79 \\
\text { correlation with } \\
\text { interviewers LSR } \\
\text { ratings }\end{array}$ & $\begin{array}{l}x=.57 \\
\text { correlation with } \\
\text { interviewers LSR } \\
\text { ratings }\end{array}$ & & & & & .774 & .799 \\
\hline $\begin{array}{l}\text { Philadelphia } \\
\text { Geriatric Center } \\
\text { Morale Scale } \\
\text { (PCG) }\end{array}$ & $\begin{array}{l}22 \text { items, a) sense of } \\
\text { satisfaction with self } \\
\text { b) feeling there is a } \\
\text { place ir the world for } \\
\text { self c) acceptance } \\
\text { of what cannot be changed }\end{array}$ & $\begin{array}{l}\mathrm{KR} 21=.81 \\
\text { on matched items } \\
x=.75, \text { test- } \\
\text { retest; } x=.91 \text {, } \\
\text { 5-week test-retest }\end{array}$ & $\begin{array}{l}r=.57 \\
\text { correlation with } \\
\text { interviewers LSR } \\
\text { ratings }\end{array}$ & & & & & & .774 \\
\hline $\begin{array}{l}\text { Attitude Inventory } \\
\text { (AI) }\end{array}$ & $\begin{array}{l}\text { 76 items, a) satisfaction } \\
\text { in relation to people. } \\
\text { activities, health and } \\
\text { income }\end{array}$ & $\begin{array}{l}r=.72,4 \text {-week } \\
\text { test-retest } \\
r=.90 \text { odd-even } \\
\text { correlation }\end{array}$ & $\begin{array}{l}x=.77 \\
\text { correlation with } \\
\text { a happiness scale } \\
\text { developed by } \\
\text { Havighurst }\end{array}$ & & $\begin{array}{l}\text { "Correl } \\
\text { by Na }\end{array}$ & $\begin{array}{l}\text { ations } \\
\text { ncy Lo }\end{array}$ & $\begin{array}{l}\text { taken } \\
\text { hamn, }\end{array}$ & $\begin{array}{l}\text { from } \\
1977 .\end{array}$ & a study \\
\hline
\end{tabular}


the same thing in differing populations. Well-being items dealing with planning ahead, goals, and life assessment might be differently interpreted across subcultural groups, across social classes, and across ages. If items have markedly different stimulus properties for different sampled groups, it is almost meaningless to compare the total scores for these items between the groups (p. 110).

In summary, psychological well-being has been measured by a number of instruments. Comparison of these measures indicates that they share a common construct that can be called subjective well-being. Caution in interpretation of the measures must be taken. Such measures do not reveal deep psychological factors, but rather, provide information at the social-psychological level of people's daily verbal behavior. Generalization of findings across different populations must take into account differing stimulus properties of selected items for groups by age, social class and subculture.

The Life Satisfaction Index

The original Life Satisfaction Index form A (ISIA) developed by Neugarten et al.(1961) was designed to include the individual's evaluation of past and present life satisfaction. This index depends upon the person's inner definition of success which in part is derived from social standards. ${ }^{2}$ The assumptions implicit in this line of inquiry into psychological well-being are, first, that the individual is the only proper one to determine his well-being; that the value judgments of the investigator can be minimized; and that it is not appropriate to measure well-being in old age by the same standards that apply to midale age, namely, standards based upon activity and social involve-

${ }^{2}$ A modified version of the ISIA as revised by Adams (1969) was the instrunent selected to measure the psychological well-being of this study sample. 
ment (Neugarten et al., 1961). The individual's internal frame of reference relative to well-being is particularly useful for the elderly selected for this research because their activities and social participation have been restricted as a result of increased impairment, poor health and low income.

Neugarten et al. (1961) developed the ISIA to reflect this theoretical framework and it has since been modified by other researchers (Adams, 1969; Wood, Wylie and Sheafer, 1969). It is a multidimensional construct coming from an extensive five-year study of a relatively healthy, low to midale class, urban Kansas City sample. Neugarten and her associates identified and operationally defined five components of life satisfaction: zest of life as opposed to apathy; resolution and fortitude as opposed to resignation; congruence between desired and achieved goals; high physical, psychological and social self-concept; and a happy, optimistic mood tone. The ISIA was constructed selecting items from already existing scales or inventing new ones in order to obtain four items representing each of the five components. Several items were taken from the Kutner Morale Scale and several from the happiness scale of the Chicago Attitude Inventory. The completed ISIA consisted of a scale of twenty items. An individual was regarded as being satisfied with life to the extent that he,

a) takes pleasure (is even enthusiastic) from the round of activities that constitute his everyday life; b) regards his life as meaningful and accepts resolutely that which life has been; c) feels he has succeeded in achieving his major goals; d) holds a positive image of self; and e) maintains happy and optimistic attitudes and mood (Neugarten et al., 1961, p. 137).

Reliability correlations ranged from .78 to .87 depending upon the statistical procedure. Reliability studies were done on the ISIA 
and earlier scales constructed by Neugarten et al. (1961). Validation measures comparing older persons' scores with observer's ratings yielded a coefficient of .64 . For a detailed description of these procedures, refer to Neugarten et al. (196I).

Since the original publication of the ISIA, it has been applied, analyzed and revised a number of times on a variety of populations. Wood et al. (1969) used the LSIA to measure life satisfaction on a population of rural elderly. They recommended the deletion of several items and generally supported the use of the ISIA. Wood and her associates (1969) report finding that the relationship between the measures on a rural aged population and an urban aged population were approximately the same.

Adams (1969) used the ISIA in yet another study of 508 older persons drawn to represent the non-institutionalized population residing in midwestern towns with populations ranging from 250 to 2,500. He concluded from his research, that "the ISIA provides as fair an estimate of life satisfaction for a small town elderly sample as it did for the urban and rural samples" (Adams, 1969, p. 473). He cautioned that,

...some question has been raised concerning the representation of the five theoretical components said to provide the basis for the scale, and it might be suggested that further research along this line be directed at finding new items which will fill out the theoretical design... (Adams, 1969, p. 473).

He reported the method of scoring as being adequate. However, based upon his research findings, he recommended the deletion of several items from the ISIA. Table II is the modified Life Satisfaction Index (ISI) which resulted from the modifications of both Adams (1969) and Wood et al. (1969). 
TABIE II

THE MODIFIED IIFE SATYSEACTION INDEX

CONFIDENTIAE

DIRECTIONS: Read the sentences and check the box as to how much you agree or disagree with each. "Probably Agree" means you agree more than you digagree with the statement. "Probably Digagree" means that you disagree more than you agree with the statement. Some items may geem similar. Actually, all items are affferent.

1. As I grow older, things seem better than I thought they would be.

2. I have gotten more of the breaks in Iife than most people I know.

3. This is the dreariest time of my life.

4. Compared to other people my age. I make a zood appearance.

5. When I think back over my life, I did not get most of the important things I wanted.

6. Most of the things I do are boring or monotonous.

7. I expect interesting and pleasant things to happen to me in the future.

8. These are the worst years of my $11 f e$.

9. The things I do are as interesting to me as they ever were.

10. My Iffe could be happier than it is now.

11. As I look back on my 1ife, I don't feel very satisfled.

12. I've gotten pretty much what I expected out of Iife.

13. I am just as happy as when I was younger.

14. If I could, I would change quite a lot about my past life.

\begin{tabular}{|l|l|l|l|}
\hline $\begin{array}{l}\text { DEFINITELY } \\
\text { AGREE }\end{array}$ & $\begin{array}{l}\text { PROBABLY } \\
\text { AGREE }\end{array}$ & $\begin{array}{l}\text { PROBABLY } \\
\text { DISAGREE }\end{array}$ & $\begin{array}{l}\text { DEFINITEIY } \\
\text { DISAGREE }\end{array}$ \\
\hline & & & \\
\hline & & & \\
\hline & & & \\
\hline & & & \\
\hline & & & \\
\hline & & & \\
\hline & & & \\
\hline & & & \\
\hline & & & \\
\hline & & & \\
\hline & & & \\
\hline & & & \\
\hline
\end{tabular}


Given the cautionary comments of previous researchers, and noting that there has been no reported use of the ISIA or the ISI on a severely impaired and economically deprived population, the modified ISI was the instrument selected as an acceptable and appropriate measure for assessing psychological well-being of the study sample.

\section{Stability of Psychological Well-Being}

Psychological well-being has been discussed from both a psychological and a sociological perspective. From a psychological perspective, personality has been suggested as the major explanatory factor accounting for individual differences in psychological well-being. Personality is typically conceptualized as a stable configuration of cognitive-emotional characteristics that operates to produce consistent behavioral outcomes (Mischel, 1969). Personality is presumed to be stable over time (Mischel, 1969; Murray, 1938) and psychological wellbeing, as a manifestation of personality, is also presumed to be stable. Neugarten, Havighurst and Tobin (1961) observed a variety of patterns in their study of older persons and suggested that the particular pattern evidenced reflected stable underlying personality factors. Reichard, Livinson and Peterson (1962) suggested that patterns of adjustment to retirement (measured in part by satisfaction with life) exhibited in their sample of older men were due to personality factors. Both of these studies measurea personality by in-depth semistructured interviews.

A test of the ability of standardized personality measures to predict psychological well-being had not been empirically addressed until 1978 when Lirda George found, in her study of oider persons aged 
50 to 76 , that both personality and social status factors were significant predictors of psychological well-being. Personality was measured by the Cattell 16 PF (Cattell, Eber and Tatsuoka, 1970). Her findings corroborate the assumption that psychological well-being is related to personality factors and therefore may be assumed to have stable components. There has been, however, little evidence to test this assumption.

From a sociological perspective, theorists have suggested that individual differences in psychological well-being and individual stability primarily reflect the impact of social status variables. Williams and wirths (1965) conclude that patterns of activity and psychological well-being reflect stable lifestyle characteristics. Recently, social status has been related to individual differences in life satisfaction (Beiser, 1974; Spreitzer and Snyder, 1974; Edwards and Klemmack, 1973; Adams, 1971). George (1978) found that social status factors were significant predictors of psychological well-being. From both a psychological and sociological perspective, psychological well-being is assumed to have stable components. However, very little research has been done to test this assumption, Resolution of the stability assumption requires the investigation of several questions. First, are there consistent identifiable age changes (i.e., development change) in psychological well-being over time? Second, to what extent is psychological well-being situationally reactive to the changes that occur in one's life situation? Third, is there an interaction between psychological well-being and the individual's perceived environment? That is, a person's psychological well-being may mediate how life situations are perceived as well as influencing 
how changes in life situations are responded to.

Correlates of Psychological Well-Being

A review of the literature dealing with psychological well-being of the elderly indicates that certain variables consistently correlate with life satisfaction, morale or psychological well-being. Larson (1978) reports in his comprehensive review of the literature,

Poor health, low income and lack of social interaction have been clearly related to lower expressed satisfaction with life, lower morale and lower contentment. Further, these negative situational conditions, particularly low income, appear to related to a greater vulnerability to the impact of other negative life situation exigencies (p. 116).

Each of these variables is discussed below.

Health. Among all of the elements of an older person's life situation, health is the most strongly related to subjective wellbeing. People who are sick or physically disabled are much less likely to express contentment about their lives.

studies utilizing the person's own assessment of his health, :

show high and consistent correlations with subjective well-being (Larson, 1978; Spreitzer and Snyder, 1974; Edwards and Klemmack, 1973; Palmore and Luikart, 1972). In these studies, people are typically asked to respond on a continuum, to a form of the question, "In general would you say your health is: very good, good, fair, poor, very poor."

Larson (1978) summarized the relationship between life situation variables and various measures of psychological well-being undertaken by a number of researchers. He used a linear model represented by correlation and regression statistics to calculate a correlation range for each life situation variable across the studies. For the 
Iife situation variable, health, he reports a range of $r=.2$ to .4 as his estimate of the independent correlation between health and well-being. Unfortunately, there have been no longitudinal studies to clarify the relationship of causality between the two variables. Three studies utilizing physicians' assessments of health, showed low but significant correlations between health and subjective well-being (Jeffers and Nichols, 1974; Palmore and Luikart, 1972; Maddox and Eisdorfer, 1962). These ratings of a person's health provided the most objective measure of health; however, it is not the most accurate assessment of the extent to which the person may be debilitated or in pain (Bild and Havighurst, 1976). Bild and Havighurst (1976) suggest that lowered well-being levels result from pain, confinement and uncertainty which may accompany poor health. There is limited information available on the subjective measurement of life satisfaction among the elderly who are in poor health. Riegel, Riegel and Meyer (1968), and Maddox (1963) have cautioned that in any study there is the tendency for persons with poor health not to become participants and this tendency is true for the elderly.

It has been suggested that poor health has a great impact on the psychological well-being of persons of lower socioeconomic status (Bultena, 1969; Kutner et al., 1956). Indeed, health does have a confounding association with socioeconomic status which also correlates with well-being (Kutner et al., 1956); however, when health and socioeconomic status are controlled for or considered simultaneous$1 y$, the association of health and psychological well-being still remains strong (Larson, 1978; Cutler, 1975; Edwards and Klemack, 1973). 
Socioeconomic status. A number of studies have established that older persons of lower socioeconomic status (SES) tend to have lower subjective well-being than persons of higher SES. When confounding variables such as health, employment and marital status are controlled for, this association is still maintained (Larson, 1978; Cutler, 1975; Edwards and Klemmack, 1973). Of the three variables used to measure SES, (income, education and occupational status) income appears to be the most consistently salient. However education and occupational status do show relationships with psychological well-being. The relationships are maintained when other variables are controlled (Cutler, 1975; Edwards and Klemmack, 1973). Spreitzer and Snyder (1974) and Edwards and Klemmack (1973) reported an association between occupational status and well-being.

In a study looking at the relationship between education and well-being, Clark and Anderson (1967) found that older persons with midale levels of education reported the highest levels of psychological well-being. Campbell, Converse and Rodgers (1976) were able to replicate their findings.

These studies suggest that the association of income with wellbeing is stronger at the lower levels of income. They discuss the implication that there is a level of income above which additional incume is inconsequential to contentment.

Finally, in relating ses to psychological well-being, findings differ depending upon which well-being instrument is used. Those well-being measures dealing with an immediate time frame, (e.g., How is your present life going?) tend to show lower associations (Palmore and Luikart, 1972; Clark and Anderson, 1967; Kutner et al., 1956) than 
do measures which include items assessing long-term satisfaction such as measured by the LSI (Edwards and Klemmack, 1973).

Again, the absence of longitudinal research prevents identification of process by which well-being and SES are related. Larson (1978) notes that "Historical data suggest that the strengths of this association may be changing". Campbell et al., (1976) observed that there has been a significant narrowing of this gap between social classes for ratings of happiness in the period from 1957 to 1972 . Activity patterns and Social Interaction. The ISI is perhaps the most frequently used measure of well-being utilized in assessing relationships between social interactions, activity and well-being. There is a positive relationship for general indices of social activity however measures of specific activities are less consistent (Wylie, 1970; Havighurst et al., 1968; Kutner et al., 1956). Some measures tabulate the frequency of informal activities such as visiting with neighbors and friends. A positive association to wellbeing was found by four researchers using this approach (Edwards and Klemmack, 1973; Pihlblad and Adams, 1972; Smith and Lipman, 1972; Iemon, Bengtson and Peterson, 1972). Palmore and Luikart (1972) were unable to obtain the same positive association. Studies using general measures of activity and its relationship to well-being consistently report positive associations (Wylie, 1970; Havighurst et al., 1968; Kutner et al., 1956).

For urban and non-urban populations, there appear to be differences in formal and informal activities. Organizational participation and church related activity are consistently associated with well-being for non-urban samples (Edwards and Klemmack, 1973; Palmore and Luikart, 
1972; Pihlblad and Adams, 1972). This relationship does not hold for urban populations (Bull and Aucoin, 1975; Iemon et al., 1972). Frequency of activity with family and well-being do not appear to be correlated in any research findings reviewed (Martin, 1973; Edwards and Klemmack, 1973; Pihlblad and Adams, 1972).

The strength of these associations was diminished when persons measured were of higher status and in good health (Smith and Iipman, 1972). Smith and Lipman (1972) reported that there was no association between LSI scores and frequency of peer contact for persons with no financial or health constraints. When controls for health and SES were introduced, participation in voluntary associations has a much weaker relation to well-being (Bull and Aucoin, 1975; Edwards and Klemmack, 1973; Cutler, 1972). Lemon et al. (1972) also found that the correlation of informal activity and well-being became insignificant when people in poorer health were not included. Bultena and Oyler (1971) did not reach these conclusions. The research done in this area has been criticized for failing to consider the quality of the activity engaged in and the intimacy of the interactions (Lowenthal and Haven 1976; Rosow, 1963). Critics point out that activities and interactions vary in the meanings they have for participants. Wagner, O'Brien and Jean (1976) reported that there was a significant relationship between morale and reporting having a confidant.

Once again, the absence of longitudinal research prevents any knowledge of the process by which these variables are related to wellbeing. Rosow (1963) has suggested that the lower level of well-being of persons with lower activity and social contacts may reflect 
personality characteristics of a life long nature and would not be influenced by any decrease or increase in activity and social interaction. Because of the cross-sectional nature of most studies, the results are ambiguous. Connor, Powers and Bultena (1979) found that both the number of persons interacted with and the frequency of the interaction, are of little importance for the adjustment of older people. They concluded:

...It seems that it is not "how often" or with "how many" one interacts, but rather under what circumstances, for what purposes, with what degree of intimacy and caring the interaction takes place that will have its impact on morale. As in other areas of life, we have been working from the assumption that "more is better" (p. 120).

Housing and Transportation. Psychological well-being is associated with various aspects of people's living situations. Cutler (1975, 1972) reported that over a period of two and one half years, there was a greater frequency of decline in well-being among persons without transportation than among those with transportation. These differences were significant when controls for income, age, sex and location of residence were introduced.

The relationship between well-being and housing has also been demonstrated by Lawton and Cohen (1974) and Carp (1968). These two studies, using a longitudinal design, demonstrated sustained increases in well-being for persons moving into improved housing. Other studies have demonstrated that differences in housing affect well-being (Martin, 1973; Smith and Lipman, 1972; Schooler, 1970). These differences appear to exist in spite of lessened social interaction which suggests that the physical aspects of the building have a direct effect upon well-being (Smith and Lipman, 1972; Schooler, 1970). 
Frequency of residential moves is not associated with well-being (Palmore and Luikart, 1972; Maddox and Eisdorfer, 1962). Research looking at urban and rural dwellers, does not demonstrate any difference in the area of housing (Bull and Aucoin, 1975; Cavan et al., 1949).

Other Variables. A number of other variables have been considered in their relationship to well-being of the elderly. The majority of studies relating age to well-being show a slight decline in well-being with age for cross-sectional samples. When controls are introduced for decreased health, decreased financial resources, widowhood, loss of friends and decreased activity, all factors which frequently accompany aging, the association between age and well-being disappear (Larson, 1978; Kivett, 1976; Edwards and Klemmack, 1973).

Larson (1978) cautions that cohort differences may account, at least in part, for the association or lack of it between age and wellbeing. On the one hand, Campbell et al. (1976) report an age-specific decline in well-being in the cohort of people who are currently of younger ages, whereas for people over 60 years of age between the period 1957-1972, data suggest that cohort flow has not altered the level of well-being. Cameron (1975) in contrast, suggests that far fewer people reported unpleasant moods in his sample than had been the case in a study done in 1925.

When the sex variable is introduced, there appears to be no consistent difference in well-being for older persons (Lawton, 1972; Neugarten et al., 1961; Kutner et al., 1956; Cavan et al., 1949). In considering racial differences, thexe appear to be no differences reported in well-being when variables such as income are 
controlled for.

The majority of studies showed a slight independent relationship between well-being and marital status. Married people tend to have higher average well-being scores than unmarried people (Larson, 1978; Spreitzer and Snyder, 1974; Edwards and Klemmack, 1973). Studies differentiating unmarried status suggest that the well-being of single people tends to be about equivalent to that of married persons. Widowed, divorced and separated persons tend to have lowered wellbeing scores (Pihlblad and Adams, 1972; Kutner et al., 1956).

Finally, a number of studies have found a slightly positive association betwen being employed and well-being for older persons. Streib and Schneider (1971) found no clear differences in mean wellbeing scores before and after retirement for men or women. Thompson et al. (1960) found lowered well-being scores in persons who expressed reluctance to retire and in persons who stated that they were unable to find things to do.

Table III is taken from the work of Reed Larson (1978) in his excellent, comprehensive review of the psychological well-being literature and evaluation of well-being research. It is a summary of correlation of major life situation variables with subjective wellbeing of older persons. The statistics are the author's estimates of the correlations between well-being and the respective variables, based upon the evidence reviewed in his paper. Larson (1978) notes that "while demonstrating the importance of situational factors, this table makes it clear that the greatest proportion of variance in wellbeing scores is unexplained by these variables" (p. 117) .

Summary and Interpretation. Measures of life satisfaction, 
TABLE III

SUMMARY TABLE OF CORRELATIONS OF MAJOR LIFE SITUATION

VARIABLES WITH SUBJECTIVE WELL-BEING FOR THE POPULATION OF AMERICANS OVER $60^{*}$

$\begin{array}{lll}\text { Life Situation } & \text { Correlation } & \text { Proportion of Variance } \\ \text { Variable } & \text { in Well-Being "Explained" } \\ & \text { to Well-Being } & \text { by Variable }\left(r^{2}\right)\end{array}$

$\begin{array}{lll}\begin{array}{l}\text { Health, physical } \\ \text { disability }\end{array} & r=.2 \text { to } .4 & 48 \text { to } 16 \% \\ \begin{array}{l}\text { Socioeconomic } \\ \text { variables }\end{array} & r=.1 \text { to } .3 & 18 \text { to } 9 \% \\ \text { Age } & r=.0 \text { to } .1 & 0 \% \text { to } 18 \\ \text { Race } & r=.0 \text { to } .1 & 08 \text { to } 18 \\ \text { Sex } & r=.0 \text { to } .1 & 0 \% \text { to } 18 \\ \text { Employment } & r=.0 \text { to } .1 & 08 \text { to } 18 \\ \text { Marital Status } & r=.1 \text { to } .2 & 18 \text { to } 48 \\ \text { Transportation } & r=.1 \text { to } .2 & 18 \text { to } 48 \\ \text { Housing } & r=.1 \text { to } .2 & 18 \text { to } 48 \\ \text { Social activity } & r=.1 \text { to } .3 & 18 \text { to } 98\end{array}$

*These statistics are the author's estimates of the correlations between subjective well-being and the respective variables, based on the evidence reviewed in this paper (Larson, 1978). 
adjustment and morale have been demonstrated to have high correlations among measures, suggesting a common underlying construct of psychological well-being. This is true for both unidimensional and multidimensional measures. Such measures are useful in that they provide information at the social-psychological level of people's daily verbal behavior.

The ISI is the instrument selected to measure psychological well-being in the present study. The LSI depends upon the person's inner definition of success. This approach is particularly valuable in the study of older persons who are experiencing restrictions because of increased impairment, poor health and low incomes. Psyrhological well-being has been assumed to be stable over time. However, longitudinal research investigating this assumption has been scarce. Only very recently have there been efforts to assess changes in psychological well-being longitudinally and such studies have been infrequent.

Populations of older persons who are experiencing increased impairment, poor health and low insomes, are infrequently studied, and in the literature, there were no studies reported assessing the psychological well-being of this group.

The relationship between psychological well-being and items that are reflective of life situations of older persons is demonstrated in a number of studies. Single items are used to represent such life situations as health, income, housing, social interactions and activity. Little research has been reported relating items measuring stress or cognitive functioning to psychological well-being. Criticisms have been leveled against the use of items that only 
measure the quantitative aspects of a life situation, noting that qualitative measures are necessary to capture the full meaning of a given situation.

There is no evidence in the literature of a systematic categorization of life situations of the elderly and the items necessary to measure such life situations. Frequently, in relating health to life satisfaction, studies do not distinguish between measures of general health and measures of chronic illness or disability, for example. Combining these items or not asking each item, can cause considerable confusion in measurement and interpretation of the data.

There is an appaxent need to, first, determine what the important Iife situations of the elderly are; second, to examine the variables that are part of each life situation; and third, to combine the critical variables into a measurement scale. For example, in the case of social interaction, items included to adequately measure that life situation would include who the person has social interactions with (children, relatives, neighbors, friends, business persons), how frequently the interactions occur, and whether those interactions are satisfactory in content and frequency. A detailed discussion of the merits of scale building is included in Chapter III, Methods.

Causality and the process by which relationships between life situations and life satisfaction occur remains unclear. Researchers consistently mention the need for careful longitudinal analysis of these relationships. On the one hand, a person's level of life satisfaction may act as a mediating or intervening variable providing a filter through which to view life situations. If this is the case, it might expected that a highly positive life satisfaction would 
indicate a positive perception of one's life situation. Positive or negative changes in life situations may be viewed in a positive light. On the other hand life satisfaction may be dependent upon life situations which provide a gauge to positive and negative changes that occur in one's life. These issues are as of now unresolved and present useful areas for further research. This study will build upon previous research using the LSI to measure psychological well-being over time on a population heretofore not investigated. This population of older persons who are reportedly in poor health and living on incomes well below the national median, is of particular concern because of what are quite likely restricted life situations, which may be accompanied by lowered levels of psychological well-being.

The studies reviewed from the literature will provide guidelines from which to construct the life situations that are critical to older persons, and will provide baseline information about variables to include in the measurement of Iife situations of older persons. In conclusion, this study assesses the stability of psychological well-being longitudinally, relating stability or change to life situations measured at three points in time on a population of older persons who are experiencing reduced incomes, poor health, and increased disabilities. 
CHAPTER III

\section{HYPOTHESES}

Exploring the concept of psychological well-being, its stability and its relationship to the life situations of older persons, led to several research questions. One of these is a preliminary question dealing with the meaning of psychological well-being. The major set of research questions for this dissertation explores the meaning of the construct psychological well-being through an examination of its stability or change. Possible relationships between stable or changing. psychological well-being and changing life situations of older persons are examined. The preliminary question is:

- Does psychological well-being have similar meaning for an elderly population in reduced circumstances similar to what it has for other more general populations of elderly as reviewed in the literature?

Resolution of this preliminary question is possible through examination of correlational data. If psychological well-being does have the same meaning for the population from which the dissertation sample was drawn as it does for better off elderly groups, there will be similar relationships between psychological well-being and variables that are frequently found to be related to it. The use of correlational techniques is a well established research method for examining the generalizability of the construct of psychological well-being across different populations.

Initial evidence of changes in psychological well-being for some persons in the sample created a challenge to the assumption of its 
stability and led to the major research questions:

What is the nature of change in psychological well-being and what is the change related to?

Are the life situations that are related to positive or negative change in psychological well-being the same as the life situations that distinguish between persons whose psychological well-being remained stable and high and those whose psychological well-being remained stable and low?

In order to pursue the research questions, it was necessary to operationally define the concept of psychological well-being and to specify the life situations to be used in generating a number of hypotheses to be statistically tested. While the operationalization of variables is elaborated in the methods chapter, a summary of these variables follows.

Psychological well-being was measured by the Life Satisfaction Index (ISI). An abbreviated form consisting of four items was used at the first interview and a modified fourteen-item ISI (Adams, 1969) was used at the last interview.

Iife situations were measured by eight scales, called well-Being Indicators (WBIs), developed by stewart and whitelaw (1977), using data from this sample taken at the first interview. Comparable scales were built using data from the second and third interviews by the author of this dissertation and Marie Beaudet-walters. Stewart and Whitelaw (1977) selected a number of items that were reflective of the life situations of the elderly. The items were chosen on the basis of gerontological literature, previous correlates of psychological wellbeing, experience of the researchers, and availability of the data. Some items were selected for the item pool because of their theoretical and practical appropriateness. It would have been desirable to include 
certain other items but because they were not part of the data collected, their inclusion was not possible. Empirical correlational procedures were used to construct the eight WBIs.

Life situations of the elderly measured by the WBIs fall into three broad categories. The first category is reflective of personal concerns and contains three WBIs, (1) a measure of medical health that includes items relating to the physical health of the sample; (2) a group of items describing the absence of physical impairment and restricted mobility; and (3) items assessing alertness and interest in the interview.

The second category encompasses the WBIs that are of a social nature. These are, (1) a measure of social involvement with children, family, friends and neighbors; and (2) a group of items that include participating in events such as grocery shopping, going to the drugstore, post office, bank and restaurant.

The final broad category includes WBIs that are more external to the sample and tends to be reflective of the environment. These WBIs are, (1) a measure of immediate concerns with neighborhood, personal safety and well-being of friends and relatives; (2) a measure related to housing and neighborhood; and (3) one assessing total income, use of income transfer programs and satisfaction with financial status. The eight WBIs are called respectively, Medical Health Status, Lack of Impairment, Cognitive Status, Social Contacts, Activities, Lack of Worry, Housing, and Income.

Table IV presents the WBIs, their descriptions and the more general categories under which they are grouped. (Chapter IV contains a detailed description of the WBI definition, construction and items 
TABLE IV

PERSONAI, SOCIAL AND ENVIRONMENTAL WELL-BEING INDICATORS DESCRIBING THE LIFE SITUATIONS OF THE ELDERLY

\begin{tabular}{|c|c|c|}
\hline Category & $\begin{array}{l}\text { Well-Being } \\
\text { Indicator }\end{array}$ & Description \\
\hline \multirow{3}{*}{ Personal } & $\begin{array}{l}\text { Medical Health } \\
\text { Status }\end{array}$ & relates to personal health \\
\hline & $\begin{array}{l}\text { Lack of } \\
\text { Impairment }\end{array}$ & $\begin{array}{l}\text { describes absence of physical } \\
\text { impairment and restricted physical } \\
\text { mobility }\end{array}$ \\
\hline & $\begin{array}{l}\text { Cognitive } \\
\text { Status }\end{array}$ & $\begin{array}{l}\text { describes alertness and interest in } \\
\text { the interview process }\end{array}$ \\
\hline \multirow{2}{*}{ Social } & Social Contacts & $\begin{array}{l}\text { reflects social interactions with } \\
\text { other people }\end{array}$ \\
\hline & Activities & $\begin{array}{l}\text { reflects participation in events } \\
\text { such as shopping for groceries, } \\
\text { going to the drugstore and bank }\end{array}$ \\
\hline \multirow{3}{*}{$\begin{array}{l}\text { Environ- } \\
\text { mental }\end{array}$} & Lack of worry & $\begin{array}{l}\text { reflects immediate concerns with } \\
\text { neighborhood, personal safety, and } \\
\text { well-being of others }\end{array}$ \\
\hline & Housing & describes housing and neighborhood \\
\hline & Income & $\begin{array}{l}\text { includes total income, welfare } \\
\text { transfers and satisfaction with } \\
\text { standard of living }\end{array}$ \\
\hline
\end{tabular}


included.)

These eight WBIs, representing the life situations of the elderly, are the measures used as predictors of the criterion of psychological well-being as measured by the LSI. Data were collected at three interviews which are referred to as time 1 , time 2 and time 3 . The interviews were about twelve months apart allowing for a measurement of change over time.

The following five hypotheses have been formulated from the research questions. The first hypothesis addresses the preliminary research question exploring the similarity in meaning of psychological well-being across different populations of older persons. The next two hypotheses focus on how the life situations of the elderly at given points in time are related to stability or change in psychological well-being. The last two hypotheses are concerned with how stability or change in the life situations of the elderly are related to stability or change in psychological well-being.

(1) It is hypothesized that the LSI scores for an elderly population in reduced circumstances are positively correlated with the same WBI variables found to correlate with measures of psychological well-being for other populations of older persons reported in previous literature. Such variables reported in past research include health and physical disability, social activity, socioeconomic variables, and housing.

The WBIs at time 1, time 2, and time 3 are expected to predict the pattern of ISI scores over time as follows:

(2) It is hypothesized that those persons whose ISI scores remained high and stable from time 1 to time 3 also had higher scores on WBIs than did those persons whose ISI scores remained stable and low.

(3) It is hypothesized that persons whose LSI scores changed in a positive direction from time 1 to time 3 also had higher scores on WBIs than did those persons whose LSI 
scores changed in a negative direction.

It is predicted that change in ISI scores is related to change on the WBIs in the following way:

(4) It is hypothesized that people whose LSI scores remained stable from time 1 to time 3 also had WBIs that remained stable.

(5) It is hypothesized that people whose ISI scores changed in either a positive or negative direction also had changes in WBIs that were in a corresponding direction.

In summary, the hypotheses delineate the research questions in a logical progression of steps designed to address the issues of the meaning of psychological well-being and its relationship to the life situations of the elderly over time. The first step is an exploratory one examining the similarity of the meaning of psychological wellbeing for the population from which this sample was drawn compared with other older persons previously studied. Evidence regarding such similarity of meaning across different groups will partially determine the extent to which the results for the major hypotheses can be generalized to other groups of elderly.

The major hypotheses suggest that life situations are related to both stable and changing psychological well-being. Those persons whose psychological well-being does not change are predicted to have fairly stable life situations. Those persons whose psychological well-being is stable and high are expected to have life situations that are stable and show evidence of more positive circumstances than do those persons whose psychological well-being is stable and low. Those persons whose psychological well-being does change are expected to experience accompanying changes in life situations. The methods for exploring these hypotheses are detailed in the following chapter. 
Empirical results regarding the major hypotheses will serve to clarify the meaning of psychological well-being in terms of its stability and its fluctuations as related to life situations of the elderly. 
CHAPTER IV

METHODS

Sample

The sampling procedures involved the selection of three groups. The original study population was selected for an Administration on Aging (AOA) model project conducted in 1972-1973. From this original population, the Supplemental security Income (SSI) study sample consisting of 400 persons was chosen in 1975. From these 400 persons, 215 were selected as the dissertation sample. These 215 persons had completed the three-year SSI study and had complete data for the Life Satisfaction Index. Following is a detailed description for each of these three groups.

The Study population. The original study population, from which the respondents for the SSI interviews were drawn, was a group of individuals who had participated in a study conducted by the Institute on Aging over the period May 1972 to June 1973. This earlier project, an evaluation of an AOA sponsored area-wide model project for the elderly in Multnomah County, Oregon (A.B.L.E. - A Better Life for the Elderly) identified the study population by an elaborate intake, screening, social service needs assessment and follow-up process. More than 2,700 persons were screened and 2,106 were selected for the study on the basis of some general characteristics (65 years of age or older; no younger person in the household; and an income of not more than $\$ 250$ per month). Additionally, the 
study population was screened according to theoretically determined high priority criteria (dominant physical disorders; severely restricted mobility; little or no social contact; and no linkage to social services). As a result of focusing on these criteria, the chosen study population is atypical of the elderly population as a whole, but the important point is that they are similar to the marginally subsisting elderly, in need of social services, found in middle-sized communities in the United States. In terms of income, the population is representative of 4 to 5 million older adults in this country.

SSI Sample selection. From the above described population, the SSI study sample was purposively selected. Given the interests of the study, income and living arrangement were further specified as critical variables for stratifying the population. The following table defines the strata of interest in selecting the SSI study sample.

TABLE V

SAMPLING STRATIFICATION DEFINITION

Monthly Household Income

Low Moderate High

Living Alone

$\$ 0-124$

$\$ 125-174$

$\$ 175+$

Living with Spouse

$\$ 0-199 \quad \$ 200-299$

$\$ 300+$

Purposely omitted from the SSI study sample were those elderly persons who reported residing in group quarters (not institutions) in the original intake process. Also excluded in the sample selection 
were those members of the study population not answering the questions pertaining to income and/or living arrangement in the original intake, since no alternative method of assessing their situation existed. Using all these criteria, the subcontractor was able to trace a pool of 892 persons. Of these 892 persons, 492 were not included in the final sample either because they were deceased, too ill, institutionalized, could not be contacted or refused to participate (refer to Figure 1). The remaining 400 were contacted and interviewed at the first data collection period (Time 1, 1975). At the completion of the second data collection period (Time 2, 1976) 289 of the original 400 respondents remained in the sample, 111 no longer participating for reasons listed above. At the final data collection period (Time 3, 1977) 224 persons remained in the sample. Figure 1 summarized the sample selection and reasons for interview attrition.

The sampling criteria resulted in a disproportionally large number of marginally existing elderly. For example, a comparison of the SSI study sample with the United states population of elderly indicates that the SSI sample is older, $57 \%$ being $75+$ as compared with $38 \%$ nationally, and female $77 \%$ as compared with the national figures of 57\%. A greater percentage of the SSI sample live alone (758) while only 318 of the national population live alone. Only $19 \%$ of the national population of elderly live below the adjusted poverty level and $59 \%$ of the SSI study sample are living below the adjusted poverty level.

Table VI presents the characteristics of persons age 65 and over for 1) the United States population, 2) the Multnomah County, 


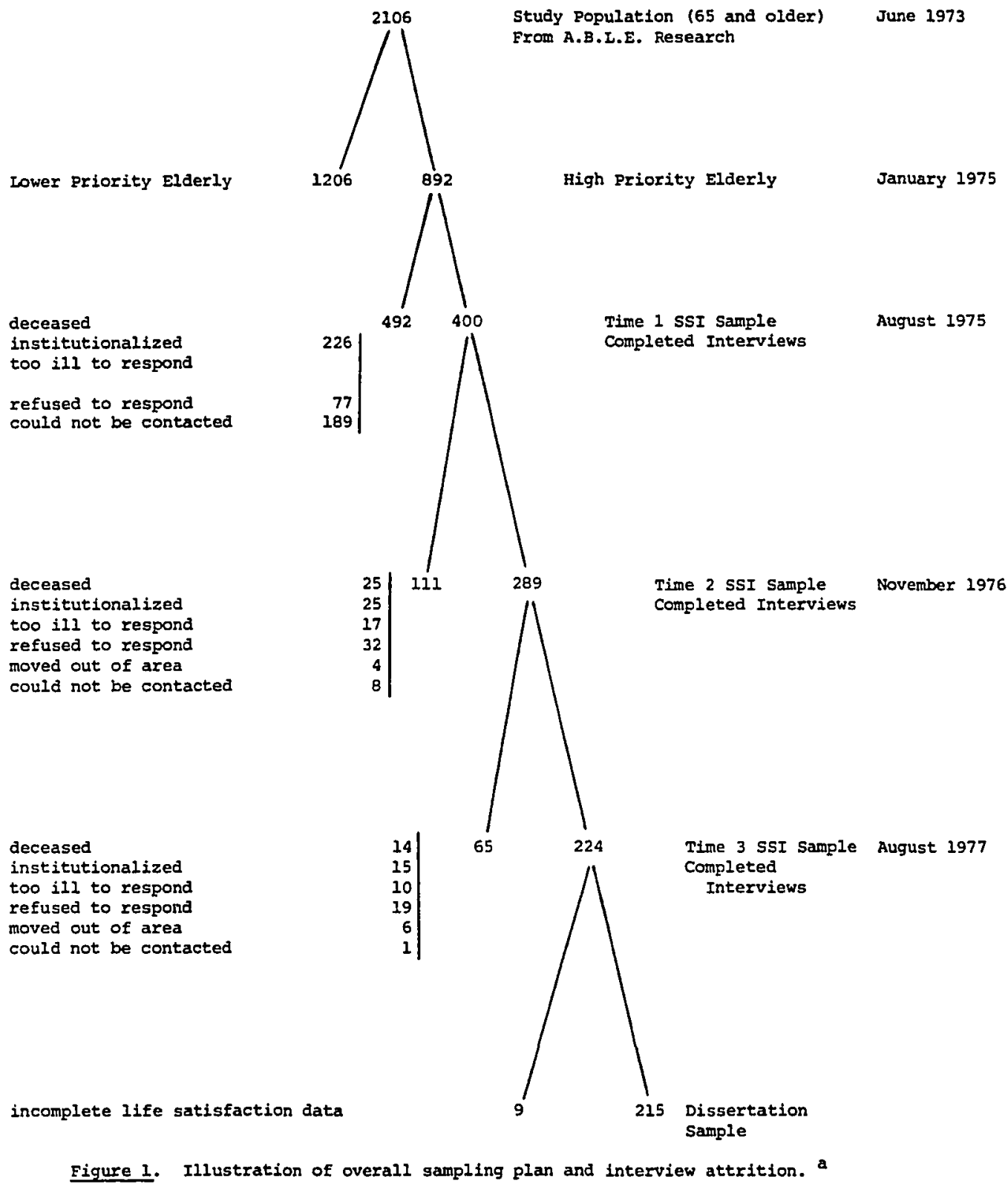

a This table is a modification of a similar table from the SSI final report and was constructed by Ellen Jean, a member of the SSI research team. 
TABLE VI

CHARACTERISTICS OF POPULATION AGED 65 AND OVER FOR THE UNITED STATES, MULTNOMAH COUNTY, THE STUDY POPULATION, AND THE SSI STUDY SAMPIE

\begin{tabular}{cccc} 
(1) & (2) & (3) & (4) \\
\hline $\begin{array}{l}\text { UNTTED STATES } \\
(1970 \text { Census) }\end{array}$ & $\begin{array}{c}\text { MUITNOMAH COUNTY } \\
\text { (1970 Census) }\end{array}$ & STUDY POPULATION & SSI STUDY SAMPLE \\
$n=20,101,874$ & $n=70,515$ & $n=2,106$ & $n=400$ \\
\hline
\end{tabular}

AGE

$\begin{array}{lllll}65-74 & 628 & 578 & 408 & 438\end{array}$

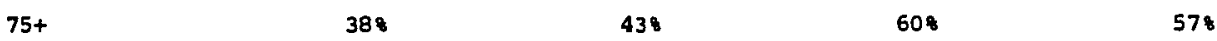

SEX

$\begin{array}{lllll}\text { MALE } & 438 & 418 & 288 & 238\end{array}$

$\begin{array}{lllll}\text { FEMLALE } & 57 \% & 598 & 728 & 77 \text { \% }\end{array}$

IIVING ARRANGEMENT

$\begin{array}{lcccc}\text { ALONE } & 318 & 33 * & 658 & 758 \\ \text { WITE SPOUSE } & 508 & \text { NA } & 268 & 178 \\ \text { OTHER } & 198 & \text { NA } & 98 & 88\end{array}$

INCOME

BELOW ADJUSTED

POVERTY THRESHOLD

$198^{a}$

$258^{a}$

$438^{a}$

$598^{b}$

$(1975=\$ 225 / \mathrm{mo})$

au.s. Bureau of Census, 1969 Poverty Line (\$150/mo)

bstimate based on USSHEN, SSA. Poverty threshold adjusted for Regional BIS price data. computation based on analysis of consumer expenditures of the SSI Study sample. 
Oregon population, 3) the ABLE study population and 4) the SSI study sample.

Sample Selection for the Dissertation Research. From the SSI study sample of 400 persons, 224 persons completed all three interviews from 1975 to 1977 and 215 were selected for this research. These individuals are referred to simply as the dissertation sample. Nine of the 224 persons were eliminated because of missing data in their interviews.

At completion of the three interviews in the summer of 1977 , the mean age of the dissertation sample was 78.09 , the median age being 78. The ethnic composition of the dissertation sample was predominantly white $(96.8 \%)$ and $2.7 \%$ were black, this ethnic distribution being the same as the portland standard metropolitan statistical area where about 2.58 of the total population is black. The dissertation sample was predominantly female (75.9\%). The widowed subgroup totalled 68.8\%, those married $16.1 \%$, divorced $11.6 \%$, and never married $3.6 \%$. Those older persons living alone were $73.8 \%$ of the dissertation sample; 14.98 reported living with spouse, 6.38 with relatives and 58 with non-relatives.

About one half $(50.5 \%)$ of the dissertation sample lived in detached single family dwellings, 31.68 lived in apartments, $6.8 \%$ resided in two-family dwellings and the remaining $11.3 \%$ reported having other living arrangements. Those who reported owning their own homes outright totalled $36.6 \%$ of the study sample. In addition, 14.68 had a mortgage on their homes and the remainder paid rent (48.88). Table VII is a summary of the median income for the dissertation sample for single and two person units. Money income 
TABLE VII

MEDIAN INCOME FOR SINGLE

AND TWO PERSON UNITSa

\begin{tabular}{lcc}
\hline & Money Income & $\begin{array}{l}\text { Money Income Plus } \\
\text { In Kind Transfers }\end{array}$ \\
\hline $\begin{array}{l}\text { Median Income Units } \\
\text { Single Person Units }\end{array}$ & $\$ 2843$ & $\$ 3751$ \\
$\begin{array}{l}\text { Median Income } \\
\text { Two Person Units }\end{array}$ & $\$ 3809$ & $\$ 5032$ \\
\hline
\end{tabular}

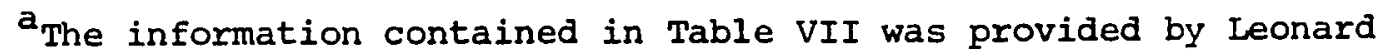
Gionet and calculated as part of his doctoral dissertation.

${ }^{b}$ In Kind Transfers were limited to Medicare/Medicaid, low rent public housing and food stamps. 
is reported in addition to money income plus a dollar value assigned to in-kind transfers.

Dependent and Independent Variables

The dependent variable for this study is psychological well-being and is operationalized by the Life Satisfaction Index. The independent variables are the life situations defined earlier and are operationalized by eight well-being indicators.

Three interview instruments were developed by the sSI study research team, one instrument for each time of data collection. The test instrument included items from a pool of items approved by the Social Security Administration. Items were selected to obtain information in a number of substantive areas including personal history, medical health status, economic status, housing and neighborhood, social participation, activities, attitudes, service utilization and interviewer observations regarding cognitive status. These items were used in operationalizing the dependent and independent variables for this dissertation.

A modified version of the Life Satisfaction Index was the instrument used to assess psychological well-being and is referred to as the ISI. Eight scales were developed to measure the personal, social and environmental life situation dimensions. These eight scales are called Well-Being Indicators (WBIs). Measures of change in the life satisfaction and measures of change for the eight WBIs were also constructed and are discussed in detail in later sections. The terms time 1, time 2 , and time 3 are used to indicate the three periods of data collection, the summers of 1975, 1976 and 1977 
respectively.

Methodological Issues in Scale Construction

Single item correlates have been researched frequently for possible relationships to LSI scores. However, there is considerable evidence to indicate that the use of scales made up of multiple items is a more effective method of obtaining relationships between measures.

There are a number of important reasons for requiring more than one item in most attribute measurements; Nunnally (1978) discusses these at length. First, individual items usually have only a low degree of relationship with the particular attribute in question. That is, each item tends to have only a low correlation with the attribute being measured. Also each item tends to relate to attributes other than the one being measured. In addition, each item has considerable specificity; "that is, it has a type of individuality that is not correlated with any general attribute or factor" (Nunnally, 1978, p. 67).

A second reason for using multi-item scaling is that most items tend to categorize people into two groups or several relatively small groups. An item requiring dichotomous responses can distinguish between, at most, only two levels of the attribute. A seven-step scale, in contrast, can distinguish between seven levels of an attribute. Nunnally (1978) states that in most measurement problems it is desirable to make fine differentiations among people. This can seldom be done with a one-item measure.

A third reason why one-item measures do not suffice, according to Nunnally (1978), is that individual items have considerable measurement 
error. That is, as single item measures, their reliabilities are often less than desirable. Each item, "occasions a considerable amount of random error" (Nunnally, 1978, p. 67). Thus there is some randomness related to any item and, as a result, the individual item cannot be trusted to give an adequately reliable measurement of an attribute. However, this unreliability averages out when scores on numerous items are summed to obtain a total score which then frequently is highly reliable.

Nunnally (1978, p. 67) states,

All three difficulties that have been discussed can be diminished by the use of multi-item measures. The tendency of items to relate to factors other than attributes being investigated usually averages out when several items measuring a comon attribute are combined. By combining items, one can make relatively fine distinctions among people. The reliability tends to increase (measurement error reduces) as the number of iterns in a combination increases.

For a detailed description of scaling reliability, Nunnally may be consulted (chapters 6 and 7, 1978).

A fourth, and equally important persuasion for multi-item scaling, is that using a single iten to measure an attribute may exclude information that is critical to the measure. For example, in construction of a measure of income, a single item, "What is your monthly income?" will tend to give a distorted measure of income. Other items must be accounted for depending upon the population being studied so that, for this sample, a measure of incone must take into account in-kind transfers, use of savings, rent subsidies, et cetera. Therefore, it was determined that the construction of multiitem scales, made up of variables selected on the basis of past research findings, theoretical significance, and judgments of this 
researcher, would be the superior method of obtaining significant relationships among the other well-being measures and life satisfaction scores. Accordingly, the eight WBIs (Well-Being Indicators) were built. Items were selected from the data and placed in the appropriate indicator. Pearson correlations were calculated for pairs of individual items within each scale and for each item with its total scale score. only those items were retained within a scale whose item-total correlations were both greater than .30 and significant at $p<.001$. A detailed description of the scale construction is presented later in this chapter.

Eight WBIs were constructed from the data collected at time 1. These were medical health status, cognitive status, lack of impairment, activity level, social contacts, lack of worry, income and housing. The same eight WBIs were constructed for times 2 and 3 , keeping the items as nearly the same as possible. Since a number of items were not repeated across times 1,2 and 3 , similar items were selected whenever possible and, of course, identical items were selected when available. The ninth scale used in this research was the LSI which was included in the test instrument used at times 1 and 3 . Only one ISI item was included in the time 2 test instrument; therefore no scale construction was possible for time 2 .

Formation of Life Satisfaction Groups

The test instrument selected for assessing the subjective psychological well-being of the dissertation sample was the fourteen item scale ISI, which was modified and tested by various researchers (BuIl and Aucoin, 1975; Cutler, 1975; O'Brien, 1974; Edwards and Klemmack, 
1973; Bultena and Oyler, 1971; Adams, 1969). As discussed earlier, the strength of the ISI is that it permits the respondents to evaluate their present, past and future lives from an internal frame of reference and tends to minimize social and investigator biases.

The ISI correlates at .989 with the original test instrument (ISIA) developed by Neugarten et al. (1969). Both Adams (1969) and Wood et al. (1969) found that when item analysis was undertaken, the instrument was improved after deleting several of the original test items. Wylie (1.970) computed a ISI test reliability of .79 using the Kuder-Richardson Formula 20, "Coefficient Alpha", which computes an average of all conceivable split halves. Wood et al. (1969) suggest that the ISI is "a useful self-report instrument in cases where a reasonable approximation of level of psychological well-being will suffice" (p. 466). Wylie (1970) reports validity statistics for the ISI when it was correlated with the original interviewers' life satisfaction ratings (Neugarten et al., 1969) of $r=.57$. For this research, an abbreviated form of the LSI was used to assess psychological well-being of the sample at time 1 . The abbreviated form consisted of four items taken from the modified LSI:

1. I am just as happy as I was when I was younger.

2. I expect some interesting and pleasant things to happen to me in the future.

3. As I grow older things seem better than I thought they would be.

4. I would not change my past life even if I could.

In view of the high correlations between other modified versions of the original LSI, it was determined that these four items would be an adequate assessment of life satisfaction for time 1 .

The complete fourteen-item modified LSI (Adams, 1969) was used 
to assess psychological well-being at time 3 . The fourteen-item modified LSI was presented earlier in Table II of Chapter II. (Slight changes in some items were made for this study. The form of the LSI used in the SSI study and subsequently in this dissertation is presented in Appendix A). At both times 1 and 3, each item was read aloud and each person was asked to respond on a continuum of "strongly agree, agree, disagree, strongly disagree, or do not know".

The four LSI items used in the time 1 test instrument were correlated with their corresponding items at time 3 . Three of the items correlated at $r=.40$ or greater; one item correlated at $r=.32$, all with significance levels of $p<.001$. The total four-item ISI scale from time 1 correlated at $r=.50$ with the fourteen-item, time 3 ISI.

While a two-year time interval is considerably longer than the usual two-week to two-month interval used in test-retest reliability, the correlation between the ISI at time 1 and time 3 suggests adequate long-term stability for this study.

A factor analysis using the principal components method and a Varimax rotation was performed to determine if the fourteen items were reflective of the original five components of life satisfaction: zest of life as opposed to apathy; resolution and fortitude as opposed to resignation; congruence between desired and achieved goals; high physical, psychological and social self-concept; and a happy, optimistic mood tone (Neugarten et al., 1969). Three factors actually emerged from analysis of these data and are reflective of three of the five dimensions defined by Neugarten et al. (1969). Table VIII presents the rotated factor loadings for the ISI items as well as the 
FACTOR 1:

A happy and optimistic mood tone.

$\underline{\text { Item }}$

This is the dreariest time of my life.

.8440

.735

These are the worst years of my life.

.8106

.726

Most of the things I do are boring or monotonous.

.5931

.419

My Iife could be happier than it is now.

.4967

.450

The things I do are as interesting to me now.

$-.5781$

.490

I am just as happy as when I was younger.

$-.4552$

.443

FACTOR 2:

Resolution and fortitude as opposed to

resignation

Item

I have gotten more of the breaks in life.

I expect interesting and pleasant things to happen.

As I grow older, things seem better than I thought

I've gotten pretty much what I expected from life.

.5011

.635

Compared to other people my age, I make a good

.4082

.350 appearance.

FACTOR 3:

Congruence between desired and achieved goals

Item

I would change quite a lot of my past life. 
communalities. This factor analysis was performed on the fourteeniten LSI used at time 3.

Of the 224 older persons completing the SSI study, 215 were selected for this research; the other nine were eliminated from the data analysis because of missing responses from their LSIs. It was determined that it would be inappropriate to calculate average scores based upon data where more than one half of the items were missing. Of the 215 persons selected for this research, 85.08 had complete data available on the LSI items. For each of the 215 older persons, the responses on the items of the LSI at time 1 were summed and divided by the number of items which the person had answered. By computing the average of the items answered, missing data could be ignored. The same procedure was followed for computing scale scores on the LSI at time 3. The result was that all subjects had scores ranging from 1 (low LS score) to 4 (high LS score).

The mean LSI score at time 1, for the dissertation sample, was 2.72 and at time $3,2.75$. While there was no significant difference between these two means, preliminary data analysis indicated that some persons did experience marked changes in LSI scores from time 1 to time 3 .

A major methodological task for this dissertation then, was to devise some way to measure change on the LSI. Harris (1963) has discussed problems associated with "difference scores" or "change scores" in his book, Problems in Measuring Change. He suggests the use of regression procedures as a more desirable solution to assessing change. Consequently, it was decided to determine individual placement into IS groups on the basis of residual scores derived from 
linear regression procedures. Specifically, the actual scores received at time 1 were used to predict ISI scores at time 3. The residual used was the deviation of the actual time 3 LSI score minus the predicted tine 3 LSI score.

The rationale for this approach was to allow compensation for statistical regression toward the mean. When the $\mathrm{XY}$ correlation is less than 1.00 , the $x$ variable (both high and low scores) have, on the average, a greater probability of their predicted $Y$ scores being closer to the mean of the $\mathrm{Y}$ distribution than their $\mathrm{X}$ scores were to the mean of the $\mathrm{x}$ distribution. This regression toward the mean has an even greater effect for extreme scores. Failure to control for statistical regression toward the mean presents a problem in interpreting changes in LSI from time 1 to time 3. Hence, the regression approach was used to generate residuals by which the IS groups were formed.

The following method was used to determine the final is groupings. The LSI scores for each person at time 1 and time 3 were converted to $z$ scores for use in some of the calculations. Predicted ISI scores at time 3 were calculated based upon ISI scores at time 1 and the correlation of ISI scores at times 1 and 3 :

For raw ISI scores:

$$
\begin{aligned}
Y_{3}^{\prime}=a+b X_{1} \text { where: } Y_{3}^{\prime} & \text { is the predicted LSI score } \\
& \text { at time } 3 \text { (in raw score form) } \\
a & \text { is the } Y \text { intercept (a=1.723) } \\
& b \text { is the regression weight for } \\
& \text { predicting ISI scores at } \\
& \text { time } 3 \text { from ISI scores at } \\
& \text { time } 1 \text { (b=.379) }
\end{aligned}
$$



$x_{1}$ is the raw LSI score at
time 1.

Using $\mathrm{z}$ scores, the formula becomes:

$$
\begin{aligned}
& z_{3}^{\prime}=0+r z_{1} \text { where: } Y_{3}^{\prime} \text { is the predicted LSI score } \\
& \text { at time } 3 \text { (in raw score form) } \\
& 0 \text { is the } \mathrm{Y} \text { intercept } \\
& r \text { is the regression constant } \\
& \text { for predicting time } 3 \text { LSI } \\
& \text { scores from time } 1 \text { LSI } \\
& \text { scores. This regression } \\
& \text { constant for } \mathrm{Z} \text { scores is } \\
& \text { simply the Pearson correla- } \\
& \text { tion between time } 1 \text { and time } \\
& 3 \text { LSI scores }(r=.500) \\
& \text { in } \mathbf{Z} \text { score form). }
\end{aligned}
$$

This regression equation yields the regression line or predicted LSI scores for individuals at time 3.

Residual scores for each person were computed, the residual being the difference between the actual LSI score at time 3 and the predicted ISI score at time 3. The formulas for these residuals are:

For raw LSI scores:

$$
\begin{aligned}
& Y_{3}-Y_{3}^{\prime}=\text { raw score residual } \\
& \text { where: } Y_{3} \begin{array}{l}
\text { is the actual ISI score at } \\
\text { time } 3
\end{array} \\
& Y_{3}^{\prime} \begin{array}{l}
\text { is the predicted ISI score } \\
\text { at time } 3 .
\end{array}
\end{aligned}
$$

For LSI scores in $\mathrm{z}$ score form:

$$
\begin{aligned}
& z_{3}-z_{3}^{\prime}=z \text { score residual } \\
& \text { where: } z_{3} \begin{array}{l}
\text { is the actual LSI score } \\
\text { (in } z \text { score form) at time } 3
\end{array} \\
& z_{3}^{\prime} \begin{array}{l}
\text { is the predicted ISI score } \\
\text { (in } z \text { score form) at time } 3 .
\end{array}
\end{aligned}
$$

The dissertation sample standard error of estimate (SE est ) for 
raw scores was used to determine dividing points for the IS groups. The SE est is simply the standard deviation of the residuals. (The population SE est of the standard deviation of the assumed normal distribution of actual $Y$ scores for any given value of $X$ and can be thought of as an index of imperfection or unreliability for the regression equation). The formula for calculating the sample SE est for raw scores is as follows:

$$
\mathrm{SE}_{\text {est }}=s_{3} \sqrt{1-r_{13}^{2}}
$$

$$
\begin{aligned}
& \mathrm{SE}_{\text {est }} \begin{array}{l}
\text { is the standard error of } \\
\text { estimate }(.4437)
\end{array} \\
& \mathrm{s}_{3} \quad \begin{array}{l}
\text { is the standard deviation } \\
\text { of the time } 3 \text { LSI scores } \\
(.511)
\end{array} \\
& \mathrm{r}_{3} \text { is the squared correla- } \\
& \text { tion of LSI scores at } \\
& \text { time I with ISI scores } \\
& \text { at time } 3\left(.500^{2}=.250\right) .
\end{aligned}
$$

The SE est was computed (.4437) and one half of the value (.22) was selected as the value to use in operationalizing stability versus change in life satisfaction. The reasons for selecting half of the $\mathrm{SE}_{\text {est }}$ as a boundary for stability versus change were several. First, since research evidence suggests that life satisfaction is fairly stable over time, it was felt that when change did occur, it would be in small increments. Furthermore, using half $S E_{\text {est }}$ as a dividing point allowed adequate numbers in each group and approximately equal distribution of persons into stable LS groups and positive and negative IS change groups. The study sample was divided into stable and change IS groups as follows:

Stable IS Groups. Older persons whose residual scores were within $\pm 1 / 2 \mathrm{SE}_{\text {est }}$ were defined as being members of the stable IS 
groups. Any person, then, who received a residual score between -.22 and $a+.22$ was placed in a stable LS group. Three stable groups were formed:

1. Low-Iow

2. Middle-Midale

3. High-High those persons whose scores were generally low at time 1 and remained low at time 3 . A person's ISI scores (in $\mathrm{Z}$ score form) for time 1 and time 3 were averaged. Those with an average ISI score falling at or below - .51 SD were defined as members of the stable-low or low-low group.

those persons whose scores were generally in the midale range at time 1 and remained there at time 3. The stable-middle or middlemiddle group was defined as those whose average LSI scores were between -.50 SD and $+.50 \mathrm{SD}$.

those persons whose scores were generally high at time 1 and remained high at time 3 . The stable-high or high-high yroup was defined as those whose average ISI scores were . $51 \mathrm{SD}$ and above.

of the 215 persons, $39.1 \%$ received stable LS scores. Those

whose scores were "stable low" number 30, or 35.7\% of the stable

group. Thirty-five (35) persons received "stable middle" scores or 41.6\% of the stable sample, and nineteen (19) persons received "stable high" scores of $22.7 \%$ of the stable population.

Change IS Groups. A change in IS scores was defined as any

person having a residual falling beyond \pm .22 . (Recall that $\pm 1 / 2 \mathrm{SE}$ est equals \pm .22$)$. Therefore, if the person's residual score was greater than +.22 , the Is score changed in a positive direction. On the other hand, if the residual score was below - .22, Is changed in a negative direction. The positive and negative Is groups were further subdivided into the following groups. The positive change groups are: 
1. Low-Middle

those persons whose residuals exceeded +.22 and whose time 3 ISI scores were less than +1.00 SD. This group had time 1 LSI scores which were generally in the low and middle range and time 3 ISI scores which were in the middle range (i.e. < 1.00 SD).

2. Middle-High those persons whose residuals exceeded +.22 and whose time 3 LSI scores were greater than or equal to $+1.00 \mathrm{SD}$. This group had time 1 LSI scores which were generally in the midale and high range and time 3 LSI scores in the high range.

The negative change groups are:

1. High-Midale those persons whose residuals fell below -.22 and whose time 3 ISI scores were greater than -1.00 SD. This group had time 1 LSI scores which were generally in the high and middle range and time $3 \mathrm{LSI}$ scores which were in the middle range.

2. Middle-Low those persons whose residuals fell below -.22 and whose time 3 ISI scores were less than or equal to $-1.00 \mathrm{SD}$. This group had time 1 ISI scores which were generally in the middle and low range and time 3 ISI scores in the low range.

It must be pointed out that while the three stable groups and the four change groups have specific quantitative boundaries, the names attached to these groups are not meant to convey precise boundaries. Instead, the names have been chosen to provide the reader with a convenient device for distinguishing the various stable, positive change, and negative change groups.

A verbal illustration of the use of residual scores to accomodate for statistical regression toward the mean and to determine group placement will be useful in understanding the methods utilized. Subject $A$ receives an ISI score of 1.75 at time 1 and at time 3 receives an ISI score of 2.08. It appears that Subject $A$ has had a positive change in her ISI score. However, the predicted time 3 score for 
Subject $A$ is 2.38 . The residual score is -.310 which indicates that Subject A's position relative to the rest of the group is in fact lower than would have been predicted. Therefore, subject $A$ is placed in a negative change LS group. Because Subject A's ISI scores, both at time 1 and time 3 , are in the low ranges, she is further placed in the negative change group referred to as Middle-Low.

Subject B receives an ISI score at time 1 of 2.75 ard at time 3 receives an ISI score of 3.31. It appears that subject $B$ has had a positive change in ISI scores. The predicted time 3 score for subject $B$ is 2.77 . The residual LSI score is +.543 which indicates that subject $B^{\prime}$ 's position relative to the rest of the group is in fact higher than would have been predicted. Subject $B$ is placed in a positive change LS group and because his scores have changed from the midale range to the high range, he is placed in the positive change group referred to as Middle-High.

A summary of the formation of LS groups is presented in Table IX. This table also contains summary statistics on the time 1 and time 3 ISI scores for the seven IS groups.

\section{Formation of Eight Well-Being Indicators}

A theoretical model and a methodological strategy for the development of eight Well-Being Indicators were discussed by stewart and Whitelaw (1977) using data collected at time 1. This model was used for constructing similar indicators at time 2 and $3^{*}$. Because of the deletion of some items or substitution or inclusion of other

*Indicators at time 3 were constructed by the author and Marie Beaudet-Walters. 
TABLE IX

LIFE SATISFACTION GROUP FORMATION AND SUMMARY STATISTICS ON THE LSI AT TIME 1 AND TIME 3

\begin{tabular}{|c|c|c|c|c|c|c|c|c|c|c|}
\hline \multicolumn{2}{|c|}{ LS GROUPS } & \multirow[b]{3}{*}{84} & \multirow{3}{*}{$\begin{array}{c}\begin{array}{l}\text { Percent of } \\
\text { Total Sample }\end{array} \\
\\
39.1\end{array}$} & \multicolumn{2}{|c|}{ BOUNDARIES USED IN FORMATION OF IS GROUPS } & \multicolumn{5}{|c|}{ ISI SUMMARY STATISTICS } \\
\hline TIME I & TIME 3 & & & \multirow{2}{*}{$\begin{array}{c}\text { Residuals about Raw } \\
\text { Score Regression Line } \\
Y_{3}^{\prime}=1.723+.379 \mathrm{x}_{1}\end{array}$} & \multirow{2}{*}{$\begin{array}{l}\text { Other Boundaries } \\
\text { Average of Time } 1 \text { and } \\
\text { Time } 3 \text { LSI (in } z \\
\text { score form) }\end{array}$} & \multicolumn{2}{|c|}{ TIME 1} & \multicolumn{3}{|c|}{ TIME 3} \\
\hline \multicolumn{2}{|c|}{ STABLE GROUPS } & & & & & $\begin{array}{l}\text { Range of } \\
\text { Scores }\end{array}$ & $\mathrm{M} \quad \mathrm{SD}$ & $\begin{array}{l}\text { Range of } \\
\text { Scores }\end{array}$ & M & SD \\
\hline High & High & 19 & 8.88 & -.22 to +.22 & $>.50 \mathrm{SD}$ & $3.00-4.00$ & 3.58 .29 & $2.79-3.43$ & 3.23 & .16 \\
\hline Middle & Midale & 35 & 16.38 & -.22 to +.22 & $-.50 \mathrm{SD}$ to $+.50 \mathrm{SD}$ & $2.25-3.25$ & 2.70 .31 & $2.50-3.00$ & 2.75 & .14 \\
\hline Low & Low & 30 & 14.08 & -.22 to +.22 & $<-.50 \mathrm{SD}$ & $1.00-2.25$ & 1.83 .31 & $1.36-2.63$ & 2.34 & .27 \\
\hline \multicolumn{2}{|c|}{ POSITIVE CHANGE GROUPS } & 64 & 29.78 & & $\begin{array}{l}\text { Tine } 3 \text { LSI scores } \\
\text { (in } 2 \text { score form) }\end{array}$ & & & & & \\
\hline Low & Middle & 31 & 14.48 & $>+.22$ & $<1.00 \mathrm{SD}$ & $1.25-3.00$ & 2.34 .43 & $2.57-3.23$ & 3.03 & .17 \\
\hline Middle & High & 33 & 15.38 & $>+.22$ & $\geqslant 1.00 \mathrm{SD}$ & $2.00-4.00$ & 3.14 .56 & $3.29-3.92$ & 3.54 & \\
\hline \multicolumn{2}{|c|}{ NEGATIVE CHANGE GROUPS } & 67 & 31.28 & & $\begin{array}{l}\text { Time } 3 \text { LSI scores } \\
\text { (in } \mathrm{z} \text { score form) }\end{array}$ & & & & & \\
\hline High & Midale & 44 & 20.58 & $<-.22$ & $>-1.00 \mathrm{SD}$ & $2.50-4.00$ & 3.14 .43 & $2.29-2.90$ & 2.51 & .17 \\
\hline Middle & Low & 23 & 10.78 & $<-.22$ & $\leqslant-1.00 \mathrm{SD}$ & $1.00-3.25$ & 2.23 .58 & $1.36-2.23$ & 1.95 & .26 \\
\hline TOTAL & & 215 & 100.08 & & & & 2.72 .68 & & 2.75 & .51 \\
\hline
\end{tabular}

Note: $M=$ mean $S D=$ standard deviation 
items in the survey instruments themselves, it was not possible to construct measures with identical items across times 1, 2, and 3 . Whenever possible identical items were used across times or similar items were substituted.

Measures of well-being at times 1,2 , and 3 were constructed as follows: Items were chosen to reflect each of the eight well-Being Indicators: Medical Health Status, Lack of Impairment, Cognitive Status, Social Contacts, Activities, Lack of Worry, Income and Housing. The possible responses to the items chosen were scaled a priori as a $4,3,2$, or 1 with 4 representing the highest level of well-being and 1 the lowest. For each of the 215 subjects completing the study, the responses on the items reflecting each dimension were summed and divided by the number of items on that dimension which the subject had answered. By computing the average of the items answered for each dimension, missing data could be ignored. The formation of these eight measures resulted in all subjects having scores ranging from 1 (low well-being) to 4 (high well-being) on all eight indicators.

Well-Being Indicators at Time 1

At time 1, six of the eight WBIs achieved complete data for at least 95 percent of the subjects, while for the Social Contacts scale and the Income scale complete data existed for 89 percent and 90 percent of the subjects respectively. On these latter two scales, an additional 9 percent and 8 percent of the subjects respectively were missing only one response.

Correlations between item and total scores for each scale were 
calculated. The 50 item-total correlations ranged from .17 to .80 with a median correlation of .56. Of the three item-total correlations below .35 , all were still significant at $p<.001$ and, consequently, remained a part of their respective scales since the items were predicted a priori as important aspects of the dimensions. For each of the five scales comprised of fewer that eight items, correlations were also computed between each item and its respective total score after that item had been subtracted from the total score. Again, all correlations were significant at $p<.001$. A description of the eight time 1 WBIs follows.

The first three indiators, Medical Health Status, Lack of Impairment, and Cognitive Status, reflect areas of personal status. The next two indicators, Social Contacts, and Activities reflect areas of social status. Finally, the last three indicators, Lack of Worry, Housing, and Income, represent environmental resources. These categories are the same for time 2 and time 3.

Personal Status Areas. (1) Medical Health Status: 5 items indicating self perceived condition of health, amount of time bedridden or in hospital during the past year, use of a visiting nurse, and observer's rating of disabilities. (2) Lack of Impairment: 5 items covering personal mobility, use of prosthesis, physical therapy, meals programs, and housework help. (3) Cognitive status: 3 items based on observer ratings of the older person's degree of alertness, lack of confusion, and level of interest in the interview.

Social Status Areas. (1) Social Contacts: 8 items reflecting having, living near, and interacting with children; the numbers of one's confidants; recency of talking with a neighbor, relative, 
friend, or other person. (2) Activities: 7 items covering the extent to which the older person is confined to home; how recently the person has gone to a grocery, post office, bank, restaurant, or church; and the means of transportation a person usually uses.

Environmental Resources Areas. (1) Lack of Worry: 8 items reflecting concern or worry about such matters as security, traffic, friends, neighbors being o.k., health, money problems, walking alone in neighborhood, and the kind of people living in their neighborhood. (2) Housing: 4 items reflecting the existence of a kitchen and the number of rooms in one's housing unit as well as observer ratings of the general condition of the housing unit and its furnishings. (3) Income: 11 items covering sources of financial support and subjective perception of current financial situation compared to others and to self in earlier years.

Well-Being Indicators at Time 2

Correlations between item and total scores for each scale were calculated. The 45 item-total correlations ranged from .28 to .86 with a median correlation of .60 . Of the four item-total correlations below .35 , all were still significant at $\mathrm{p}<.001$ and, consequently, remained a part of their respective scales since the items were predicted a priori as important aspects of the dimensions. For each of the eight scales, correlations were computed between each item and its respective total score after that item had been subtracted from the total score. Again, all correlations were significant at $p<.001$. A description of the eight time 2 WBIs follows:

Personal Status Areas. (1) Medical Health Status: 4 items 
indicating self perceived condition of health, amount of time bedridden or in hospital during the past year, and observer's rating of disabilities. (2) Lack of Impairment: 5 items covering personal mobility, the use of meals programs, and housework help. (3) Cognitive status: 2 items including observer ratings of the older person's degree of alertness and his or her level of interest in the interview.

Social Status Areas. (I) Social Contacts: 11 items reflecting having, living near, and interacting with children; the numbers of one's confidants; recency of talking with a neighbor, relative, friend, or other person; and subjective measures of satisfaction with social contacts. (2) Activities: 7 items covering the extent to which the older person is confined to home; how recently the person has gone to a grocery, post office, bank, restaurant, or pharmacy; and a subjective measure of satisfaction with activities.

\section{Environmental Resources. (1) Lack of Worry: 6 items} reflecting concern or worry about security, health, money problems, walking alone in neighborhood, the kind of people living in their neighborhood and safety of neighborhood for older people. (2) Housing: 5 items reflecting observer ratings of the general condition of the housing unit and its furnishings and a subjective measure of satisfaction with housing. (3) Income: 6 items covering sources of financial support and subjective perception of current financial situation compared to others and to self in earlier years.

Well-Being Indicators at Time 3

Correlations between item and total scores for each scale were 
calculated. The 53 item-total correlations ranged from .28 to .92 with a median correlation of .57 . Of the four item-total correlations below . 35, all were still significant at $p<.001$ and, consequently, remained a part of their respective scales since the items were predicted a priori as important aspects of the dimensions. For each of the eight scales correlations were computed between each item and its respective total score after that item had been subtracted from the total score. Again, all correlations were significant at $p<.001$. Descriptions of the eight time 3 WBIs follows.

Personal Status Areas. (1) Medical Health Status: 5 items indicating self perceived condition of health, amount of time bedridden or in hospital during the past year, use of a visiting nurse, and observer's rating of disabilities (Duplicates of time 1 indicators). (2) Lack of Impairment: 5 items covering personal mobility, physical therapy, meals programs, and housework help. (3) Cognitive status: 2 items including observer ratings of the older person's degree of alertness and level of interest in the interview (Duplicates of time 2 indicators).

Social status Areas. (1) Social Contacts: 8 items reflecting having, living near, and interacting with children, friends, and relatives, use of telephone, having someone with whom to discuss problems, speaking with neighbors or friends, and visiting senior citizen centers. (2) Activities: 5 items duplicating time 1, with the addition of a subjective measure of satisfaction with activities. Environmental Resources Areas. (1) Lack of Worry: 7 items reflecting concern or worry about such matters as security of home, health, money, walking alone at night, the kind of people living in 
the neighborhood, and well-being of friends. (2) Housing: 7 items reflecting subjective satisfaction with the home, size of home, and observer ratings of the general condition of exterior and interior of the home. (3) Income: 8 items covering sources of financial support, subjective perception of current financial situation, standard of living, cost of necessities, and well-being of friends.

Measures of Time 1 to Time 3 Change for Well-Being Indicators In addition to absolute scores on the WBIs, some measure of change from time 1 to time 3 was needed for these measures. Consequently, residualized change scores were obtained for each of the eight well-being areas. The same regression technique as described earlier in construction of the life satisfaction change scores were used to calculate the WBI change scores.

Reliability, Stability, and Validity Measures of Well-Being Indicators at Times 1,2 , anc 3

The issues of reliability, stability and validity of research data are always of paramount importance in the interpretation of data if meaningful conclusions are to be drawn. Self-report survey research is subject to a certain amount of measurement error and data used in the dissertation have these same problems in common with other survey research. The difficulties in resolving such problematic issues may very well be exacerbated when gathering information that demands accuracy of recall, and perceptions of one's life situations. The research team relied on the ability and willingness of the respondents to recall and relate many factual pieces of information that were sensitive, personal, and easily distorted through the individual's own 
perception of his or her life situations. These factors, coupled with the advanced age and poor health of many persons in the sample, may tend to make the data appear more suspect than they actually are.

In building a case for social science research, the point should be made that transactions and interactions between human beings are assumed to have credibility. That is, we trust or believe what people tell us and the order of our daily existence is based upon believing what we are told. The events surrounding and evolving from the transactions of people are based on some trust in the reliability of what went on during the encounter. Social science research is built around the assumption that we can, at least to a degree, believe what people tell us. There are some who contend that all social research is fantasy; however, for the purposes of this dissertation, that is a moot issue. The real issue is that, as with all self-report data, it is assumed that the level of respondent reporting is as accurate for these data as any other previous research involving self-report.

The fact that the respondents are now old should not disproportionally affect the credibility of the data. There was no indication of these older persons being unduly incapacitated as far as their mental functioning was concerned. Most appeared alert and lacking confusion as well as being interested in their surroundings according to interviewer rating, and there was considerable concrete evidence of the continued functional capacity of the people in the sample. The respondents had survived, independent of institutionalization, to a mean age of 72 years. They held jobs, owned homes, supported and raised families, retired, lived through all the changes accompanying aging. 
They paid bills, kept track of increasing cost of living, and carried on their daily lives much the same as most people do. They were, at the time of the study, still living in their own homes, caring for themselves, conducting their daily affairs, managing by diverse strengths and self-reliance to survive with a measure of independence. There is no reason to believe that the accuracy of self-report is any better or worse for this sample of older persons than it is with most populations studied.

The data do, in fact, have some strengths. All items selected for the three data collection times were gathered from a pool of items already tested and approved by the Social Security Administration. In previous research, many of the items had been found to be fairly good measurement tools of the characteristics they were designed to measure. Second, the data were collected at three points in time and the findings can be compared longitudinally thus allowing a greater degree of confidence in the data. Most research of this kind is typically crosssectional without any indication of how the items may change over time. These data offer an opportunity for obtaining information regarding reliability and stability of the WBIs by looking at them longitudinally.

The interviewers for this study were especially trained and alerted to the problems inherent in interviewing older persons and paid special attention to accommodating to their physical limitations and allowing additional time for responses when necessary.

Finally, it has been commonly observed by this researcher, and others as well, that many old people welcome the opportunity to have someone to talk with, to pay attention to them and listen to what they have to say. They are frequently very willing to take the time to 
answer questions and provide information. In sum, while it is true that mood swings, daily events, and day-to-day changes in health, may have a limiting effect on response credibility, the positive aspects of the interview for the older person may have a positive effect on the quality of his or her responses.

Statistical measures of reliability, stability, and validity of the WBIs provided additional support for the quality of the data. Appendix C, Tables XXV, XXVI, and XXVII contain, respectively, correlational data for internal consistency of the WBIs, stability of the WBIs over times 1,2 , and 3 , and intercorrelations of the WBIs over time. The intercorrelations of the WBIs give support to the construct validity of the scales.

While it would have been desirable to use the more traditional tests of reliability such as test-retest, it was not possible given the length of time between the three data collection periods. Therefore, measures of internal consistency using coefficient alpha were used as a test of reliability of the WBIs. Coefficient alpha can be computed for a scale administered once at one point in time. As indicated in Table XXV, some of the coefficient's fell well below desirable limits. Coefficient alpha was computed for the eight WBIs at times 1,2 , and 3 , and for ISI at times 1 and 3 , for a total of 26 coefficients of internal consistency. Of these 26 , ten fell within the acceptable range of .685 or better. Eleven were marginal with coefficients ranging between .485 and .631 ; three coefficients were low ranging from .439 to .469 . Two coefficients for Medical Health Status at time 2 and Social Contacts at time 3 were unacceptably low (.212 and .384 respectively). The low bound estimate of reliability was not unexpected because 
of the conceptual nature of the scales, some of which were heterogeneous. Had the scales been homogeneous, higher correlations would have been expected. As an illustration, Medical Health Status and Social Contacts, in their conceptualization, were not internally consistent. It was not expected that correlations would be high between contact with friends, children, and relatives; contact with one group does not necessarily mean contact with another. Yet, in assessing Social Contacts, it is necessary to take all three into account. For this reason, it was anticipated that internal consistency measurement would be inappropriately low. Another factor contributing to lower internal consistency coefficients were the relativey few items measuring the construct. Generally, the more items included in a measurement scale, the higher the coefficient, if the items are, in fact, measuring the construct.

Stability coefficients suggested that reliability of the WBIs was higher than indicated by the coefficients alpha. Although the scales were not equivalent, they were very similar, making it possible to compute statistics on their stability. As indicated in Table XXVI, Appendix C, stability coefficients for the eight WBIs across times I, 2 , and 3 , were all above .40 , significant at $p<.001$ with the exception of the stability coefficients computed for Cognitive status. Stability coefficients for Medical Health Status and Social Contacts were .565 and .652 , computed for time 1 and time 3 , both higher than the coefficients alpha. These coefficients were well within acceptable limits. The strength of the stability coefficients permitted the conclusion that the WBIs were satisfactory for research purposes. There is considerable supportive evidence for the construct 
validity of the WBIs as indicated in Table XXVII, Appendix C. The WBIs correlated in a logically predictable fashion in personal, social and environmental areas. In the personal area, Medical Health Sțatus correlated with Lack of Impairment as expected. The correlations of Cognitive Status with Medical Health Status were quite low, however, Stewart and Whitelaw (1977) found that Cognitive Status was one of the best predictors of later institutionalization. This finding gives support to the criterion related validity of Cognitive Status.

In the social area, Social Contacts correlated highly with Activities and this, once again, was a logical outcome. As discussed in the literature, patterns of activity are a source of social contacts. Furthermore, in this sample, social contacts were also instumental in the maintenance of levels of activity.

In the environmental area, Housing was highly correlated with Income which, again, was a reasonable outcome. People with higher incomes were able to afford better housing, adequate home maintenance, and were able to exercise a greater degree of control over where they lived. At the same time, older people with low income would be expected to live in housing of lower quality.

In addition to the WBIs correlating within personal, social, and environmental areas, the correlation between Medical Health Status, Lack of Impairment and Activities reflected the relationship between health, mobility, impairment and the individual's ability to maintain activity levels.

In conclusion, examination of reliability, stability and validity of the WBIs, indicated that the scales were sufficiently reliable and valid to use for the purposes of this research. While the WBIs cannot 
be rated as excellent measures of life situations, they are, in their present state, good and satisfactory measures. Further refinement through continued testing will undoubtedly increase both their reliability and validity. This initial attempt to develop the WBIs was sufficiently rewarding to warrant further inprovement for further research.

\section{Statistical Methods}

Investigation of the research question was accomplished, in part, by the use of SPSS (Statistical Package for the Social Sciences) computer programs on the CYBER 70 (Model 73) computer located at Oregon State University, Corvallis, Oregon.

Frequency Distributions. Preceding all the statistical techniques used in this research project, an initial examination of the distribution of responses to the variables was made. Absolute and relative frequencies provided a simple description of the study sample in raw numbers and percentages. In addition, averages (means, medians, modes) were used to summarize many of the characteristics and behaviors of the sample. Measures of dispersion (standard deviations, skewness, kurtosis) of the variables' distributions were examined to determine the usefulness of a variable for higher level of statistical analyses. Scale Building. Items for scale construction were chosen as potential components of a scale based upon theory and results of past research. Using Pearson $r$, item intercorrelations were examined as a first check for inclusion in the scale. The Pearson $r$ was then computed between each item score and the total score. In order for an item to be included in the final scale, its item-total correlation had to be significant at the .01 level. In addition for nearly all items, 
the item-total correlation exceeded .30.

Internal Consistency Reliability. Internal consistency reliability was determined for all WBI and LSI measures using coefficient alpha. These coefficients ranged from .21 to .85 with a median coefficient of .57 . These reliability coefficients are included in Appendix C. While test-retest or alternate forms reliability would have been preferable for these scales, the nature of the data gathering procedures and the limited number of items in each scale precluded the use of such techniques.

Pearson Correlations. Pearson correlations between the ISI (time 1 and time 3 ) and the eight WBIs (time 1 , time 2 and time 3) were used for the purposes of testing hypothesis 1. Analogous sets of correlations were also computed separately for change and stable ISI subjects. One set of LSI-WBI correlations was computed for the 84 older persons comprising the three stable IS groups (HH, MM, and LI). A second set of LSI-WBI correlations was computed using data from the 131 older persons comprising the four change LS groups (LM, MH, HM, MI). Multiple Regression. Prior to testing hypotheses 2, 3, 4 and 5 , multiple regression procedures typically used to analyze change in past research of this type were also employed here to examine how change in ISI scores were related to the WBIs. Four separate multiple linear regression analyses were employed to examine residualized change in life satisfaction for the sample as a whole. The criterion variable for all four analyses was the LSI at time 3. Entering LSI at time 1 as the first predictor for all analyses resulted in the creation of residualized change scores for the ISI. Following this step the eight WBIs were entered. The first regression analysis used time 1 WBIs as 
predictors, the second analysis used time 2 WBIs, the third analysis used time 3 WBIs, and the fourth used the residualized change scores (time 1 to time 3) for the eight WBIs.

Analysis of Variance. Analysis of variance (ANOVA) procedures were used to compare IS group means on the eight WBIs at time 1, at time 2 , and at time 3 as well as on the residualized change scores for the eight WBIs. (This resulted in 32 ANOVAs.) A priori tests (i.e. planned comparison techniques followed the ANOVAs for the purpose of testing hypotheses $2,3,4$, and 5 .

Selected Case Studies

Fourteen persons were selected from the sample for the purpose of illustrative case studies. Two persons were selected from each of the seven LS groups, using the median ISI residual score as the basis for selection. Residual scores were rank ordered within each LS group and the median residual and next closest residual to it were chosen for case studies.

Test instruments at times 1,2 , and 3 were examined for each of the fourteen persons, giving particular attention to each item contained within the WBIs. Comments made by the interviewers as well as comments made by subjects themselves and recorded by the interviewers were noted. Summaries of WBI responses at each interview time were written and are appended to this report (See Appendix D). These case studies have been referred to in the discussion chapter to illustrate quantitative findings as well as to identify limitations of the findings. In addition, examination of the case studies was used as one means for generating hypotheses for future research. 
CHAPTER V

\section{RESULTS}

The five hypotheses generated to explore the relationship between psychological well-being and life situations of the elderly were tested using Pearson correlations, multiple linear regression and analysis of variance procedures. It will be recalled that the first hypothesis concerns the meaning of psychological well-being for a population of older persons in reduced circumstances as compared to other older populations. The second and third hypotheses focus on how stability versus change in psychological well-being, as measured by the ISI, is related to the life situations of older persons, as measured by eight WBIs at each of three interview periods. The last two hypotheses predict how stability and change in LSI scores are related to stability and change in WBIs. In this section, each hypothesis is presented followed by the results obtained from statistical analysis.

Findings Regarding Hypothesis 1

Hypothesis 1. It is hypothesized that the LSI scores for an elderly population in reduced circumstances are positively correlated with the same WBI variables found to correlate with measures of psychological well-being for other populations of older persons reported in previous literature. Such variables reported in past research include health and physical disability, social activity, socioeconomic variables, and housing.

Pearson correlations were obtained for the dissertation data and then compared to correlations reported in the literature. Table $\mathrm{X}$ presents four sets of correlations: time 1 WBIs with time 1 LSI, 
time 1 WBIs with time 3 LSI $^{\mathrm{a}}$, time 2 WBIs with time 3 LSI, and finally time 3 WBIs with time 3 LSI. The range of correlations for five life situations (Larson, 1977) are also presented in Table $\mathrm{X}$ and are used for visual comparison with corresponding correlations from the dissertation data.

Generally, the dissertation correlations are in agreement with the findings presented by Larson. The five WBIs which correspond to Larson's life situation variables are Medical Health Status, Lack of Impairment, Social Contacts, Housing and Income. Of the 20 correlations in Table $x$ involving these five WBIs and the ISI measures, all are positive as predicted and fourteen correlations are in the ranges reported by Larson. Three correlations fell below the expected range (time 1 Medical Health Status with time 1 ISI; time 1 Lack of Impairment with time 1 ISI; and time 2 Lack of Impairment with time 3 ISI). However, none of these three correlations is significantly less than the lower limit of Larson's range $(z=-1.35,-1.79$ and -.31 respectively; critical $z=-1.96$ for two-tailed test, $\alpha=.05)$. Three correlations exceeded the upper limit reported by Larson (time 1 Social Contacts with time 1 LSI; time 2 social Contacts with time 3 LSI; and time 3 Housing with time 3 LSI). Again, none of these

a One reason for computing the time $1 \mathrm{WBI} / \mathrm{time} 3 \mathrm{LSI}$ correlations was to see if time 3 LSI yielded higher correlations with the time 1 WBIs than did the time 1 LSI. Since the time 1 ISI consisted of only four items, it was possible that there was a restricted response range. This restriction of range could limit the magnitude of the computed correlations. In contrast, the ISI at time 3 had fourteen items which allowed for both a broader range of responses and a more reliable measure of life satisfaction. Consequently correlations of time 3 ISI with the WBIs were generally expected to be higher than those at time 1 ISI with the WBIs. 
TABLE X

CORRELATIONS BETWEEN WBIS AND ISI SCORES AND CORRESPONDING CORRELATIONS FROM PREVIOUS RESEARCH

\begin{tabular}{|c|c|c|c|c|c|}
\hline WBI & $\begin{array}{l}\text { Time } 1 \mathrm{WBI} / \text { Time } 1 \\
\text { LSI Correlations }\end{array}$ & $\begin{array}{l}\text { Time } 1 \mathrm{WBI} / \text { Time } 3 \\
\text { LSI Correlations }\end{array}$ & $\begin{array}{l}\text { Time } 2 \mathrm{WBI} / \mathrm{Time} 3 \\
\text { ISI Correlations }\end{array}$ & $\begin{array}{l}\text { Time } 3 \text { WBI/Time } 3 \\
\text { LSI correlations }\end{array}$ & $\begin{array}{l}\text { Correlations between } \\
\text { Life situation } \\
\text { Variables and Psycho- } \\
\text { logical Well seing }\end{array}$ \\
\hline $\begin{array}{l}\text { PERSONAL } \\
\text { Medical Health Status }\end{array}$ & $.11 *$ & $.31 * * *$ & $.33^{ \pm \pm \pm}$ & $.38 * \star \star$ & $\begin{array}{l}\text { health variables } \\
x=.2 \text { to } .4\end{array}$ \\
\hline Lack of Impairment & .08 & $.18^{* \star *}$ & $.20 * *$ & $.27 * * *$ & $\begin{array}{l}\text { physical disability } \\
\qquad=.2 \text { to } .4\end{array}$ \\
\hline Cognitive Status & $.21 * * *$ & $.17 * *$ & .05 & $.12 *$ & \\
\hline \multicolumn{6}{|l|}{ SOCIAL } \\
\hline Social Contacts & $.31 * * *$ & $.22 * * *$ & $.35 * * *$ & $.24 * \hbar *$ & $\begin{array}{l}\text { social activity } \\
x=.1 \text { to } .3\end{array}$ \\
\hline Activities & .09 & .09 & $\begin{array}{l}.15^{\star} \\
(\mathrm{N}=214)\end{array}$ & $.21 * \hbar *$ & \\
\hline \multicolumn{6}{|l|}{ ENVIRONMENTAL } \\
\hline Lack of Worry & $.11 *$ & $.18 * *$ & $.31 * * *$ & $.31 * * *$ & \\
\hline Housing & .10 & $.14^{\star}$ & $.15 *$ & $.25 * * *$ & $\begin{array}{l}\text { housing } \\
x=.1 \text { to } .2\end{array}$ \\
\hline Income & $.22 * * *$ & $.23^{* \star *}$ & $\frac{.15^{\star}}{(N=213)}$ & $.25 * \hbar *$ & $\begin{array}{l}\text { SES variables } \\
x=.1 \text { to } .3\end{array}$ \\
\hline
\end{tabular}

Note. All time 1, 2, and 3 correlations are based on $N=215$ unless noted otherwise.

a Data taken from R. Larson, 1977.

$\begin{aligned} * p & <.05 \\ * x_{0} & <.01 \\ * * *^{*} & <.001\end{aligned}$ 
correlations is significantly higher that the upper limit of its expected range $(z=.16, .80$ and .76 respectively; critical $z=1.96$ for two-tailed test, $\alpha=.05$ ).

The findings are in the hypothesized direction. ISI scores for this group of older persons living in reduced circumstances are positively correlated with the same life situation variables that are reported to correlate with measures of psychological well-being for other populations of older persons.

Since one purpose of this dissertation was to examine the differential meaning of ISI scores for older persons whose ISI scores were stable versus changing over time, sets of correlations analogous to those used in testing Hypothesis 1 were computed separately for stable and change ISI subjects. Using first the total dissertation sample $(N=215)$, next LSI scores that remained stable over time $(N=84)$, and third, LSI scores that changed over time $(N=131)$, Pearson correlations were obtained for the following sets of data: time 1 WBIs and time 1 LSI (set 1); time 1 WBIs and time 3 LSI (set 2); time 2 WBIs and time 3 LSI (set 3); and time 3 WBIs and time 3 LSI (set 4). These four sets of correlations are presented in Table XI. As the data in Table XI indicate, the relationship between ISI scores and WBIs differed when these correlations were computed separately for the total, the stable and the change LS groups. For the total sample, of the possible 32 correlations ( 8 WBIs and 4 sets), 27 were significant. Four WBIs correlated significantly with ISI on all four sets. They were Medical Health Status, Social Contacts, Lack of Worry, and Income. Lack of Impairment, Cognitive Status, and Housing correlated significantly on three of the four sets and 
TABLE XI

CORRELATIONS BETWEEN WBI AND LSI SCORES USING

TOTAL, STABIE, AND CHANGE IS GROUPS

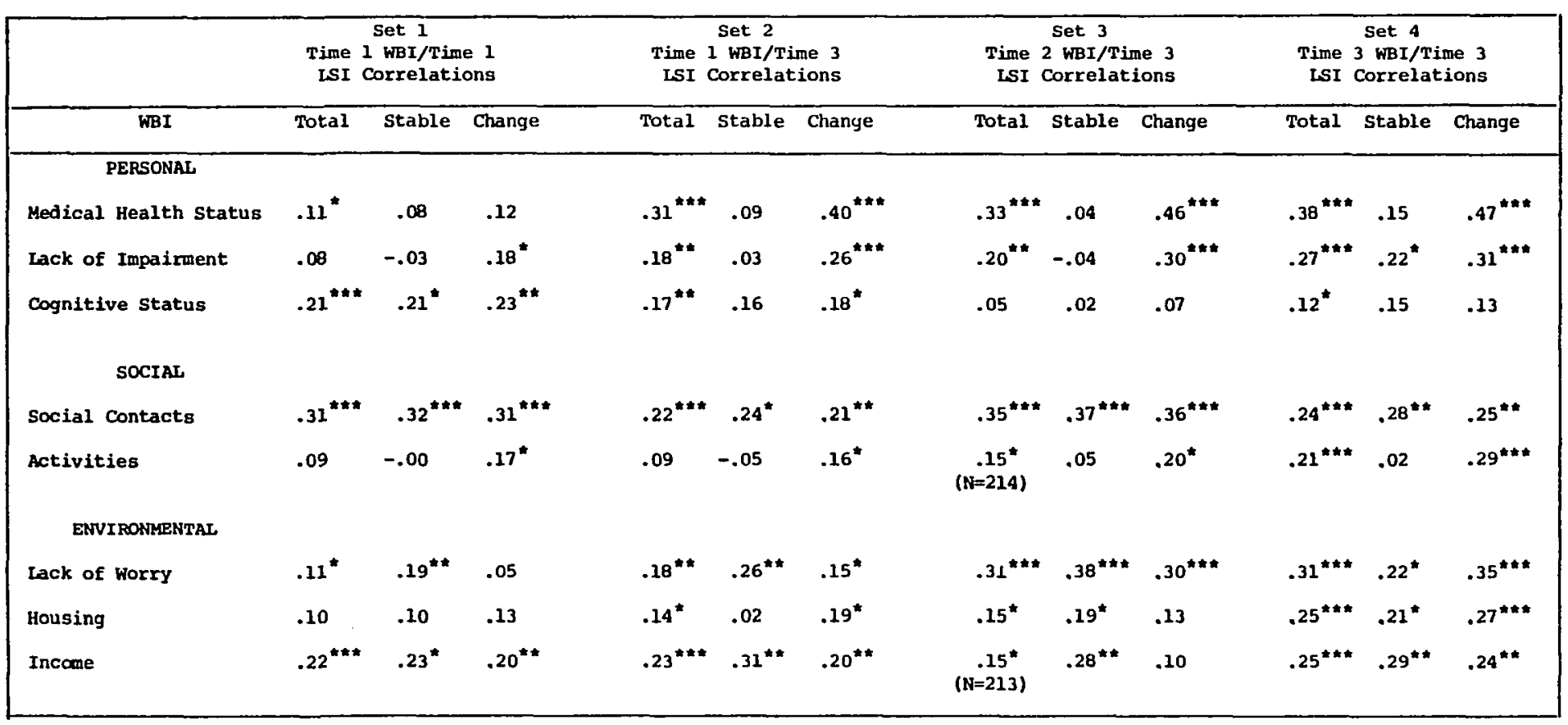

Note. All time 1, 2, and 3 correlations are based on total sample $N=215$; stable is group sample $N=84$; change is group sample

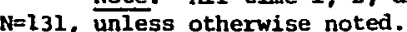

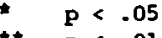

i*: $p<.001$ 
Activities on two of the four sets.

When correlations were obtained for those 84 persons whose LSI scores remained stable, a somewhat different picture emerged. Only 16 of the 32 possible correlations were significant. Three WBIs, Social Contacts, Lack of Worry and Income were significant on all four sets; Housing was significant on two of the four sets; and Lack of Impairment and Cognitive Status were significant on one of the four sets. However neither Medical Health Status nor Activities was significantly correlated with LSI scores for the stable IS group.

In contrast, for those persons whose ISI scores changed, 25 of the possible correlations were significant. Lack of Impairment, Social Contacts, and Activities correlated significantly on all four sets. Medical Health Status, Lack of Worry and Income correlated significantly on three of four sets; and Cognitive Status and Housing were significantly correlated on two of four sets.

In conclusion, a different pattern of correlates of the Life Satisfaction Index did emerge when such correlations were computed for older persons whose LSI scores remained stable over a two-year period versus older persons whose ISI scores had changed more than predicted during the same two-year period. Table XII summarizes the number of significant correlations occuring on the four sets for total, stable, and change LSI scores. As can be seen in this table, both stable and change IS groups had ISI scores which correlated significantly with the WBIs of Social Contacts, Lack of Worry and Income on at least three of the four sets. However, for the change Is group only, three additional WBIs were significant correlates of LSI scores on at least three of the four sets. Those WBIs were 
Medical Health Status, Lack of Impairment, and Activities. A consistent pattern of significant correlations for these latter three WBIs failed to occur for the stable IS group.

TABLE XII

NUMBER OF SIGNIFICANT CORRELATIONS

BY TOTAL, STABLE AND CHANGE

LSI SCORES

WBIs

Total Sample

$(n=215)$

Stable LSI
Scores
$(n=84)$

Change ISI

Scores

$(n=131)$

PERSONAL

Medical Health

Status

Lack of Impairment

Cognitive status

$4 / 4^{*}$

$3 / 4$

$3 / 4$

$4 / 4$

$2 / 4$

$4 / 4$

$3 / 4$

$4 / 4$
$0 / 4$

$1 / 4$

$1 / 4$

$4 / 4$

$0 / 4$

$4 / 4$

$4 / 4$
$3 / 4$

$4 / 4$

$2 / 4$

ENVIRONMENTAL

Lack of Worry

Housing

Income
$4 / 4$

$2 / 4$

$4 / 4$

*4/4 indicates that four of the four sets correlated significantly.

Findings Regarding Hypotheses 2 and 3

Prior to testing Hypotheses 2 and 3, multiple regression

procedures typically used to analyze change in past research of this type were employed here to obtain a global picture of how change in LSI scores was related to the WBIs. Multiple linear regression, stepwise inclusion, was used to calculate the statistical relationship between the criterion variable, ISI at time 3 (ISI3), and the predictor variables, LSI at time $I$ and WBIs at times 1,2 , and 3 . 
The first predictor variable brought into the regression equation was ISI at time 1 (LSII). Entering LSIl as the first predictor produced for each older person a residualized score which reflected how much one's actual LSI3 score is above or below what would have been predicted from one's ISII score. By entering time I LSI into the regression equation first, the variance in ISI3 that was accounted for by ISIl was partialled out, giving a more accurate account of the variance attributable to the eight WBIs.

Results of the regression analyses at times 1, 2, and 3 are summarized in Table XIII. At time 1, LSII accounted for $25 \%$ of the variance and the eight WBIs accounted for $8 \%$ of the variance in LSI3. After time 1 LSI was partialled out of time 3 ISI, four WBIs, Medical Health Status, Lack of Impairment, Lack of Worry, and Income were significantly related to time 3 LSI.

The same procedure was followed using WBIs at time 2 as the predictor variables. ISIl again accounted for $25 \%$ of the variance and four WBIs, Medical Health Status, Lack of Impairment, Lack of Worry, and Social Contacts accounted for 138 of the variance.

Using WBIs at time 3 as predictor variables, the third regression equation was computed. LSIl accounted for $25 \%$ of the variance and six WBIs, Medical Health Status, Lack of Impairment, Lack of Worry, Housing, Activities, and Income accounted for $18.5 \%$ of the variance. The WBIs accounted for a progressively greater portion of the variance in ISI scores at times 2 and 3 than at time 1 . Medical Health Status, Lack of Impairment, and Lack of Worry were significant in the prediction equation at times 1,2 , and 3 and Income was significant at times 1 and 3. Social Contacts, Activities, and Housing were 
TABIE XIII

MULTIPLE LINEAR REGRESSION ANALYSES FOR PREDICTING TIME 3 LST EROM TIME I ISI AND WBIS AT TIMES 1, 2, AND 3

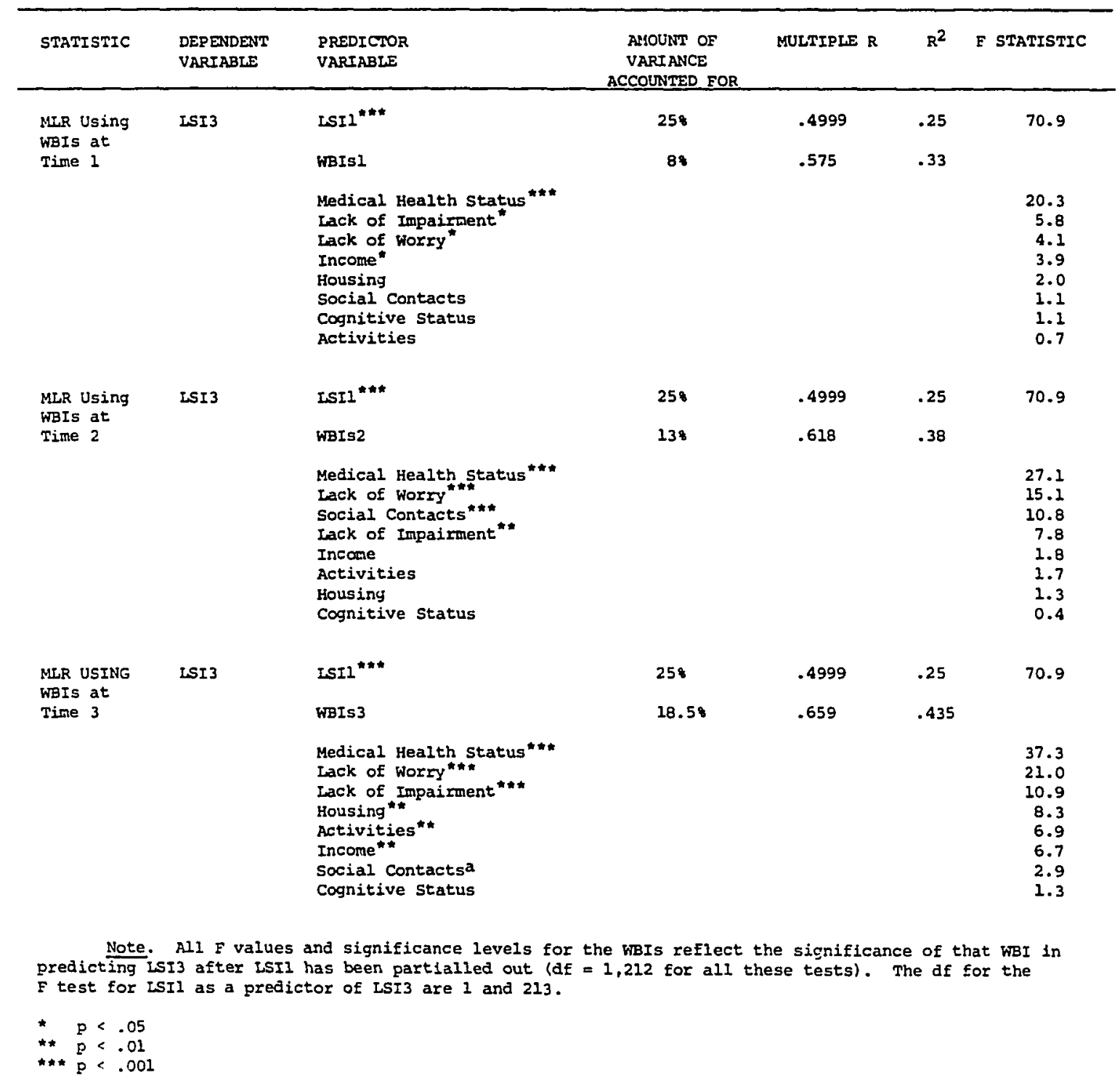


significant predictors only at time 2, time 3 and time 3 , respectively. Cognitive Status was not a significant predictor of ISI in any of the three regressions.

Based on their time 1 and time 3 LSI scores, the older persons in this study were divided into the seven IS groups as described in Chapter IV. It will be recalled that the stable ISI scores were divided into three groups, persons whose scores remained high (HH), persons whose scores remained in the middle range (MM), and persons whose scores remained low (II) from time 1 to 3 . Change ISI scores were divided into two positive change groups, the first consisting of persons whose LSI scores changed from low to midale (LM) and the second consisting of persons whose ISI scores changed from miadle to high (MH); and two negative change groups, persons whose LSI scores changed from high to middle (HM), and persons whose ISI scores changed from middle to low (LM).

Differences among the means of the seven LS groups on each of the WBIs at time 1,2 , and 3 were examined using analysis of variance procedures (ANOVA). IS groups were the outcome variables and the WBIs at times 1,2 , and 3 were the predictor variables. Means, standard deviations and overall $\mathrm{F}$ values are reported in Appendix $\mathrm{E}$. Figures 2, 3, and 4 are graphic illustrations of the mean comparisons at times 1, 2, and 3 respectively. The findings are presented under their respective hypotheses, 2 and 3 .

Hypothesis 2. It is hypothesized that those persons whose ISI scores remained high and stable from time I to time 3 also had higher scores on WBIs than did those persons whose LSI scores remained stable and low.

A comparison of means for those persons whose LSI scores remained high 


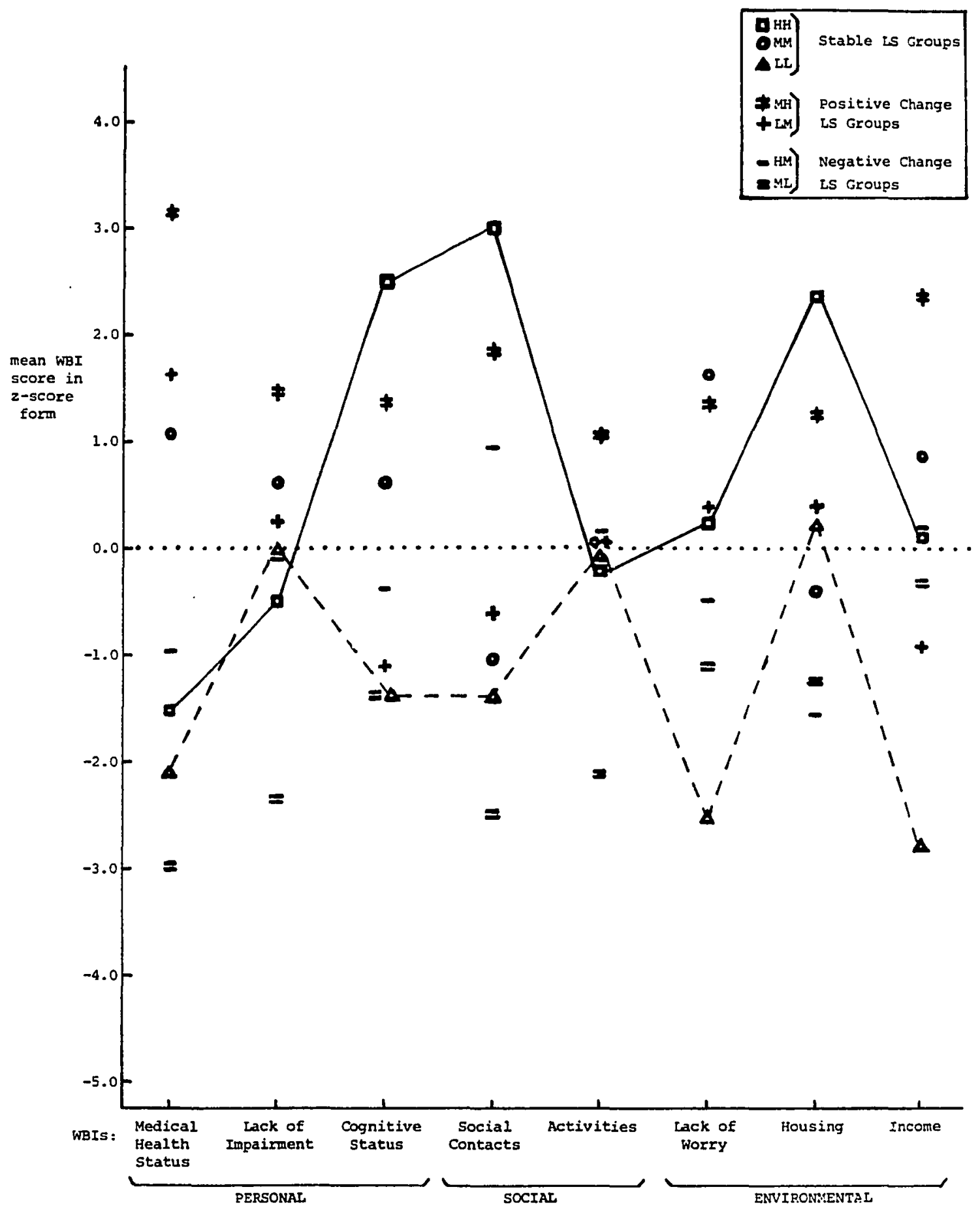

Eigure 2. A comparison of the is group means on the eight time 1 well-being indicators.

Note. For each WBI, the mean score for each IS group was standardized using

$$
z=\frac{\bar{x}_{\text {group }}-\bar{x}_{\text {overall }}}{\text { pooled } s_{\bar{x}}}
$$

The WaI means have been connected by a solid line and a dashed line for the HH and LI groups respectively to form their profiles across the elght wBIs. These two profiles were constructed to facilitate visual examination of the figure. A dotted line for $z=0.0$ has been included as an additional reference point. 


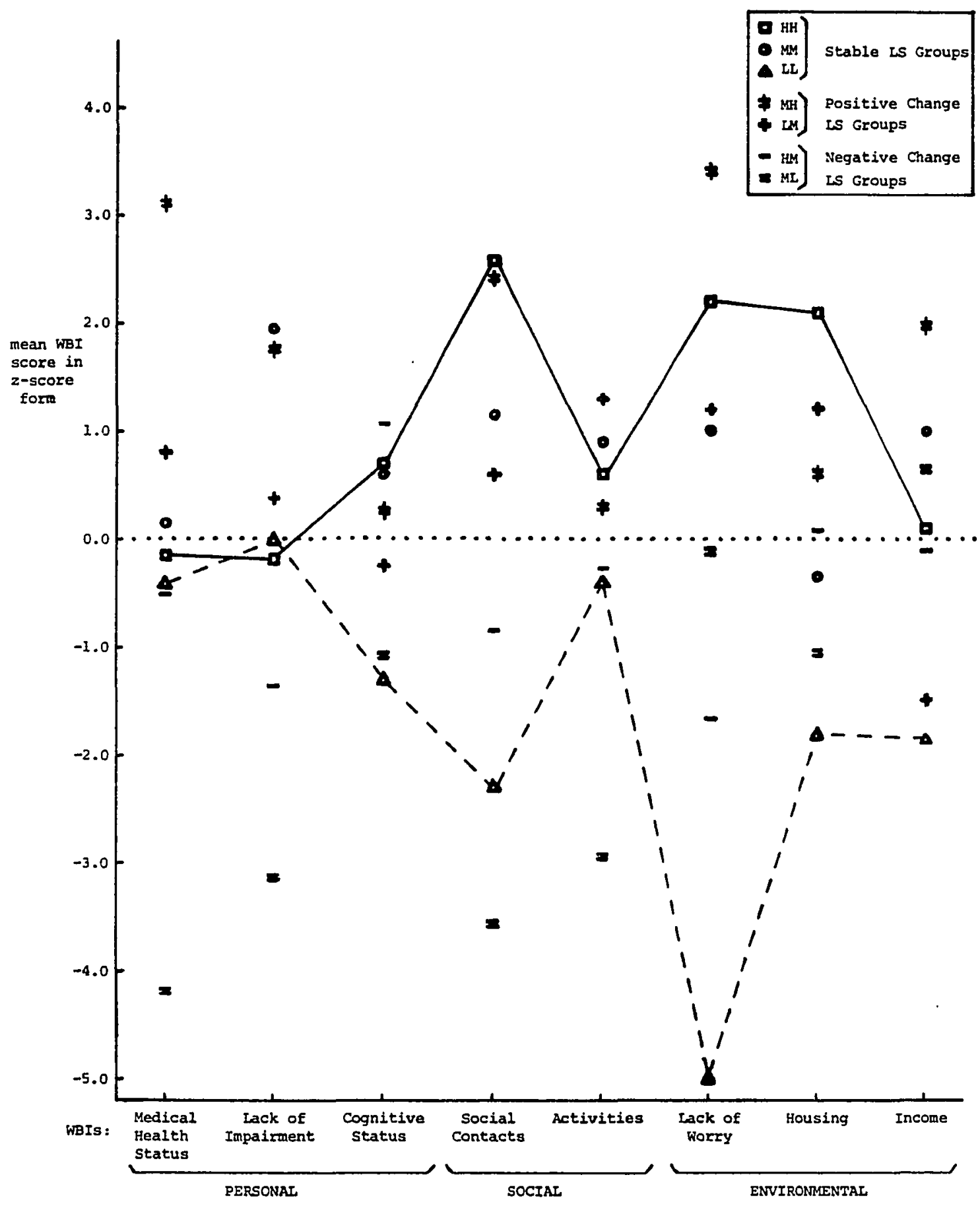

Eigure 3. A comparison of the is group means on the eight time 2 well-being indicators.

Note. For each WBI, the mean score for each tS group was standardized using

$$
z=\frac{\bar{x}_{\text {group }}-\bar{x}_{\text {overall }}}{\text { pooled } s}
$$

The WBI means have been connected by a solid line and a dashed Iine for the HI and if groups respectively to form their profiles across the eight wBIs. These two profiles were constructed to factlitate fisual examination of the figure. A dotted line for $z=0.0$ has been included as an additional reference point. 


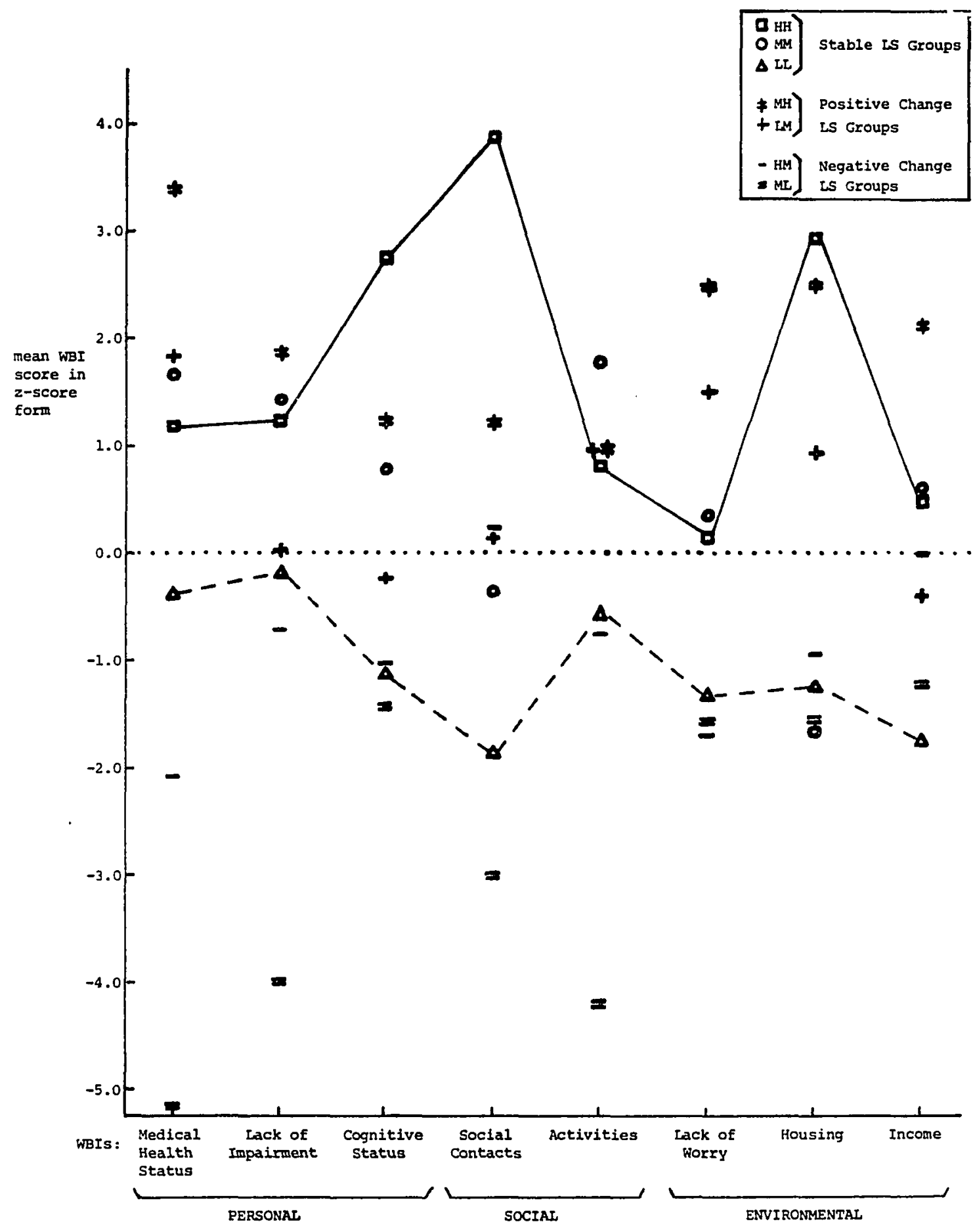

Eimure 4. A comparison of the is grous means on the eight time 3 well-being indicators.

Note. For each WBI, the mean score for each LS group was standardized using $z=\frac{\bar{x}_{\text {group }}-\bar{x}_{\text {overall }}}{\text { pooled s s }}$

The WBI means have been connected by a solid line and a dashed line for the HAl and LI groups respectively to form their profiles across the eight WBIs. These two profiles were constructed to facilitate vigual examination of the figure. A dotted line for $z=0.0$ has been included as an additional reference point. 
and stable from time 1 to time 3 , with persons whose ISI scores remained low and stable, indicated that of the twenty four possible comparisons, eight were significant and in the hypothesized direction. Those were Social Contacts, significant at times 1,2 , and 3 ( $p<.01$ ); Housing, significant at times $I$ and 3 ( $p<.01)$; Cognitive status significant at times 1 and $3(p<.05)$, and Lack of Worry significant at time $2(p<.01)$. There were no significant differences between these two IS groups on Medical Health Status, Lack of Impairment, Activities, and Income. Table XIV lists those pairs of means that are significantly different.

The findings were only partially in the hypothesized direction and it was concluded that the stable-high LS group was not significantIy different from the stable-low IS group on five WBIs. Social Contacts followed by Housing and Cognitive status were the WBIs evidencing significant differences between these two LS groups. In addition to examining differences between the stable-high and stable-low IS groups, comparisons were also made with persons whose ISI scores remained stable and in the middle range. Comparisons indicated that there were few significant differences between the three stable Is groups. The stable-high LS group and the stablemiddle IS group had similar scores on all WBIs except Housing (times 1, 2, and 3) and Social Contacts (times 1 and 3). Comparison of the stable-middle IS group with the stable-low IS group indicated that the former scored significantly higher on the WBIs of Lack of Worry, (times 1 and 2), Medical Health status (time 1), Income (time 1), and Social Contacts (time 2). 
TABLE XIV

COMPARISON OF MEANS FOR STABLE-HIGH AND STABLE-LO

IS GROUPS ON EIGHT INDICATORS OR

\begin{tabular}{|c|c|c|c|c|c|c|c|c|c|c|c|c|c|c|c|c|}
\hline \multicolumn{17}{|c|}{ WELL-BEING INDICATORS } \\
\hline \multicolumn{7}{|c|}{ Personal } & \multicolumn{4}{|c|}{ Social } & \multicolumn{6}{|c|}{ Environmental } \\
\hline \multirow[t]{2}{*}{ Time } & \multicolumn{2}{|c|}{$\begin{array}{c}\text { Medical } \\
\text { Health Status }\end{array}$} & \multicolumn{2}{|c|}{$\begin{array}{c}\text { Lack of } \\
\text { Impairment }\end{array}$} & \multicolumn{2}{|c|}{$\begin{array}{l}\text { Cognitive } \\
\text { status }\end{array}$} & \multicolumn{2}{|c|}{$\begin{array}{l}\text { Social } \\
\text { Contacts }\end{array}$} & \multicolumn{2}{|c|}{ Activities } & \multicolumn{2}{|c|}{$\begin{array}{l}\text { Lack of } \\
\text { Worry }\end{array}$} & \multicolumn{2}{|c|}{ Housing } & \multicolumn{2}{|c|}{ Income } \\
\hline & HH & LL & Hн & LL & нн & LL & Іин & LL & แи & LL & HII & LL & нн & LL & НH & LL \\
\hline 1 & & & & & 3.09 & 2.78 & 2.89 & $2.47^{67}$ & & & & & & & & \\
\hline 2 & & & & & & & 3.53 & $3.19^{\star *}$ & & & 3.51 & $2.79^{* \star}$ & 3.61 & $3.16^{* *}$ & & \\
\hline 3 & & & & & 2.95 & $2.47^{*}$ & 2.86 & $2.39^{* * \hbar}$ & & & & & 3.81 & $3.41^{* *}$ & & \\
\hline
\end{tabular}

Note. Listed are those pairs of means for which the stable-high (HH) and stable-low (LL) groups are significantly different.

$$
* \begin{aligned}
& \mathbf{p}<.05 \\
& \mathbf{p}<.01
\end{aligned}
$$

$\because \mathrm{p}<.001$ 
Hypothesis 3. It is hypothesized that persons whose ISI scores changed in a positive direction from time 1 to time 3 also had higher scores on WBIs than did those persor.s whose LSI scores changed in a negative direction.

A comparison of mean scores for persons whose LSI scores changed in a positive direction with persons whose ISI scores changed in a negative direction revealed a number of significant differences. of the 24 possible comparisons, 14 were significant and in the hypothesized direction and 10 were not significant. Medical Health Status and Lack of Impairment were significant at times 1, 2, and 3 ( $p<.05)$, Social Contacts, Activities, Lack of Worry, significant at times 2 and $3(p<.05)$, and Housing, significant at times 1 and $3(p<.01)$. There were no significant differences between the positive and negative change groups on WBIs Cognitive status and Income. Table XV summarizes the means for these groups.

The findings were partially in the hypothesized direction. Over half of the comparisons indicated that persons whose LSI scores changed in a positive direction had higher WBI scores than did those whose ISI scores changed in a negative direction. These two LS groups were not significantly different on only two of the WBIs, Cognitive status and Income. The positive change IS group scored significantly higher than the negative change IS group on the remaining six WBIs, on at least two of the three times.

Additional comparisons were made within the positive and negative change groups. Within the positive change group, persons whose scores changed from low to middle (IM) were compared with persons whose scores changed from middle to high (MH). There were no significant differences between the LM and MH groups on seven WBIs. Income was 
TABLE XV

COMPARISON OF MEANS FOR POSITIVE AND NEGATIVE CHANGE

IS GROUPS ON EIGHT INDICATORS OF WELL-BEING

\begin{tabular}{|c|c|c|c|c|c|c|c|c|c|c|c|c|c|c|c|}
\hline \multicolumn{16}{|c|}{ WELL-BEING INDICATORS } \\
\hline \multicolumn{7}{|c|}{ Personal } & \multicolumn{4}{|c|}{ Social } & \multicolumn{5}{|c|}{ Environmental } \\
\hline \multirow[t]{2}{*}{ Time } & \multicolumn{2}{|c|}{$\begin{array}{c}\text { Medical } \\
\text { Health Status }\end{array}$} & \multicolumn{2}{|c|}{$\begin{array}{c}\text { Lack of } \\
\text { Impairment }\end{array}$} & \multicolumn{2}{|c|}{$\begin{array}{l}\text { Cognitive } \\
\text { Status }\end{array}$} & \multicolumn{2}{|c|}{$\begin{array}{c}\text { Social } \\
\text { Contacts }\end{array}$} & \multicolumn{2}{|c|}{ Activities } & \multicolumn{2}{|c|}{$\begin{array}{c}\text { Lack of } \\
\text { Worry }\end{array}$} & \multicolumn{2}{|c|}{ Housing } & Income \\
\hline & + & - & + & - & + & - & + & - & + & - & + & - & + & - & + \\
\hline 1 & 3.03 & $2.58^{m \times n}$ & 2.93 & $2.75^{2}$ & & & & & & & & & & & \\
\hline 2 & 2.98 & $2.44^{* \hbar \hbar}$ & 3.32 & $2.44^{* \star *}$ & & & 3.50 & $3.20^{\star}$ & 2.50 & $2.26^{\star}$ & 3.52 & $3.20^{\star}$ & 3.10 & $2.89^{\star}$ & \\
\hline 3 & 2.95 & $2.48^{\star * *}$ & 3.40 & $3.08^{\star * *}$ & & & 2.60 & $2.43^{\star}$ & 2.62 & $2.25^{* * *}$ & 3.03 & $2.60^{* \hbar \star}$ & 3.70 & $3.41^{* * *}$ & \\
\hline
\end{tabular}

Note. Listed are those pairs of means for which the positive change $(+)$ and negative change $(-)$ groups are significantly different.

$\begin{aligned} p & <.05 \\ \mathrm{p} & <.01\end{aligned}$

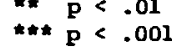


significantly higher for the MH group at times $I$ and 2 .

Within the negative change group, persons whose scores changed from high to middle (HM) were compared with persons whose scores changed from midale to low (ML). The HM group scored significantly higher than the ML group on social contacts (times 1, 2, and 3), Lack of Impairment (times 2 and 3), Medical Health Status (time 2), and Activities (time 3). There were no significant differences between the HM and ML groups on Cognitive Status, Lack of Worry, Housing and Income. Table XVI presents the comparisons within the positive and negative IS groups.

A final set of comparisons was made to test for similarities between the stable-high IS group and the two positive change IS groups and between the stable-low IS group and the two negative change IS groups.

The stable-high LS group was significantly different from the positive change LS groups on only three WBIs including Medical Health Status (times 1 and 2) where the MH group was significantly higher than the stable-high IS group and on Cognitive Status (time 1) and Social Contacts (times 1 and 3 ) where the stable-high group was significantly higher than the IM change group.

The stable-1ow IS group was significantly different from the negative change IS groups on only three WBIs. The stable-low group scored significantly higher than the ML change group on Medical Health Status and Lack of Impairment at times 2 and 3, and Activities at time 3. On the WBI, Lack of Worry at time 2, the ML group scored significantly higher than the stable-low group (See Table XVII). 
TABLE XVI

COMPARISON OF MEANS WITHIN THE POSITIVE AND NEGATIVE CHANGE IS GROUPS ON EIGHT INDICATORS OF WELL-BEING

\begin{tabular}{|c|c|c|c|c|c|c|c|c|c|c|c|c|c|c|c|}
\hline \multicolumn{16}{|c|}{ WELLL-BEING INDICATORS } \\
\hline \multicolumn{7}{|c|}{ Personal } & & \multicolumn{3}{|c|}{ Social } & \multicolumn{5}{|c|}{ Environmental } \\
\hline \multirow[t]{2}{*}{ Time } & \multicolumn{2}{|c|}{$\begin{array}{c}\text { Medical } \\
\text { Health Status }\end{array}$} & \multicolumn{2}{|c|}{$\begin{array}{l}\text { Lack of } \\
\text { Impairment }\end{array}$} & \multicolumn{2}{|c|}{$\begin{array}{l}\text { Cognitive } \\
\text { Status }\end{array}$} & \multicolumn{2}{|c|}{$\begin{array}{l}\text { Social } \\
\text { Contacts }\end{array}$} & \multicolumn{2}{|c|}{ Activities } & \multicolumn{2}{|c|}{$\begin{array}{l}\text { Lack of } \\
\text { Worry }\end{array}$} & Housing & \multicolumn{2}{|c|}{ Income } \\
\hline & MH & IM & HH & LM & MH & IM & $\mathrm{MH}$ & LM & MH & LM & SHI & LM & LM & $\mathrm{mH}$ & LM \\
\hline 1 & & & & & & & & & & & & & & 3.06 & $2.81^{4}$ \\
\hline 2 & & & & & & & & & & & & & & 3.02 & $2.74^{*}$ \\
\hline \multicolumn{16}{|l|}{3} \\
\hline & HM & ML & HM & ML & HM & ML & HM & ML & HM & ML & HM & MI & HM & HM & ML \\
\hline 1 & & & & & & & 2.69 & $2.36^{*}$ & & & & & & & \\
\hline 2 & 2.67 & $2.20^{*}$ & 3.05 & $2.86^{* \pi}$ & & & 3.29 & $3.10^{*}$ & & & & & & & \\
\hline 3 & & & 3.24 & $2.92^{*}$ & & & 2.56 & $2.29^{*}$ & & & 2.43 & $2.07^{\star}$ & & & \\
\hline
\end{tabular}

Note. Listed are those pairs of means for which the positive change groups (MH and LM) are siginficantly different or for which the negative change groups (HM and M(T) are significantly different.

$\mathrm{P}<.05$

$\ldots$.... $\mathrm{P}<.01$

$* t \mathrm{p}<.001$ 
TABLE XVII

COMPARISON OF MEANS FOK STABLE AND CHANGE IS GROUPS ON ETGHT INDTCATORS OF WELL-BEING

WELL-BEING INDICATORS

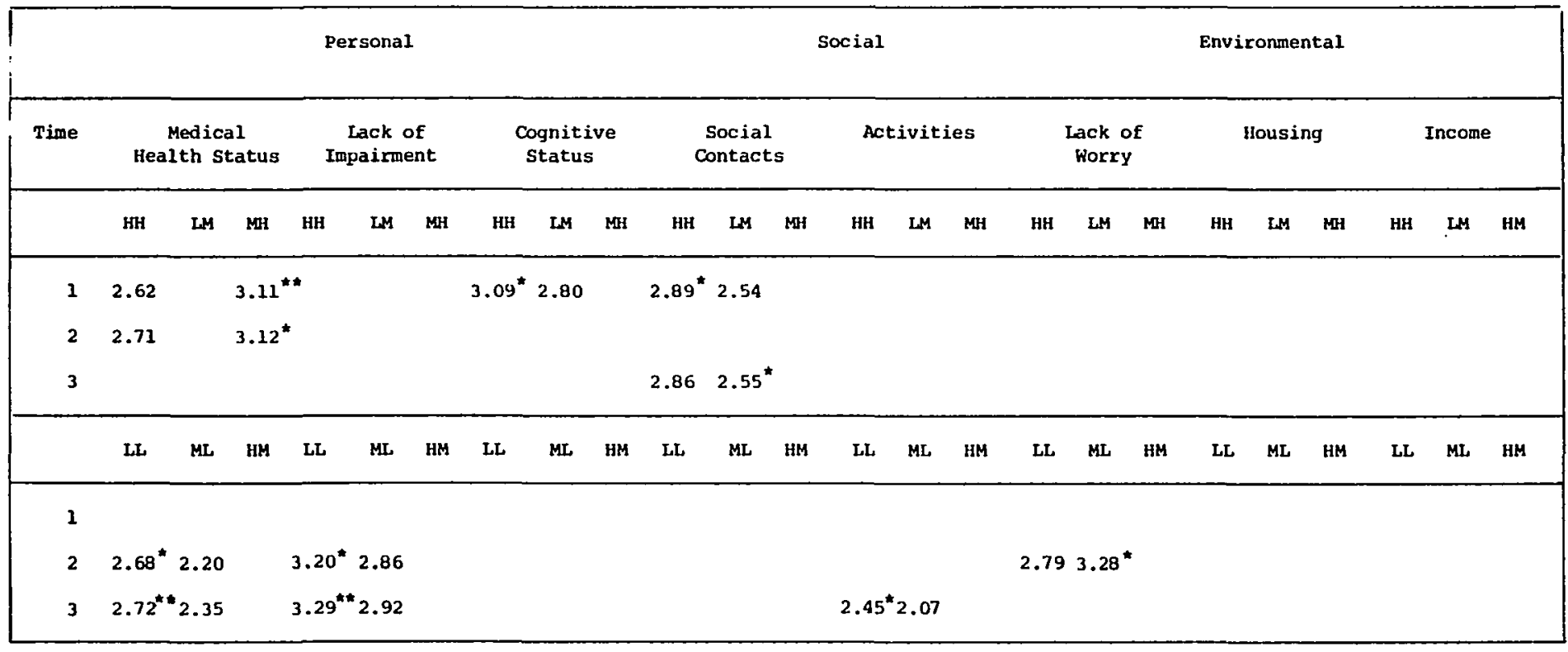

Note. Listed are those pairs of means for which the HH group is significantly different from elther the LM or MH group or for which the LL group is significantly different from the ML or HM group.

* $p<.05$

\#**p<.01 $p<.001$ 
Findings Regarding Hypotheses 4 and 5

Prior to testing hypotheses 4 and 5 , multiple regression procedures typically used to analyze change in past research of this type were employed here to obtain a global picture of how change in LSI scores was related to change in on the WBIs. To examine the relationship between change in LSI scores ( $\triangle \mathrm{LSI}$ ) and change in WBI scores $(\triangle W B I)$, absolute scores were converted to residualized change scores using scores at time 1 and time 3 .

Multiple linear regression, stepwise inclusion, was the first analysis performed using residualized change scores for both LSI and the WBIs. In the regression equation, $\Delta$ LSI was the outcome variable and the $\triangle W B I s$ were the predictors. The eight $\triangle W B I s$ accounted for 20.48 of the variance in $\triangle I S I$. Four $\triangle W B I$ s were significant, Lack of Worry, Medical Health Status, Housing, and Activities. Table XVIII presents these results.

A greater portion of the variance in $\Delta$ ISI was accounted for by $\triangle W B I$ s than was the case when absolute scores were used in the regression equation. The variance in $\triangle$ LSI accounted for by $\triangle W B I S$ was 20.48 compared to $8 \%$ time $1,13 \%$ time 2 , and 18.58 time 3 , using absolute scores.

A one-way analysis of variance for comparing the seven LS groups was computed using residualized change scores on the eight WBIs. Table XIX presents the results from this analysis. Figure 5 is a graphic presentation of the ANOVA results.

Hypothesis 4. It is hypothesized that people whose ISI scores remained stable from time 1 to time 3 also had WBIs that remained stable.

Hypothesis 4 was tested by comparing the stable-high, stable- 
TABLE XVIII

MULTIPLE LINEAR REGRESSION ANALYSES FOR PREDICTING TIME 1 TO TIME 3 CHANGE IN LSI FROM TIME 1 TO TIME 3 CHANGE IN WBIS

\begin{tabular}{|c|c|c|c|c|c|c|}
\hline $\begin{array}{l}\text { STATISTIC } \\
\text { MLR Using }\end{array}$ & $\begin{array}{l}\text { DEPENDFNT } \\
\text { VARI ABLEE }\end{array}$ & PREDICTOR VARIABLE & $\begin{array}{c}\text { AMOUNT OF } \\
\text { VARIANCE } \\
\text { ACCOUNTED YOK }\end{array}$ & MULTIPLE $R$ & $\mathrm{R}^{2}$ & F STATISTIC \\
\hline \multirow{9}{*}{$\begin{array}{l}\text { MLR Using } \\
\text { Residualized } \\
\text { Change Score }\end{array}$} & $\Delta L S I$ & $\triangle W B I S$ & 20.48 & .45 & .20 & $\begin{array}{c}6.62 \\
(\mathrm{df}=8,206)\end{array}$ \\
\hline & & Lack of Worry *** & & & & 17.0 \\
\hline & & Medical Health Status $* \star *$ & & & & 11.9 \\
\hline & & Housing* & & & & 4.3 \\
\hline & & Activities* & & & & 4.29 \\
\hline & & Lack of Impairment & & & & 1.5 \\
\hline & & Cognitive Status & & & & .7 \\
\hline & & Social Contacts & & & & .5 \\
\hline & & Income & & & & .4 \\
\hline
\end{tabular}

Note. All F values and significance levels for the $\triangle$ WBIs reflect the significance of that WBI at step 1 of the regression analysis (df $=1,213$ for all these tests).

$\mathrm{p}<.05$
$* * .001$ 


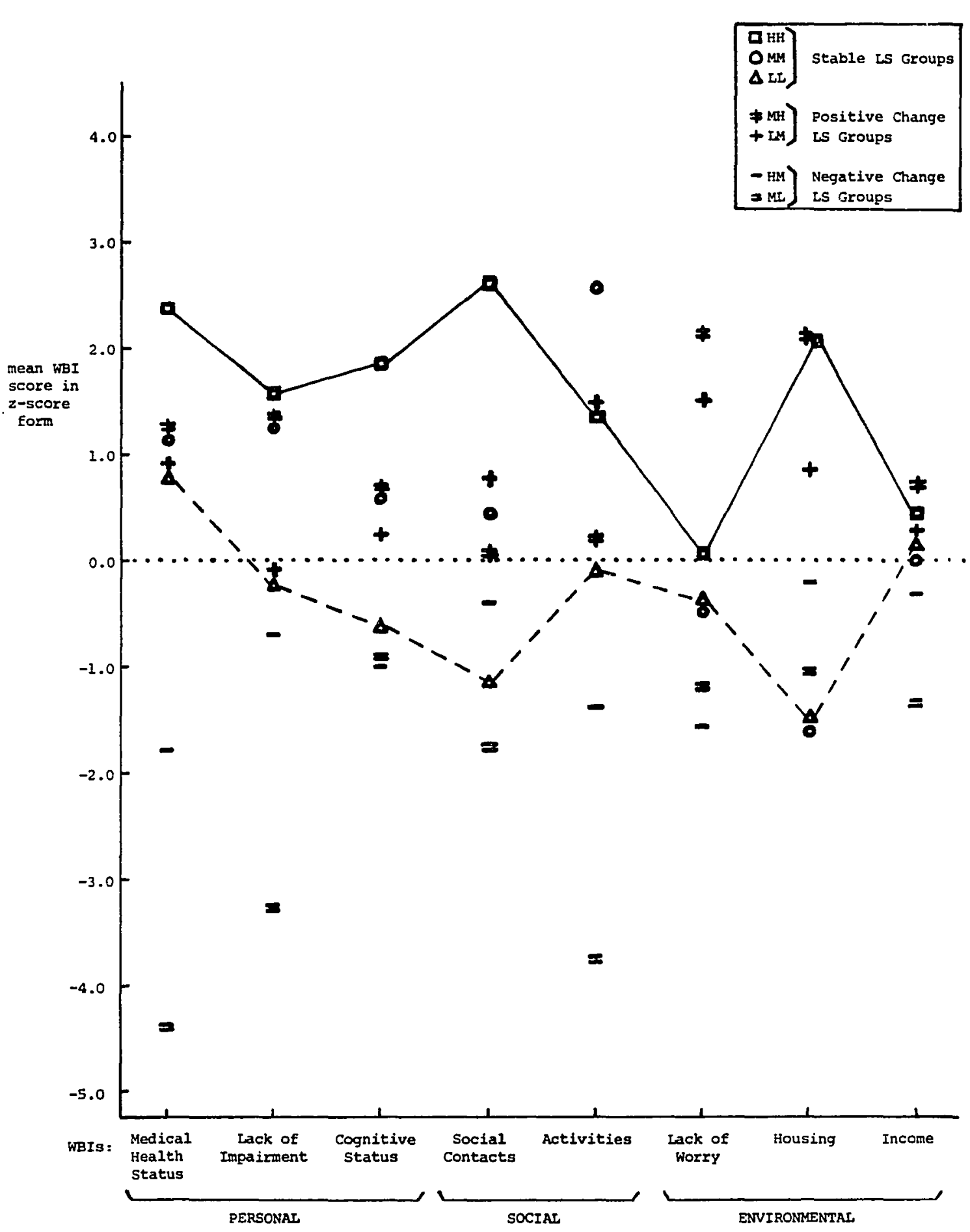

Figure 5. A comparison of the LS groun means on eight WBI residualized change measures.

Note. For each WBI, the mean score for each is group was standardized using

$z=\vec{x}_{\text {group }}-\bar{x}_{\text {overa11 }}$

pooled $\mathbf{s}_{\mathbf{x}}$

The WBI means have been connected by a solid line and a dashed line for the HH and LL groups respectively to form their profiles across the eight wBIs. These two profiles were constructed to facilitate visual examination of the figure. A dotted line for

$z=0.0$ has been included as an additional reference point. 
middle, and stable-low Is groups on the $\triangle$ WBIs. Support for hypothesis 4 would occur if these three groups were not significantly different from one another on the $\triangle W B I$ scores. Of the 24 possible comparisons, 20 were non-significant as hypothesized. The three stable Is groups had similar scores on all $\triangle W B I s$ with the following exceptions: the stable-high IS group exhibited significantly more positive change on Social Contacts and Housing than did the stable-low Ls group. The stable-high IS group also reflected significantly more positive change on Housing than the stable-middle IS group. The stable-middle IS group expressed significantly more positive change on Activities when compared with the stable-low IS group.

The findings were, for the most part, in the hypothesized direction and persons whose $\Delta$ ISI scores remained stable from time 1 to time 3 , also had $\triangle$ WBIs that remained stable.

Hypothesis 5. It is hypothesized that people whose LSI scores changed in either a positive or negative direction, also had changes in WBIs that were in a corresponding direction.

of the eight possible comparisons, five were in the hypothesized direction. When persons whose ISI scores changed in a positive direction were compared with persons whose LSI scores changed in a negative direction, the positive change LS group had significantly higher scores on five $\triangle$ WBIs, Medical Health Status, Lack of Impairment, Activities, Lack of Worry, and Housing. There were no significant differences between these two groups on their change scores in the areas of Cognitive status, Social Contacts, and Income. The findings are partially in the hypothesized direction. Change in WBIs was found to correspond with change in ISI scores on all $\triangle$ WBIs except Cognitive Status, Social contacts, and Income. 
Comparisons of the stable IS groups with positive and negative change IS groups indicated that there were no significant differences between the stable-high and the positive change groups on any $\triangle$ WBIs. Comparison of the stable-low with negative change IS groups however, indicated that persons whose ISI scores changed in a negative direction had significantly lower scores on $\triangle W B I s$ Medical Health Status, Lack of Impairment, and Activities. Within the negative change grupp, ISI scores changing from middle to low, also had the lowest scores on these $\triangle W B I$.

\section{Case Studies}

Fourteen cases were selected from the dissertation sample to illustrate statistical findings. Using median residual ISI scores, two persons were selected from each of the seven ISI groups. The interview instruments at times 1,2 , and 3 , were reviewed, responses recorded and interviewer comments noted. A summary of each case is presented here and the complete case studies are provided in Appendix D. All ages reported were those given at the time of the first interview and names used here are fictitious.

The case studies, in addition to providing material illustrative of the general findings, gave indications of ways in which individuals adapted to changing life situations. Flexibility of both life situations and the older persons themselves allowed the continuation of independent living when health and mobility declined. Interviewer comments were espectally useful in gaining inslght into the life situations of these older persons.

Stable Itfe Satisfaction Groups. Mrs. Evans, 80 and Mrs. Fisher, 
73, both had stable high life satisfaction. They had high levels of well-being on all indicators. They were in good health and very active. Their social contacts were frequent and varied and included children, grandchildren, friends and neighbors. Both women were involved in activities outside their homes and had hobbies they enjoyed. Both had comfortable homes and adequate financial means including savings. Mrs. Evans occasionally still drove her own car and particularly enjoyed helping older persons who were confined to their homes.

Mrs. Close, 79, and Mr. Davis, 65, of the stable-middle LSI group, presented a somewhat different picture. Mrs. Close, similar to the stable-high LSI group on personal indicators, purposely limited her social contacts and activities, preferring to see few people and to remain at home. Her home was in fair to poor condition and her income less than adequate.

Mr. Davis was recovering from a health problem during the study, however this problem did not result in any limitation of his activities. By objective measures, Mr. Davis had high levels of well-being on Social Contacts, Housing and Income however subjective measures of these indicators indicated that he was very dissatisfied with all three as well as with his activities.

Mrs. Andrews and Mr. Black, who had stable-low life satisfaction, were both 74 years old. They shared many characteristics including poor health, physical impairment and limited mobility that restricted their activities. Both had very satisfactory homes but incomes that barely allowed them to get by. Mr. Black had hospital bills he was unable to pay, both for himself and for his deceased wife who had 
suffered a long illness before she died several years earlier. Neither Mrs. Andrews nor Mr. Black had children and their soctal contacts were with relatives, friends and neighbors. They relied on social services to provide many of their daily needs such as meals and housework help. The life situations of these two people gave clear evidence of low levels of well-being.

Positive Change Life Satisfaction Groups. Mrs. Newgate, 78, and Mrs. Monroe, 75, experienced posittve change in life satisfaction, from low to midale range. However only Mrs. Newgate had accompanying positive change in life situations. Mrs. Newgate was newly widowed at the first interview and by time 3 had made social adjustments that she was very satisfied with. She had become active in a senior citizens center and was satisfied with her frequent social contacts. She had no children. She experienced transitory health problems and had a physical impairment that made walking difficult but did not restrict her mobility. Her home was in good condition. She did experience a decline in income which was adequate at time 1, and barely allowed her to get by at time 3 .

Mrs. Monroe's life situations indicated decline in health and increased confinement to home. She was in a wheelchair and interviewer comments indicated that she was very frail. She had frequent contact with children, friends and neighbors and it was with their assistance, combined with social services, that she was able to remain in her own home. Her home was in good condition and her finances adequate.

Mrs. Kemp, 80, and Mrs. Levttt, 75, also experienced positive change in life satisfaction, from the middle to high range. 
Mrs. Levitt's life situations were similar in almost all respects, to those of the stable-high ISI group. The interviewer commented that Mrs. Levitt particularly loved to dance at the local senior citizens center. She reported increased social contact with children at time 3 .

Mrs. Kemp's positive change in life satisfaction, however, was not reflective of overall positive well-being. On the contrary, Mrs. Kemp experienced quite severe physical decline accompanied by increasingly limited activities. She was healthy and active at time 1 and by time 3 , she was being treated for cancer. She was forced to give up her car, her church work, and could only leave her home with help. Over time, contact with children, grandchildren, neighbors and friends increased and these people provided her with the assistance necessary for her to continue many of her former activities. Mrs. Kemp had a satisfactory income and a home that was in good condition.

Negative Change Life Satisfaction Group. Mrs. Groves, 81, and Mrs. Hughes, 87, experienced a negative change in life satisfaction, from high to middle range. Both were in poor health and had physical impairments that restricted both activities and personal mobility. In both cases these health and mobility problems became more severe by time 3. At time 1, these women were able to leave their homes occasionally, requiring help from family and friends. At time 3 , Mrs. Hughes rarely left her home. Both were dependent upon social services for housework help and meals. Mrs. Groves had frequent social contact with children, friends, and neighbors whereas Mrs. Hughes saw friends and neighbors about once a month. She had no children and 
was not satisfied with her social contacts. Their homes were in good condition although Mrs. Hughes was not satisfled with hers because it was too large for her to take care of. Both had adequate incomes. The last two cases, Mrs. Jacobs, 90, and Mr. Irving, 80, whose ISI scores dropped from middle to low, appeared to be worse off in many other life situations than other cases reviewed. Each experienced decline in a different way and Mr. Irving was by far in the most dire straits.

Mrs. Jacobs was one of the oldest persons in the sample. At the age of 90 she was still living in her own home. She felt that her health was good for her age even though she was badly crippled with arthritis. The interviewer commented that she was alert, cheerful and active within her own limitations. She had frequent contact with children, friends and neighbors. Her son took her to church and to the store frequently. By time 3, Mrs. Jacobs had moved to a boarding house where she lived with four other women who provided her with meals, housekeeping services and necessities other than personal maintenance. Her social contact with people outside the boarding house was less frequent but her son continued to take her out monthly. Her finances, which were adequate, were managed by her son at time 3. Mrs. Jacobs experienced decline in health, mobility, social contacts and activities and she changed Iiving arrangements during the time between the first and third interviews. Hers is a picture of advanced age and decline in all Iife situations.

Mr. Irving was by far the most isolated and destitute of the cases reviewed. He had never married and had lost track of all 
relatives years ago. His health was poor and although he had no observable physical disabilities, the interviewer commented that he appeared very frail and spent most of his time in bed. He had meals delivered to his home and housework provided occasionally, both through social services. The interviewer commented that he was without a radio or television and his only actlvities were walking, resting and reading. He saw friends and neighbors and went frequently to a senior citizens center but he was not satisfied with his social contacts. He relied on his hotel manager to assist him when he needed help. He was able to get out alone frequently. His home was a one-room upstairs apartment in a dilapidated hotel without an elevator at time 1. At time 3, he had moved to another room in a hotel that was also dilapidated, but did have an elevator. He was not satisfied with his living arrangement and wanted to go to a nursing home. His income barely allowed him to get by.

Summary Results

Four of the five hypotheses generated to explore the relationship between psychological well-being of the elderly, as measured by the LSI, and their life situations, as measured by the WBIs were confirmed or partially confirmed. Statistical tests for the first hypothesis indicated that the meaning of psychological well-being for a population of older persons in reduced circumstances was similar to that of other older populations.

Statistical tests for the second and third hypothesis confirmed the relationship between stability or change in psychological wellbeing and life situations of older persons. However, the relationship 
between stable ISI scores and WBIs was not in the hypothesized direction for several WBIs. Contrary to predictions, persons with stable-high, middle, and low LSI scores reported having similar life situations in areas of health, lack of impairment, and activities. Persons who experienced positive changes in psychological well-being reported higher levels of well-being in their life situations than did persons experiencing negative changes.

statistical findings for the last two hypotheses confirmed the relationship between stability or change in psychological well-being and stability or change in life situations. The results for both stable and change LSI groups were generally in the hypothesized direction. 
CHAPTER VI

DISCUSSION

Examination of the data at the aggregate and individual levels has provided insights into the queries motivating this research. The concluding chapter of the dissertation discusses the results and their application to psychological well-being and its relationship to life situations of the aging, the theoretical implications of the findings and directions for future research.

Psychological Well-Being and Its Relationship to Life Situations

In previous research, single-item measures of some life situations of the elderly have consistently correlated with psychological well-being. These were health variables, physical disability measures, social activity, housing and SES variables. These same correlates were significant for the dissertation sample.

Eight life situations critical to older persons were identified and scales were constructed to measure them. The use of scaling techniques permitted fine differentiation within each scale and allowed more thorough and comprehensive measures of each life situation. Each of the eight life situations was correlated with psychological well-being. The findings of this dissertation supported previous research, and in addition, gave evidence that life situations including Cognitive Status, Lack of Worry and Income were significant correlates of psychological well-being. 
The data suggest that psychological well-being had the same meaning for this sample of marginally subsisting older persons, heretofore unsampled, as it did for other older persons discussed in the literature.

The historical and conceptual treatment of psychological wellbeing as a stable characteristic contradicts its use as an outcome measure subject to change with manipulation of life situation variables. Empirical testing of the construct has been limited by lack of longitudinal measures of both psychological well-being and life situations. Dissertation data provided strong evidence that psychological well-being was situationally reactive to changes occuring in the lives of some of the persons studied. While psychological well-being remained stable for some, about half experienced change either in a positive or negative direction. Furthermore, different correlational patterns emerged when stable and changing scores were correlated separately with life situations.

stable psychological well-being consistently correlated with the life situations, Social Contacts, Lack of Worry, and Income. Changing psychological well-being on the other hand, consistently correlated with Medical Health Status, Lack of Impairment, Social Contacts, Activities, Lack of Worry and Income. For those persons with stable psychological well-being then, the findings of previous research were no longer substantiated and health variables, physical impairment and activities did not correlate significantly with psychological well-being that remained stable.

Differences in life sttuations of people with stable and changing psychological well-being were further confirmed through 
subsequent analyses although these differences were not always in the expected direction. Among those who had stable psychological wellbeing, the predicted differences between stable-high and stable-low were significant only for Soclal Contacts, Housing and Cognitive status. This finding that the stable-high and stable-low psychological wellbeing groups were not different on a number of life situations as expected can be better understood by an examination of the case study material.

The mediating influence of psychological well-being on perception of one's surroundings was frequently apparent for the stable psychological well-being groups. For example, some persons with low levels of psychological well-being expressed dissatisfaction with their life situations even though, by objective measurement, they were just as well off as persons with high levels of psychological well-being. Conversely, some with low levels of well-being in life situations by objective measurement, expressed satisfaction with them. This occurence may also, in part, account for differences between stablehigh and stable-low groups on most life situations even though the differences were not statistically significant. (For evidence of existing differences between the stable-high, -middle and -low LS groups on life situations, refer to Figures 2, 3, and 4 presented in Chapter V.)

Mr. Black and Mrs. Andrews are cases in point, offering useful illustrations in the group whose psychological well-being remained stable and low. Mr. Black's IIfe situations indicated that his levels of well-being were simtlar to people whose psychological well-being remained high. Although he did experlence minor 
fluctuations in health, he remained active and his life situations were stable. Objective Indicators of Income, Housing and Social Contacts were Indicative of high levels of well-being. However Mr. Black expressed dissatisfaction with most of his life situations. Mrs. Andrews, in contrast, experienced low levels of wellbeing on most life situations by objective measures, but expressed high levels of satisfaction with them. Her health was poor, she was confined to a walker and rarely left her home. She had no activities other than light housework, reading and watching television. She received no assistance from social services and was completely dependent upon a friend to attend to needs requiring leaving her home. She saw relatives about twice a year and friends once a week. Her income was barely adequate; her home in excellent condition. Her situation remained stable throughout the study.

In contrast to Mr. Black and Mrs. Andrews, illustrations of optimal aging in stable environments were provided by Mrs. Evans and Mrs. Fisher. Both were in good health, were very active and had hobbies that occupied much of their time. Mrs. Fisher had minor fluctuations in health but she was not concerned about them. Their social contacts were frequent and included contacts with children, grandchildren, friends and neighbors. Both had small but adequate monthly incomes and savings to use in case of emergency. Mrs. Fisher earned extra money each month by taking in ironing. She was able to do this because her health permitted, but this response was not typical of persons in the sample who did not have enough money to get by. Both women were, by subjective measures, well satisfied with their life situations. 
Stability of life situations of persons whose psychological well-being remained stable was one of the salient outcomes of this research, as was the relationship between changing life situations and changing psychological well-being. Among the people experiencing change in psychological well-being, the results were consistent with predicted findings. Low levels of well-being for the negative change group were experienced in two or more life situations in personal, social and environmental areas. Further, people with the lowest levels of well-being in four life situations had psychological well-being that changed to the very lowest levels. That is, the middle to low Is group had the lowest levels of well-being for the entire sample on Medical Health Status, Lack of Impaiment, Activities and Lack of Worry.

Changes in life situations corresponded to changes in psychological well-being on five life situations, Medical Health status, Lack of Impairment, Activities, Lack of Worry and Housing. Once again, the lowest levels of well-being were evidenced for the middle to low IS group.

Within the group whose psychological well-being changed in a negative direction, negative changes in life situations were more pervasive, there were fewer options for strengthening them, and the options themselves were less than optimal. Poor health and increased impairment were accompanted by loss of mobility and decreased activity. Social contacts were minimal leaving this group isolated and largely dependent upon a few family members or friends and social services to assist them with their needs. Housing conditions were sometimes poor but frequently unsatisfactory because home maintenance 
had become difficult or too costly. Low levels of subsistence on life situations were reflected in increased worries about health, money, neighborhood and personal safety. Decreased options in most life situations made the feasibility of drawing upon one to strengthen another, for the most part, a remote possibility.

Examples from the case studies provide clarity for these points. Mrs. Hughes and Mrs. Groves, whose psychological well-being changed from high to middle, experienced decline in most life situations. Both women had poor health, limited mobility and few activities at the first interview. By the third interview, increased poor health and physical impairment resulted in complete confinement to home for the two women. They were dependent on others to get out of their homes, which they rarely did. Mrs. Hughes was reliant upon social services for her maintenance needs. She had no children but saw friends and neighbors regularly. She was not satisfied with contact with relatives whom she seldom saw. Mrs. Groves also became increasingly dependent on social services as her daughter became less able to provide all the assistance she required.

Mr. Irving, whose psychological well-being changed from midale to low, experienced serious decline in all life situations. At the first interview, he was already living in precarious circumstances in a two-room apartment on the second floor of a rundown hotel without an elevator and had worsened by the last interview. The interviewer comments indicated that he spent most of his time in bed. In poor health, scrially isolated with no family, relatives and few friends, he depended on his landlord for whatever assistance he needed. His activities consisted of short walks to the store; he neither read nor 
watched television. He had few soclal supports, received no social services, and lived in poor conditions on an income that was far from adequate. Mr. Irving had few resources in any life situation left to draw upon.

Mrs. Hughes, also of the middle to low IS group, presented quite a different picture of decline; nonetheless the point still held that there was steady decline in most life situations until few options were left to draw upon. During the course of the study Mrs. Hughes, who was ninety years old, experienced decline in health, mobility, and increased impairment until she was no longer able to remain in her home. Her son took charge of her finances and she moved to a group home where her needs were met by other people living there. She never left the home but was visited occasionally by her son.

In contrast to persons in the sample whose psychological wellbeing changed in a negative direction, those who experienced positive changes were frequently able to draw upon personal, social and environmental resources to assist themselves in their daily survival. To the extent that they were able to tap resources from one life situation to strengthen another, they increased the likelihood of continued maintenance in their own homes and accompanying positive levels of psychological well-being.

Mrs. Kemp, of the middle-high Is group, provides an illustration of decreased levels of well-being in one area, being strengthened by another. At the time of the first interview she was in good health, no physical impairments and very active. At the third interview, despite serious decline in health with accompanying physical 
impairment, her activity level remained as high as it had been previously. This was possible through additional support provided by social contacts. Children, friends and neighbors assisted her in maintaining her past activities. She responded to these changing life situations with a positive change in psychological well-being and one can almost hear Mrs. Kemp reflecting on her good fortune at having family and friends who cared for her.

For Mrs. Kemp, there was clear evidence of one life situation, Social Contacts, supporting two that were deteriorating, Medical Health Status and Lack of Impairment. The result was maintenance of a fourth life situation, Activities. Mrs. Kemp's affective response to these life situation changes was a positive increase in psychological wellbeing. The extent to which the positive increase was mediated by past behaviors cannot be determined by these data. However, comparisons with persons whose psychological well-being changed in a negative direction indicated that when life situations deteriorated without support from other life situations, there was an accompanying decline in psychological well-being.

Two prominent outcomes of the analyses were, 1 . emergence of some life situations as more critical than others and, 2. different patterns that became evident for the stable and change Is groups. Declines in Medical Health Status and Lack of Impairment were accompanied by decline in Activities for those persons whose psychological well-being changed in a negative direction, with the group who changed from midale to low having the lowest well-being levels on these three life situations. In contrast, persons whose psychological well-being remained stable maintained fairly high and 
stable levels of well-being on all three of these life situations. Further, these same three life situations of Medical Health Status, Lack of Impairment, and Activities did not appear to be critical components of psychological well-being for those persons whose psychological well-being changed in a positive direction. One notable difference between the positive and negative change psychological well-being groups was that in the positive change group the strength of some life situations seemed to have the capacity to accommodate for loss in others. In other words, those persons whose psychological well-being changed in a negative direction appeared to have used up about all their options while those persons whose psychological well-being changed in a positive direction still had options to draw upon. The resources of Social Contacts and Housing appeared to be critical components of psychological well-being for all three psychological well-being groups, stable, positive change, and negative change.

The results strongly indicate that while some life situations may change without necessarily affecting psychological well-being, when Medical Health Status, Lack of Impairment and Activities all decline, there will very likely be a concomitant negative change in psychological well-being.

\section{Theoretical Implications}

The theoretical interest of this dissertation centered largely around the seldom tested assumption that psychological well-being is a stable characteristic. From a psychological perspective, as a component of personality, it is assumed to be relatively stable. 
Sociological perspectives have related psychological well-being to individual differences reflecting the impact of social status indicators that remain fairly stable, thus implicitly assuming the stability of the construct.

Theories of aging suggest that changes in predictor or independent variables such as health or activities are critical to psychological well-being as an outcome measure. Support for these assumptions has been derived from empirical tests where both predictor and outcome measures are typically obtained at one point in time. This has been the case for investigations of activity and disengagement theories and for the currently popular continuity theory of aging. The dissertation data provided evidence, through testing longitudinal data, that psychological well-being did remain stable under certain conditions, however, under other conditions it changed. The stability or change in psychological well-being was dependent upon attendant stability or change in life situations.

The relationship betwecn stability and change in psychological well-being and stability and change in life situations suggests that people may react to stable life situations in a way that is similar to what is referred to in the biological sciences as homeostatic equilibrium. Homeostasis is simply the tendency of an organism to maintain a relatively stable state. In the homeostatic state, an individual is likely to maintain his "usual" psychological outlook, psychological well-being remaining stable and within a range typical for the individual. While some fluctuations in life situations would be tolerated without an accompanying change in psychological well-being, continuous, incremental change or large, abrupt change in life 
situations would reach a point where a psychological effect would be produced. In other words, there may be a threshold of tolerance for changes in life situations and once that threshold is exceeded, there will be accompanying changes in psychological well-being.

The threshold at which the change in psychological well-being occurs cannot be conclusively determined from these data. There is considerable evidence, however, that the threshold limit is exceeded with the occurence of a combination of critical events. Those events are declines in three Well-Being Indicators, Medical Health Status, Lack of Impairment, and Activities. It may also be that the threshold limit can be exceeded by other combinations of events and also that threshold differ for other populations. These questions remain to be investigated in future research.

A logical conclusion follows from these data. It is not likely or expected that all old people will have happy, optimistic outlooks on life if, for example, they somehow manage to have good health, numerous activities, and abundant and satisfactory social contacts. Rather, people have developed different levels of psychological wellbeing that act as mediating influences on their perceptions of life situations. When lives remain relatively stable, perceptions remain stable and typical but when a combination of changes in critical life situations cause the threshold level to be exceeded, there will be accompanying change in psychological well-being.

Absence of longitudinal data has limited our knwoledge of both outcome and process and allowed us to ignore two important areas, the abilities of older persons to adapt to change, and the capacity for adaptation within and between life situations. The interaction 
between these areas was well illustrated by the case study of Mrs. Kemp who was able to maintain her previous high level of activity even when her health deteriorated and physical impairment would predict limited activities. Only by examination of the process by which her activities were maintained, was it learned that increased social contacts enabled her to continue her activities. Furthermore, contrary to the positions of some researchers, frequency and number of social contacts were important in that the more options a person had for social interaction, the greater the probability that there would be people available to meet various needs. That is, frequent contact with many people across networks that included family, friends and neighbors, increased the Itkelihood that the older person who experienced decline would have more opportunity for assistance and social contact than would the person whose contacts were limited. In a phrase then, "more was better" simply because it increased chances that people were available to provide help on an ongoing basis. The critical theoretical implications of this dissertation research center around three salient outcomes:

supportive evidence that psychological well-being, as an outcome measure, reflects accompanying changes in certain life situations;

findings which clarify the ways in which stable and changing life situations are related to stable and changing psychological well-being; and

identification of specific life situations that play critical roles in stable and changing psychological well-being.

In the developmental study of aging, regardless of the theoretical position under consideration, future research must take into account that psychological well-being, as an outcome measure is, 
in fact, subject to change. Further, the impact of change in life situations on psychological well-being will depend on availability of other personal, social and environmental supports as well as the individual's own ability to adapt. Finally, the impact of change is probably specific to the change itself, that is, different kinds of change within and between life situations produce different kinds of consequences.

Directions For Future Research

Directions for future research lie in further examination of the relationship between stable and changing psychological well-being and stability or change in life situations of the aging. This can only be accomplished through longltudinal research that provides data on the nature of specific change and its qualitative and quantitative impact on personal, social, and environmental areas of a person's 1ife.

Some of the dissertation results did not replicate other research. Because of the longitudinal nature of the data, and the strength of the significant relationships, further investigation and attempts at replication of this work have considerable merit, both from a theoretical and an applied standpoint. Specifically, stable psychological well-being did not correlate with variables of health, physical impairment or activities when it was examined separately from the total sample. These correlations, commonly reported as significant in the literature, were in fact, also siginficant for this sample as a whole. Only when such correlations were computed for the stable and change psychological well-being 
groups separately, did the differences emerge. Because these data were obtained from a sample of marginally subsisting adults not sampled in previous research, it is not known to what extent the findings can be generalized to other aging populations. Longitudinal data gathered on samples representative of the age, sex, and social composition of the total older population are requisite conditions for generalizability of these research findings.

One of the major findings of the dissertation was that the relationship between stable or changing psychological well-being and life situations was markedly different, and that within the stable psychological well-being group, people with high, middle and low scores were remarkably similar on life situations. Because longitudinal measures have rarely been available for life situations and psychological well-being, there have been few opportunities to account for these outcomes. Explanations of why part of the sample experienced change in psychological well-being were forthcoming in the data through the relationships with critical life situations; however, this was not the case for the stable psychological wellbeing group. The data are, perhaps, suggestive of a homeostatic equilibrium existing between the individual's affective state and other aspects of his or her life. This relatively stable balance between psychological well-being and life situations is maintained until changes occur in the three critical life situations. Again, only through longitudinal research can such findings be further tested.

The relative importance of the eight life situations bears further investigation, and their refinement will undoubtedly improve 
both the reliability and validity of the scales. Each life situation scale was constructed with data already gathered and some variables were omitted because they were not available. Several scales would be strengthened by inclusion of specific items. The addition of a ninth scale measuring personal maintenance ability would add valuable information in the overall assessment of personal areas of individual well-being.

A cautionary note on the utility of the dissertation results is warranted. The conclusions are not definitive. They do offer substantial support that psychological well-being is not static but, as an outcome measure, it is subject to change and the change is related to combinations of critical events. The data clearly indicate directions for future research and underscore the need to replicate the findings before conclusions can be generalized to other samples of older persons.

A systematic observance of several methodological tasks would add considerable strength to future replications of this study. These include gathering baseline data as a standard by which to measure change, stability and threshold level. Data gathered over a longer time span, beginning early in the retirement years, would give a more complete representation of longitudinal data.

Both the LSI and the WBIs would be strengthened by their exact replication over time. The Adams modified LSI (1969), replicated in its entirety at each interview, is likely to increase the reliability and validity coefficients resulting in greater confidence in the research results.

Well-Being Indicators will benefit from the inclusion of items 
not available in these data and from the construction of the additional scale measuring personal self-maintenance. The strength of the dissertation findings supports refinement and testing of these Indicators on other populations.

Replications of the study, varying both location and sample, will be useful in determining generalizability of the findings. It is not known what the effect of geographic location and city size would be on these data. Nor is it known if samples of older people who are more representative of the total older population would respond in the same way.

Now, and in the foreseeable future, cities will be called upon to meet many needs of increasing numbers of aging people. The diversity of urban places and alternatives already available in middle-sized and large cities offer the potential for adequately serving this papulation. While it is quite likely that the basic requirements for independent living are similar for both urban and rural elderly populations, the ease of meeting these requirements as well as the ways in which they will be most successfully met, undoubtedly varies by geographic location. For example, there is evidence that rural elderly participate in church and social organizations more frequently than do urban elderly. It might be assumed that assistance with housekeeping, grocery shopping, and care of ailing old people, might be most effectively administered by these organizations when dealing with the rural elderly.

Future research that takes into account the effect of place would be of considerable value in determining how the needs of the elderly can most effectively be met. 
Finally, the importance of the case study should not be overlooked in gathering data on the well-being of older persons. The case study contains a wealth of information, providing rich illustrations of the general findings and shedding light on the processes involved in the relationship of one life situation to another. In conclusion, these data have provided useful insights into the ways a group of older persons subsisting under marginal personal, social, and environmental circumstances, have been able to continue to maintain themselves. Evidence supporting the situationally reactive nature of psychological well-being offers a challenge for further exploration through future longitudinal research. Further careful delineation of the life situstions of older persons will serve as useful tools in assessing stability or change within their environments, and in identifying their needs. Identification of such needs as they arise increases the likelihood and opportunity of responding in a timely and appropriate manner thereby maintaining an optimal quality of life for older persons. 


\section{A SELECTED BIBLIOGRAPHY}

Adams, D. Correlates of satisfaction among the elderly. Gerontologist, $1971,11,64-48$.

Adams, L. Analysis of a life satisfaction index. Journal of Gerontology, 1969, 24, 470-474.

Administration on Aging. Guidelines for preparation of grant application. Research and Development Projects in Aging, Title 4B, Older Americans Act, fiscal year 1978. Office of Human Development Services, Department of Health, Education and Welfare.

Administration on Aging. Guidelines for preparation of grant application. Research and Development Projects in Aging, Title 4B, Older Americans Act, fiscal year 1979. Office of Human Development Services, Department of Health, Education and Welfare.

Atchley, R. C. Social forces in later life. Belmont, California: Wadsworth Publishing Co., Inc., 1977.

Back, K. W. Personal characteristics and social behavior: Theory and method. In R. Binstock \& E. Shanas (Eds.), Handbook of aging and the social sciences. New York: Van Nostrand Reinhold, 1976.

Beale, C. I. The revival of population growth in nonmetropolitan America (Report No. 605). Washington, D. C.: Department of Agriculture, Economic Research Service, 1975.

Becker, H. Personal change in adult life. In B. Neugarten (Ed.), Middle age and aging. Chicago, Illinois: University of Chicago Press, 1968.

Beiser, M. Components and correlates of mental well-being. Journal of Health and Social Behavior, 1974, 15, 320-327.

Bell, B. D. The limitations of crises theory as an explanatory mechanism in social gerontology. International Journal of Aging and Human Development, 1975, 6, 153-168.

Bengtson, V., Chiriboga, D., \& Keller, A. Occupational differences in retirement: Patterns of role activity and life outlook among Chicago teachers and steelworkers. In R. J. Havighurst (Ed.), Adjustment ot retirement: A cross-national study. Assen, Netherlands : Van Gorcum, 1969. 
Bennett, J. W. Anticipation, adaptation and the concept of culture in anthropology. Science, 1976, 192, 847-853.

Bild, B., \& Havighust, R. Senior citizens in great cities: The case of Chicago. Gerontologist, 1976, 16, 4-88.

Bishir, J.W. \& Drewes, D. W. Mathematics in the behavioral and social sciences. New York: Harcourt, Brace \& World, Inc., 1970.

Blau, 2. S. Old age in a changing society. New York: New Viewpoints, 1973.

Bradburn, N. M. The structure of psychological well-being. Chicago: Aldine, 1969.

Brehm, J., \& Cohen, A. R. Exploration in cognitive dissonance. New York: Wylie, 1962 .

Brotman, H. B. Every tenth American: The problem of aging. In M. P. Lawton, R. J. Newcomer, \& T. O. Byerts (Eds.), Community planning for an aging society. Strondsburg, Pa.: Dowden, Hutchinson and Ross, Inc., 1976.

Buhler, R. Aging and life adjustment. In J. Birren (Ed.), Handbook of aging and the individual. Chicago, Illinois: University of Chicago Press, 1971.

Bull, C. N., \& Aucoin, J. Voluntary association participation and life satisfaction: A replication note. Journal of Gerontology, 1975, 30, 73-76.

Bultena, G. Iife continuity and morale in old age. Gerontologist, $1969, \underline{9}, 251-253$.

Bultena, G. \& Oyler, R. Effects of health on disengagement and morale. International Journal of Aging and Human Development, $1971, \underline{2}, \overline{142-148 .}$

Busse, E. W., \& Wang, H. The multiple factors contributing to dementia in old age. In E. Palmore (Ed.), Normal aging II. Durham, North Carolina: Duke University Press, 1974.

Butler, R. N. How to grow old and poor in an affluent society. International Journal of Aging and Human Development, 1973, 4; 277-279.

Butler, R. N. Why survive? Being old in America. New York: Harper and Row Publishers, 1975.

Butler, R. N. \& Lewis, M. I. Aging and mental health. St. Louis: C. V. Mosby Company, 1973. 
Cameron, P. Mood as an indicant of happiness: Age, sex, social class and situational differences. Journal of Gerontology, 1975,30 , 216-224.

Campbell, A., Converse, P., \& Rodgers, W. The quality of American life. New York: Russell Sage Foundation, 1976.

Cantor, M. H. Life space and the social support system of the inner city elderly of New York. Gerontologist, 1975, 15, 23-24.

Cantor, M. H., \& Mayer, M. Factors in differential utilization of services by urban elderly. Proceedings of the 28th Annual Scientific Meeting of the Gerontological Society, October 1975.

Caplan, G. Support systems and community mental health. New York: Behavioral Publications, 1974 .

Carp, F. Effects of improved housing on the lives of older people. In B. N. Neugarten (Ed.), Middle age and aging. Chicago: University of Chicago Press, 1968.

Carp, F. Lifestyle and location within the city. Gerontologist, 1975, $15,27-34$.

Carp, F. Housing and living environments of older people. In R. H. Binstock \& E. Shanas (Eds.), Handbook of aging and the social sciences. New York: Van Nostrand Reinhold Company, 1976.

Cattell, R. B., Eber, H. W., \& Tatsuoka, M. M. Handbook for the 16 personality factor questionnaire (16PF) (4th ed). Champaign, Illinois: Institute for Personality and Ability Testing, 1970.

Cavan, R. S., Burgess, E. W., Havighurst, R. J., \& Goldhamer, H. Personal adjustment in old age. Chicago: Science Research Associates, 1949.

Chen, Yung-Ping. Potential income from home ownership: An actuarial mortage plan. In U.S. Congress Joint Economic Comittee. Old age income assurance, part 2. Washington, D.C.: U.S. Government Printing Office, 1967.

Clark, M., \& Anderson, B. G. Culture and aging. Springfield, Illinois : Charles C. Thomas, 1967.

Clemente, F., \& Sauer, $w$. Race and morale of the urban aged. Gerontologist, 1974, 14, 342-344.

Conner, K. A., Powers, E. A., \& Bultena, G. L. Social interaction and life satisfaction: An empirical assessment of late life patterns. Journal of Gerontology, 1979, 34, 116-121.

Coombs, C. H. Psychological scaling without a unit of measurement. Psychological Review, 1950, 57, 145-158. 
Coombs, C. H. A theory of data. New York: Wiley, 1964.

Craven, P., \& Wellman, B. The network city. Social Inquiry, 1972-73, $42-43,57-88$.

Cumming, E., \& Henry, w. Growing old. New York: Basic Books, 1961.

Curtis, R., Jr., \& Zurcher, L. A., Jr. Voluntary association: Integration of the poor. Social Problems, 1971, 18, 339-357.

Cutler, s. The availability of personal transportation, residential location, and life satisfaction among the aged. Journal of Gerontology, 1972, 27, 282-289.

Cutler, s. Transportation and changes in life satisfaction. Gerontologist, 1975, 15, 155-159.

Dawes, R. M. Fundamentals of attitude measurement. New York: Wiley, 1972 .

Dobra, J. L. Future directions in Social Security. Testimony before the U.S. Special Senate Committee on Aging, 94th Congress, first session, part 21, Portland, Oregon, November 25, 1975.

Dobroff, R., \& Litwak, E. Maintenance of family ties of long-term care patients: Theory and guide to practice. (U.S. Department of Health, Education and Welfare Publication No. (ADM) 77-400) Washington, D.C.: U.S. Government Printing office, 1977.

Dye, D., Goodman, M., Roth, M., Bley, N., \& Jensen, K. The older adult volunteer compared to the non-volunteer. Gerontologist, $1973,13,215-218$.

Edwards, J. N., \& Klemmack, D. I. Correlates of life satisfaction: A reexamination. Journal of Gerontology, 1973, 23, 497-502.

Forston, R., \& Kitchens, L. Criminal victimization of the aged: The Houston Model Neighborhood Area. Denton: North Texas State University, Department of Sociology, 1974.

Fowler, F. J., Jr. Knowledge, need and use of services among the aged. In C. C. Osterbind (Ed.), Health care services for the aged. Florida: University of Florida, Institute of Gerontology, 1970.

Frenkel-Brunswick, E. Adjustment and reorientation in the course of the life span. In B. Neugarten (Ed.), Middle age and aging. Chicago, Illinois: University of Chicago Press, 1968.

George, L. The impact of personality and social status factors upon levels of activity and psychological well-being. Journal of Gerontology, 1978, 33, 840-847. 
George, L., \& Maddox, G. L. Subjective adaptation to loss of the work-role: A longitudinal study. Journal of Gerontology, 1977, $32,456-462$.

Gionet, I. An analysis of socio-economic well-being: A case study of the urban elderly. Unpublished doctoral dissertation, Portland State University, (in progress).

Goode, W. J., \& Hatt, P. K. Methods in social research. New York: McGraw-Hill Book Co., Inc., 1952.

Goodwin, L. Do the poor want to work? A social psychological study of work orientations. Washington, D.C.: The Brookings Institution, 1972.

Graney, M. Happiness and social participation in aging. Journal of Gerontology, 1975, 30, 701-706.

Graney, M., \& Graney, E. Communication activity substitutions in aging. Journal of Communications, 1974, 24, 88-95.

Gurin, G., Veroff, J., \& Feld, S. Americans view their mental health. New York: Basic Books, 1960.

Hall, C. S. \& Lindzey, G. Theories of Personality (2nd ed.). New York: John Wiley, 1970.

Handler, J. F., \& Hollingsworth, E. J. Stigma, privacy, and other attitudes of welfare recipients (Reprint No. 50). Wisconsin: University of Wisconsin, Institute for Research on Poverty, 1975.

Harris, C.w. (Ed.). Problems in measuring change. Madison: University of wisconsin Press, 1963.

Havighurst, R. The social competence of midale aged people. Genetic Psychology Monographs, 1957, 56, 297-375.

Havighurst, R., \& Albrecht, R. Older people. New York: Longmans Green, 1953.

Havighurst, R., Neugarten, B., \& Tobin, S. Disengagement and patterns of aging. In B. N. Neugarten (Ed.), Middle age and aging.

Chicago: University of Chicago Press, 1968.

Heyman, D., \& Jeffers, F. The influence of race and socioeconomic status upon the activities and attitudes of the aged. Journal of Gerontology, 1969, 19, 225-229.

Hollister, R. Social mythology and reform: Income maintenance for the aged. The Annals, 1974, 415, 19-40.

Huck, W., William, C. H., \& William, B. G. Reading statistics and research. New York: Harper \& Row, 1974. 
Jeffers, F., \& Nichols, C. R. The relationship of activities and attitudes to physical well-being in older people. In $\mathbf{E}$. Palmore (Ed.), Normal Aging II. Durham, N. C.: Duke University Press, 1974.

Jeffers, F., Nichols, C. R., \& Eisdorfer, C. Attitudes of older persons toward death; a preliminary study. Journal of Gerontology, 1961, 16, 53-56.

Kadushin, C. The friends and supporters of psychotherapy: On social circles in urban life. American Sociological Review, 1966, 31, 786-802.

Kallen, D. J., \& Miller, D. Public attitudes toward welfare. Social Work, 1971, 16, 83-90.

Keith, P. M. Life changes and perceptions of life and death among older men and women. Journal of Gerontology, 1979, 34, 870-877.

Keller, S. The urban neighborhood. New York: Random House, 1968.

Kistin, H., \& Morris, R. Alternatives to institutional care for the elderly and disabled. Gerontologist, 1972, 12, 139-142.

Kivett, V. Physical, social and environmental characteristics and sources of assistance (Technical Bulletin No. 237). North Carolina: Agricultural Experimental Station, 1976.

Kuhlen, R. G. Age trends in adjustment during the adult years as reflected in happiness ratings. American Journal of Psychology, 1948,3 , 307. (Abstract)

Kutner, B., Fanshel, D., Togo, A., \& Langner, T. Five hundred over sixty. New York: Russell Sage Foundation, $1 \overline{956 .}$

Lambert, C., Jr., \& Morris, G. R. Reopening doors to community participation for older people: How realistic? Social Service Review, 1969, 38, 42-50.

Larson, R. Thirty years of research on the subjective well-being of older Americans. Journal of Gerontology, 1978, 33, 109-125.

Lawton, M. P. The dimensions of morale. In D. P. Kent, R. Kastenbaum, \& S. Sherwood (Eds.), Research planning and action for the elderly. New York: Behavioral Publications, 1972.

Lawton, M. P. Morale: What are we measuring? In C. Nydegger (Ed.), Measuring morale: A guide to effective assessment. Washington, D.C.: Gerontological Society, 1977.

Lawton, M. P., \& Cohen, J. The generality of housing impact on the well-being of older people. Journal of Gerontology, 1974, 29, 194-204. 
Lawton, M. P., \& Kleban, M. H. The aged resident of the inner city. Gerontologist, 1971, 22, 277-283.

Lawton, M. P., \& Nahemow, L. Ecology and the aging process. In C. Eisdorfer \& M. P. Lawton (Eds.), Psychology of adult development and aging. Washington: American Psychological Association, 1973, 619-674.

Lawton, M. P., Brody, E. M., \& Turner-Massey, P. The relationships of environmental factors to changes in well-being. Gerontologist, 1978, 18, 133-137.

Lebo, D. Some factors said to make for happiness in old age. Journal of Clinical Psychology, 1953, 9 , 385-390.

Lebowitz, B. D. Age and fearfulness: Personal and situational factors. Journal of Gerontology, 1975, 30, 696-700.

Lebowitz, B. D., \& Dobra, J. I. Income security for the elderly. Paper presented at the Tenth International Congress of Gerontology, Jerusalem, June 1975.

Lemon, B. W., Bengtson, V. L., \& Peterson, J. A. An exploration of the activity theory of aging, activity types and life satisfaction among inmovers to a retirement community. Journal of Gerontology, 1972, 27, 511-523.

Lewis, H. Culture and poverty? What does it matter? In E. Leacock (Ed.), The culture of poverty. New York: Simon and Schuster, 1971.

Liberman, R. Personal influence in the use of mental health resources. Human Organization, 1965, 24, 231-235.

Lind, S. D. Social service utilization: Application of behavioral model of demand to an elderly population. Unpublished doctoral dissertation, Brandeis University, 1978.

Lohmann, N. Correlations of life satisfaction, morale, and adjustment measures. Journal of Gerontology, 1977, 32, 73-75.

Lopata, H. A. Support systems of elderly urbanites: Chicago of the 1970's. Gerontologist, 1975, 15, 34-41.

Lowenthal, M. F. Social isolation and mental illness in old age. In B. Neugarten (Ed.), Middle age and aging. Chicago: University of Chicago Press, 1968.

Lowenthal, M. F. \& Berkman, C. Interaction and adaptation: Intimacy as a critical variable. In Neugarten (Ed.), Middle age and aging. Chicago: University of Chicago Press, 1968. 
Lowenthal, M. F. \& Haven, C. Interaction and adaptation: Intimacy as a critical variable. In Atchley \& M. Seltzer (Eds.), The sociology of aging: selected readings. Belmont, Calif.: Wadsworth Publishing Co., 1976.

Lowenthal, M. F., \& Robinson, B. Social networks and isolation. In R. H. Binstock \& E. Shanas (Eds.), Handbook of aging and the social sciences. New York: Van Nostrand Reinhold Company, 1976.

Maddox, G. L. Activity and morale; a longitudinal study of selected elderly subjects. Social Forces, 1963, 42, 195-204.

Maddox, G. L. Persistence of life style among the elderly: A longitudinal study of patterns of social activity in relation to lifesatisfaction. In $B$. Neugarten (Ed.), Middle age and aging. Chicago: University of Chicago Press, 1968.

Maddox, G. I. \& Eisdorfer, C. Some correlates of activity and morale among the elderly. Social Forces, 1962, 40, 254-260.

Man, P. Welfare stigmatization and the elderly: The case of the Supplemental Security Income Program. Unpublished doctoral dissertation, Portland State University, 1979.

Mancini, N. W. Role exits among the aged. Unpublished master's thesis, Portland state University, 1975.

Markides, K. S., \& Martin, H. W. A causal model of life satisfaction among the elderly. Journal of Gerontology, 1979, 34, 86-93.

Martin, w. C. Activity and disengagement: Life satisfaction of inmovers into a retirement community. Gerontologist, 1973, 13, 224-227.

McCoy, J. L., \& Brown, D. I. Health status among low-income elderly persons: Rural-urban differences. Social Security Bulletin, $1978, \underline{41}, 14-26$.

Mischel, w. Continuity and change in personality. American Psychologist, 1969, 24, 1012-1018.

Moen, E. W., \& Moen, T. H. What do the elderly want? Oregon: Office of Elderly Affairs, $19 \overline{77 .}$

Morgan, J. N., David, M. H., Cohen, W. J., \& Blazer, H. E. Income and welfare in the United States. New York: McGraw Hill, 1962.

Morris, J. N., \& Sherwood, S. A retesting and modification of the Philadelphia Geriatric Center Morale Scale. Journal of Gerontology, 1975, 30, 77-84. 
Moss, M. S., Gottesman, L. E., \& Worts, F. P. Elderly community residents: Is their statement of "wants" reflective of their subsequent acceptance of services? Proceedings of the 28th Annual Scientific Meeting of the Gerontological Society, October 1975.

Murray, H. A. Explorations in personality. New York: Wiley, 1938.

Neugarten, B. I. Continuities and discontinuities of psychological issues in adult life. In D. C. Charles \& W. I. Croft (Eds.), Readings in psychological development through life. New York: Holt Rinehart and Winston, Inc., 1973.

Neugarten, B. I., Havighurst, R. J., \& Tobin, S. S. The measurement of life satisfaction. Journal of Gerontology, 1961, 16, 134143 .

Neugarten, B. L., Havighurst, R. J., \& Tobin, S. S. Personality and patterns of aging. In B. I. Neugarten (Ed.), Middle age and aging. Chicago: University of Chicago Press, 1968.

Neugarten, B. L., Moore, J. W., \& Lowe, J. C. Sociological aspects of aging. In E. W. Busse \& E. Pfeiffer (Eds.), Behavior and adaptation in late life. Boston: Little, Brown and Company, 1969.

Nie, N. H., Hull, C. H., Jenkins, J. G., Steinbrenner, K., Bent, D. H. Statistical package for the social sciences (2nd ed.). New York: McGraw-Hill, 1975.

Nunnally, J. C. Psychometric theory (2nd ed.). New York: McGraw-Hill, 1978.

Nystrom, E. P. Activity patterns among the elderly. American Journal of Occupational Therapy, 1974, 28, 337-345.

O'Brien, J. E. Project ABLE impact analysis comparing institutionalized persons and ABLE clients. Portland, Oregon: Institute on Aging, Portland State University, 1974.

O'Brien, J. E., Alexander, R. A longitudinal study of a high risk elderly population: An analysis of the environmental, social, and personal aspects of everyday life. Portland, Oregon: Institute on Aging, Portland state University, July 1978.

O'Brien, J. E., Alexander, R., Lind, S., Wagner, D., \& Whitelaw, N. Lifestyle adjustments of the aged poor: A three year study of a west coast population. Paper presented at the meeting of the Eastern Sociological Society, Philadelphia, PA, April 1978.

Palmer, J. L. Inflation, unemployment, and poverty. Lexington, Mass.: Lexington Books, 1973. 
Palmore, E. The effects of aging on activities and attitudes. Gerontologist, $1968, \underline{8}, 259-263$.

Palmore, E., \& Luikart, C., Jr. Health and social factors related to life satisfaction. Health and Social Behavior, 1972, 13, 68-80.

Palmore, E., Cleveland, W. P., Ramm, N. D., \& Siegler, J. C. Stress and adaptation in later life. Journal of Gerontology, 1979, 34, 841-851.

Perlman, R. Consumers and social services. New York: Wiley and Sons, 1975.

Pihlblad, C. T., \& Adams, D. L. Widowhood, social participation and life satisfaction. Aging and Human Development, 1972, 3, 323-330.

Piven, C. T., \& Cloward, R. A. Regulating the poor. New York: Vintage Books, 1971.

Pollak, 0 . Social adjustment in old age. New York: Social Science Research Council, 1948.

Projector, D. S., \& Weiss, G. S. Income-net work measures of economic welfare. Social Security Bulletin, 1969, 32, 14-17.

Radin, B. A. The implementation of SSI: Guaranteed income or welfare. Public Welfare, 1974, 32, 7-19.

Rainwater, I. What money buys. New York: Basic Books, 1974.

Regnier, V. Neighborhood planning for the urban elderly. In D. S. Woodruff, \& J. E. Birren (Eds.), Aging: Scientific perspectives and social issues. New York: Van Nostrand Company, 1975.

Reichard, S., Livinson, F., \& Peterson, P. G. Aging and personality. New York: Wiley and Sons, 1962.

Riegel, K. F., Riegel, R. M., \& Meyer, G. The prediction of retestresisters in longitudinal research on aging. Journal of Gerontology, 1968, 23, 370-374.

Riley, M., \& Foner, A. Aging and society (Vol. 2). New York: Russell Sage Foundation, 1968 .

Rose, A. M. Factors associated with life satisfaction of middle-class middle-aged persons. Marriage and Family Living, 1955, 17, 15-19.

Rosow, I. Adjustments of the normal aged. In R. H. Williams, C. Tibbits, \& W. Donahue (Eds.), Process of aging (Vol. 2). New York: Atherton Press, 1963.

Rosow, I. Social integration of the aged. New York: Free Press, 1967. 
Rosow, I. Socialization to old age. Berkeley: University of California Press, 1974.

Schieber, S. J. First year impact of SSI on economic status of 1973 adult assistance populations. Social Security Bulletin, 1978, 41, $18-46$.

Schiltz, M. E. Public attitudes toward Social security 1935-1965 (Research Report No. 33). Washington, D. C.: Social Security Administration, Office of Research and Statistics, 1969.

Schooler, K. K. Effect of environment on morale. Gerontologist, 1970, 10, 194-197.

Sellitz, C., Jahoda, M., Deutsch, M., \& Cook, S. W. Research methods in social relations. New York: Holt, Rinehart and Winston, 1959.

Shanas, E. Family relationships of older people (Research Series 20). New York: Health Information Foundation, 1961.

Shanas, E. The health of older people: A social survey. Cambridge, Mass.: Harvard University Press, 1962.

Shanas, E., \& Sussman, M. B. Family, bureaucracy and the elderly. Durham, North Carolina: Duke University Press, 1977.

Smith, K. J., \& Lipman, A. Constraint and life satisfaction. Journal of Gerontology, 1972, 27, 77-82.

Spreitzer, E., \& Snyder, E. E. Correlates of life satisfaction among the aged. Journal of Gerontology, 1974, 29, 454-458.

Stake, R. The case study method in social inquiry. Educational Research, 1978, ㄱ, 5-8.

Stewart, B. J., \& Whitelaw, N. Testing a model of late life decline. Paper presented at the meeting of the Gerontological Society, San Francisco, November 1977.

Streib, G. F., \& Schneider, C. J. Retirement in American society: Impact and process. Ithaca, New York: Cornell University Press, 1971.

Suchman, E. A. Stages of illness and medical care. Journal of Health and Human Behavior, 1965, 6, 114-128.

Taietz, P. Two conceptual models of the senior center. Journal of Gerontology, 1976, 31, 219-222.

Thompson, W. E., Streib, G. F., \& Kosa, J. The effect of retirement on personal adjustment: A panel analysis. Journal of Gerontology, $1960,15,165-169$. 
Tissue, T. Old age and the perception of poverty. Sociology and Social Research, 1972, 56, 331-344.

Tissue, T. Patterns of aging on welfare. California: Human Relations Agency, Department of Social Welfare, July 1972.

Tissue, T. The survey of the low-income aged and disabled: An introduction. Social Security Bulletin, 1977, 40, 3-10.

Tobin, S. S., \& Neugarten, B. L. Life satisfaction and social interaction in the aging. Journal of Gerontology, 1961, 16, 344-346.

Townsend, P. The last refuge: A survey of residential institutions and homes for the aged in England and Wales. Iondon: Routledge and Paul Kegan, 1962.

U.S. Department of Commerce, Bureau of the Census. 1970 Census. Washington, D.C.: U.S. Government Printing Office, 1970.

U.S. Department of Commerce, Bureau of the Census. Current population reports, (Series P-60, No. 87). Washington, D.C.: U.S. Government Printing Office, 1973.

U.S. Department of Commerce, Bureau of the Census and Manpower Administration. Urban atlas, GE80-6440, Portland, Oregon-Washington, SMSA. Washington, D.C.: U.S. Government Printing Office, 1974.

U.S. Department of Commerce, Bureau of the Census. Demographic aspects of aging and the older population in the U.S. Current population reports. (Special studies, Series P-23, No. 59). Washington, D.C.: U.S. Government Printing Office, May 1976.

U.S. Department of Commerce, Bureau of the Census. Household and family characteristics: March 1976. Current population reports, (Series P-20, No. 311). Washington, D.C.: U.S. Government Printing Office, 1977.

U.S. Department of Health, Education \& Welfare, Office of Human Development Services, Federal Council on Aging. Public Policy and the frail elderly: A staff report (DHEW Publication No. (OHDS) 7920959). Washington, D.C.: U.S. Government Printing office, December 1978.

Wagner, D. I., \& Keast, F. D. Primary associations and intervention effectiveness. Paper presented at the annual meeting of the Gerontological Society, San Francisco, 1977.

Wagner, D. L., O'Brien, J. E., \& Jean, E. Primary associations, social networks, and services for the elderly. Paper presented at the annual meeting of the Gerontological Society, New York, 1976. 
Wagner, D. L., \& White, D. L. The use of survey data and case histories in gerontological research: A call for the revision of methodological approaches. Paper presented at the annual meeting of the Gerontological Society, Dallas, Texas, 1978.

White, D. Self concepts of institutionalized and community residing elderly. Unpublished master's thesis, Portland State University, 1978 .

Wilensky, H. Life cycle, work situation, and participation in formal associations. In R. W. Kleemeier (Ed.), Aging and leisure. New York: Oxford University Press, 1961.

Wilkinson, A. An analysis of the process of change prior to institutionalization. Paper presented at the annual meeting of the Gerontological Society, Portland, Oregon, 1974.

Williams, R. H., \& Wirths, C. G. Lives through the years. New York: Atherton Press, 1965.

Williams, $W$. The SSI program: Potentially the next crucial step toward Social security and welfare reform. (Public Policy Paper No. 5), Seattle, Washington: Institute of Governmental Research, University of Washington, January 1973.

wood V., Wylie, M. I., \& Sheafer, B. An analysis of short self-report measure of life satisfaction: Correlation with rater judgments. Journal of Gerontology, 1969, 24, 465-469.

Woodruff, D. S., \& Birren, J. E. (Eds.). Aging: Scientific perspectives and social issues. New York: Van Nostrand Co., 1975.

Wylie, M. Iife satisfaction as a program impact criterion. Journal of Gerontology, 1970, 25, 36-70. 
APPENDIX A

IIFE SATISFACTION INSTRUMENT 
TABIE XX

THE FORM OF THE MODIFIED LIFE SATISFACTION INDEX USED IN THE SSI STUDY AND FOR THIS DISSERTATION.

(Items were read to the respondents by an interviewer as part of a larger interview schedule.)

Items.

1. As I grow older, things seem better than I thought they would be.

*2. I have gotten more of the breaks in life.

3. This is the dreariest time of my life.

4. Compared to other people my age, I make a good appearance.

* 5. When I think back over my life, I dian't get most of what I wanted.

6. Most of the things I do are boring or monotonous.

* 7. I expect interesting and pleasant things to happen.

8. These are the worst years of my life.

* 9. The things I do are as interesting to me now.

10. My life could be happier than it is now.

11. As I look back on my life, I don't feel very satisfied.

*12. I've gotten pretty much what I expected from life.

13. I am just as happy as when I was younger.

*14. I would change quite a lot of my past life.
Alternatives presented with each item:

1. Strongly disagree

2. Disagree

3. Agree

4. Strongly agree

other alternatives coded:

- Does not apply

- Don't know

- Missing information

* Items which have slight changes from Adans (1969) ISI (See Table II in Chapter II). 
APPENDIX B

A COMPARISON OF MEANS ON INDICATORS OF WELI-BEING FOR SEVEN LIFE SATISFACTION GROUPS 
TABLE XXI

A COMPARISON OF MEANS ON TIRE 1 INDICATORS OF WELL-BEING FOR SEVEN IIFE SATISFACTION GROUPS

LIFE SATISFACTION GROUP

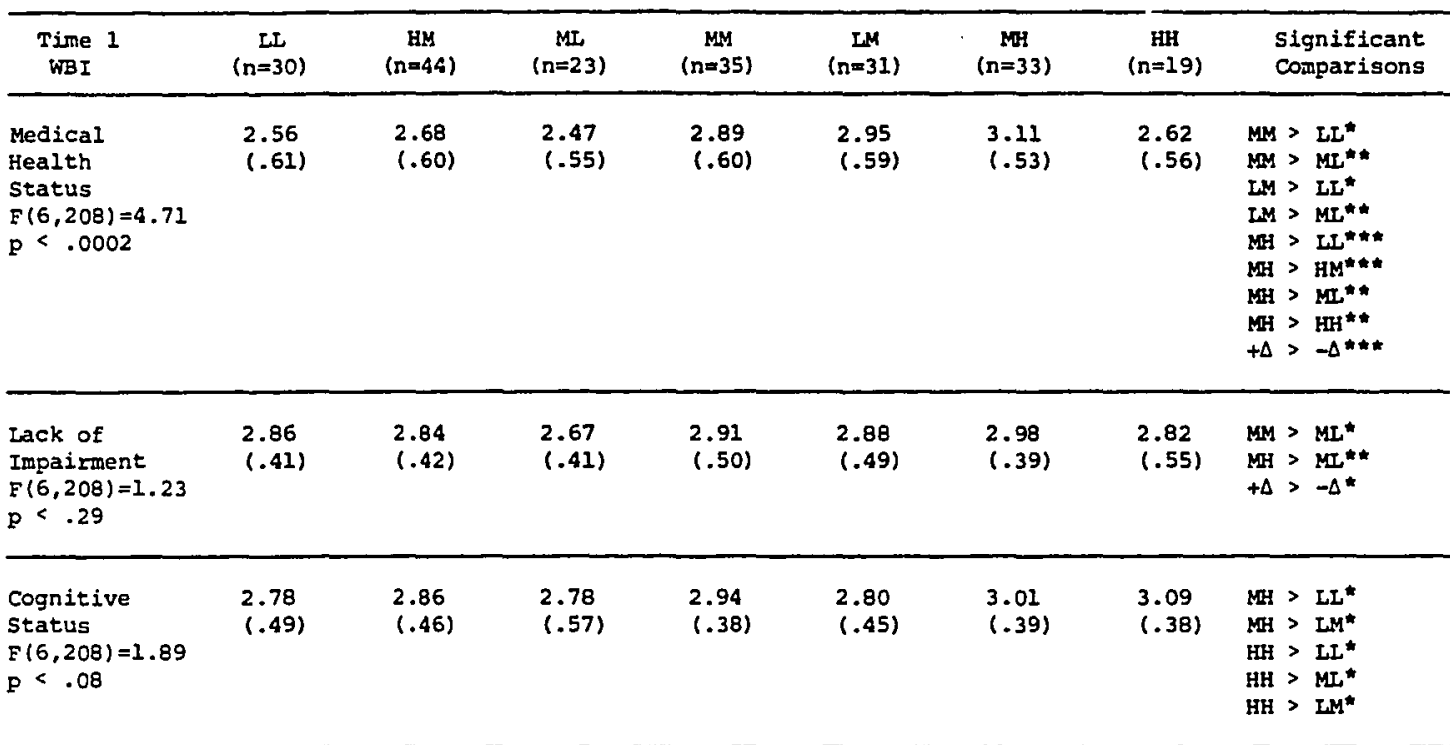

$\begin{array}{lllllllll}\text { Social } & 2.47 & 2.69 & 2.36 & 2.50 & 2.54 & 2.78 & 2.89 & \mathrm{HM}>\mathrm{MI}\end{array}$

$\begin{array}{lllllllll}\text { Contacts } & (.51) & (.58) & (.58) & (.51) & (.54) & (.57) & (.43) & \mathrm{LM}>\mathrm{ML}\end{array}$

$F(6,208)=2.98 \quad$ MEI > LL*

$\mathrm{P}<.008+\mathrm{MH}^{>} \mathrm{MM}^{*}$

HH > LL**

$\mathrm{HH}>\mathrm{ML} *$

$\mathrm{HH}>\mathrm{MM}^{*}$

$\mathrm{HH}>\mathrm{LM}^{*}$

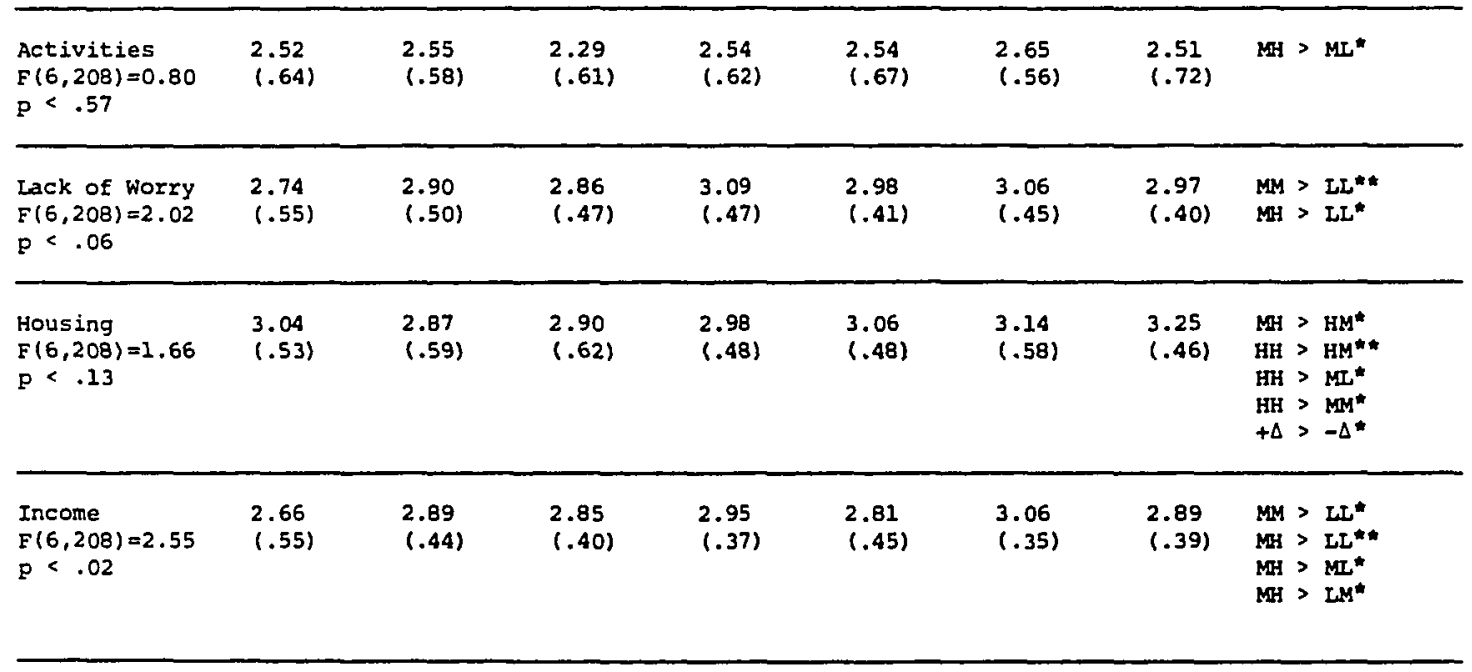

Note. Entries in the above table are means with standard deviations in parentheses.

$+\Delta=$ persons whose ISI scores changed in a positive direction.

$-\Delta=$ persons whose LSI scores changed in a negative direction.

$\star \mathrm{p}<.05$

$* \mathrm{p}<.01$

*** p<.001 
TABLE XXII

A COMPARISON OF MEANS ON TIME 2 INDICATORS OF MELL-BEING FOR SEVEN LIFE SATISFACTION GROUPS

LIFE SATISFACTION GROUP

\begin{tabular}{|c|c|c|c|c|c|c|c|c|}
\hline$\underset{\text { WBI }}{\operatorname{Time}} 2$ & $\begin{array}{c}L L \\
(n=30)\end{array}$ & $\underset{(n=44)}{H M}$ & $\underset{(n=23)}{M n}$ & $\underset{(n=35)}{M M}$ & $\underset{(n=31)}{L M}$ & $\begin{array}{c}\mathrm{MH} \\
(n=33)\end{array}$ & $\begin{array}{c}\mathrm{HH} \\
(\mathrm{n}=19)\end{array}$ & $\begin{array}{l}\text { Significant } \\
\text { Comparisons }\end{array}$ \\
\hline $\begin{array}{l}\text { Medical } \\
\text { Health } \\
\text { Status } \\
F(5,208)=4.26 \\
P<.0005\end{array}$ & $\begin{array}{l}2.68 \\
(.79)\end{array}$ & $\begin{array}{l}2.67 \\
(.64)\end{array}$ & $\begin{array}{l}2.20 \\
(.77)\end{array}$ & $\begin{array}{l}2.75 \\
(.71)\end{array}$ & $\begin{array}{l}2.84 \\
(.63)\end{array}$ & $\begin{array}{l}3.12 \\
(.64)\end{array}$ & $\begin{array}{l}2.71 \\
(.69)\end{array}$ & 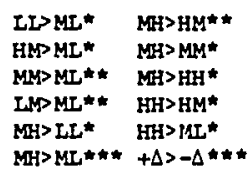 \\
\hline $\begin{array}{l}\text { Lack of } \\
\text { Impairment } \\
F(6,208)=2.87 \\
p<.01\end{array}$ & $\begin{array}{l}3.20 \\
(.54)\end{array}$ & $\begin{array}{l}3.05 \\
(.62)\end{array}$ & $\begin{array}{l}2.86 \\
(.62)\end{array}$ & $\begin{array}{l}3.41 \\
(.61)\end{array}$ & $\begin{array}{l}3.24 \\
(.61)\end{array}$ & $\begin{array}{l}3.39 \\
(.68)\end{array}$ & $\begin{array}{l}3.18 \\
(.56)\end{array}$ & $\begin{array}{ll}L L>M L * & L M>M L * \\
H M>M L * * & M H>H M^{*} \\
M M>M M^{* *} & +\Delta>-\Delta^{* *} \\
M M>M L * & \end{array}$ \\
\hline $\begin{array}{l}\text { Cognitive } \\
\text { Statis } \\
F(6,208)=.81 \\
p<.56\end{array}$ & $\begin{array}{l}3.20 \\
(.57)\end{array}$ & $\begin{array}{l}3.39 \\
(.45)\end{array}$ & $\begin{array}{l}3.22 \\
(.42)\end{array}$ & $\begin{array}{l}3.36 \\
(.38)\end{array}$ & $\begin{array}{l}3.29 \\
(.44)\end{array}$ & $\begin{array}{l}3.33 \\
(.54)\end{array}$ & $\begin{array}{l}3.37 \\
(.44)\end{array}$ & NDS \\
\hline $\begin{array}{l}\text { Social } \\
\text { Contacts } \\
F(6,208)=4.55 \\
F<.0002\end{array}$ & $\begin{array}{l}3.19 \\
(.42)\end{array}$ & $\begin{array}{l}3.29 \\
(.40)\end{array}$ & $\begin{array}{l}3.10 \\
(.45)\end{array}$ & $\begin{array}{l}3.43 \\
(.41)\end{array}$ & $\begin{array}{l}3.39 \\
(.40)\end{array}$ & $\begin{array}{l}3.52 \\
(.32)\end{array}$ & $\begin{array}{l}3.53 \\
(.30)\end{array}$ & $\begin{array}{ll}H M>M L^{* *} & M H>M L * * * \\
M M>L L^{*} & H H>L L^{* *} \\
L M>M L * & H H>H M^{*} \\
M H>L L^{* * *} & H H>M L^{* * *} \\
M H>H^{* *} & +\Delta>-\Delta^{*}\end{array}$ \\
\hline $\begin{array}{l}\text { Activities } \\
F(6,208)=1.62 \\
p<.1444\end{array}$ & $\begin{array}{l}2.38 \\
(.60)\end{array}$ & $\begin{array}{l}2.39 \\
(.51)\end{array}$ & $\begin{array}{l}2.12 \\
(.61)\end{array}$ & $\begin{array}{l}2.51 \\
(.50)\end{array}$ & $\begin{array}{l}2.55 \\
(.61)\end{array}$ & $\begin{array}{l}2.45 \\
(.54)\end{array}$ & $\begin{array}{l}2.49 \\
(.56)\end{array}$ & $\begin{array}{l}M M>M L \\
I M>M L \\
M H>M L \\
H H>M L \\
+\Delta>-\Delta\end{array}$ \\
\hline $\begin{array}{l}\text { Lack of Worry } \\
F(6,208)=7.48 \\
p<.0000\end{array}$ & $\begin{array}{l}2.79 \\
(.80)\end{array}$ & $\begin{array}{l}3.22 \\
(.65)\end{array}$ & $\begin{array}{l}3.28 \\
(.58)\end{array}$ & $\begin{array}{l}3.39 \\
(.49)\end{array}$ & $\begin{array}{l}3.41 \\
(.49)\end{array}$ & $\begin{array}{l}3.63 \\
(36)\end{array}$ & $\begin{array}{l}3.51 \\
(.38)\end{array}$ & 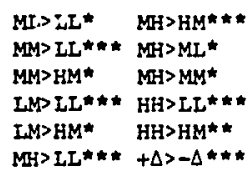 \\
\hline $\begin{array}{l}\text { Housing } \\
F(6,208)=1.68 \\
P<.13\end{array}$ & $\begin{array}{l}3.16 \\
(.65)\end{array}$ & $\begin{array}{l}3.38 \\
(.46)\end{array}$ & $\begin{array}{l}3.25 \\
(.80)\end{array}$ & $\begin{array}{l}3.33 \\
(.66)\end{array}$ & $\begin{array}{l}3.51 \\
(.59)\end{array}$ & $\begin{array}{l}3.44 \\
(.59)\end{array}$ & $\begin{array}{l}3.61 \\
(.34)\end{array}$ & $\begin{array}{l}L M>L L^{*} \\
H H>L L^{*} \\
H H>H M^{*} \\
H H>M M^{*}\end{array}$ \\
\hline $\begin{array}{l}\text { Income } \\
F(6,208)=1.74 \\
p<.11\end{array}$ & $\begin{array}{l}2.71 \\
(.53)\end{array}$ & $\begin{array}{l}2.85 \\
(.48)\end{array}$ & $\begin{array}{l}2.91 \\
(.44)\end{array}$ & $\begin{array}{l}2.94 \\
(.42)\end{array}$ & $\begin{array}{l}2.74 \\
(.49)\end{array}$ & $\begin{array}{l}3.02 \\
(.39)\end{array}$ & $\begin{array}{l}2.87 \\
(.33)\end{array}$ & $\begin{array}{l}M H>L L * \\
M H>L M^{*}\end{array}$ \\
\hline
\end{tabular}

Note. Entries in the above table are means with standard deviations in parentheses.

$+\Delta=$ persons whose ISI scores changed in a positive direction.

$-\Delta=$ persons whose ISI scores changed in a negative direction.

- p<.05

* $P<.01$

$* n<.001$ 
TABLE XXIII

A COMPARISON OF MEANS ON TIME 3 INDICATORS OF WELL-BEING FOR SEVEN LIEE SATISEACTION GROUPS

\begin{tabular}{|c|c|c|c|c|c|c|c|c|}
\hline \multicolumn{9}{|c|}{ IIFE SATISFACTION GROUP } \\
\hline$\underset{\text { WBI }}{\text { Time }} 3$ & $\begin{array}{c}L L \\
(n=30)\end{array}$ & $\underset{(n=44)}{H M}$ & $\underset{(n=23)}{M}$ & $\underset{(n=35)}{M M}$ & $\underset{(n=31)}{L M}$ & $\begin{array}{c}\text { MH } \\
(n=33)\end{array}$ & $\underset{(n=19)}{\mathrm{HH}}$ & $\begin{array}{l}\text { Significant } \\
\text { comparisons }\end{array}$ \\
\hline $\begin{array}{l}\text { Medical } \\
\text { Health } \\
\text { Status } \\
F(6,208)=7.77 \\
P<.0000\end{array}$ & $\begin{array}{l}2.72 \\
(.34)\end{array}$ & $\begin{array}{l}2.60 \\
(.41)\end{array}$ & $\begin{array}{l}2.35 \\
(.56)\end{array}$ & $\begin{array}{l}2.89 \\
(.43)\end{array}$ & $\begin{array}{l}2.90 \\
(.41)\end{array}$ & $\begin{array}{l}2.99 \\
(.39)\end{array}$ & $\begin{array}{l}2.85 \\
(.40)\end{array}$ & 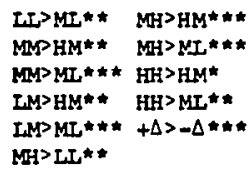 \\
\hline $\begin{array}{l}\text { Lack of } \\
\text { Impa inment } \\
F(6,208)=3.18 \\
p<.005\end{array}$ & $\begin{array}{l}3.29 \\
(.47)\end{array}$ & $\begin{array}{l}3.24 \\
(.57)\end{array}$ & $\begin{array}{l}2.92 \\
1.50)\end{array}$ & $\begin{array}{l}3.45 \\
(.57)\end{array}$ & $\begin{array}{l}3.32 \\
(.62)\end{array}$ & $\begin{array}{l}3.49 \\
(.60)\end{array}$ & $\begin{array}{l}3.43 \\
(.50)\end{array}$ & $\begin{array}{ll}L L>M L \star * & M H>M L * \star * \\
H M>M L * & H H>M L * * \\
M M>M L \star * & +\Delta>-\Delta \star \star \\
L M>M L * & \end{array}$ \\
\hline $\begin{array}{l}\text { Cognitive } \\
\text { Status } \\
F(6,208)=1.81 \\
p<.10\end{array}$ & $\begin{array}{l}2.47 \\
(.82)\end{array}$ & $\begin{array}{l}2.48 \\
(.74)\end{array}$ & $\begin{array}{l}2.43 \\
(.55)\end{array}$ & $\begin{array}{l}2.71 \\
(.77)\end{array}$ & $\begin{array}{l}2.58 \\
(.68)\end{array}$ & $\begin{array}{l}2.76 \\
(.60)\end{array}$ & $\begin{array}{l}2.95 \\
(.66)\end{array}$ & $\begin{array}{l}\mathrm{MH}>\mathrm{ML*} \\
\mathrm{HH}>\mathrm{LL} \\
\mathrm{HH}>\mathrm{HM} \\
\mathrm{HH}>\mathrm{ML}\end{array}$ \\
\hline $\begin{array}{l}\text { Social } \\
\text { Contacts } \\
E(6,208)=3.54 \\
P<.002\end{array}$ & $\begin{array}{l}2.39 \\
(.44)\end{array}$ & $\begin{array}{l}2.56 \\
(.45)\end{array}$ & $\begin{array}{l}2.29 \\
(.49)\end{array}$ & $\begin{array}{l}2.51 \\
(. .45)\end{array}$ & $\begin{array}{l}2.55 \\
(.46)\end{array}$ & $\begin{array}{l}2.64 \\
(.49)\end{array}$ & $\begin{array}{l}2.86 \\
(.43)\end{array}$ & $\begin{array}{ll}H M>M L * & H H>M L * * \\
M H>L L^{*} & H H>M M^{* *} \\
M H>M L * & H H>I M^{*} \\
H H>L L^{*} * & +\Delta>-\Delta * \\
H H>H M^{*} & \end{array}$ \\
\hline $\begin{array}{l}\text { Activities } \\
E(6,208)=3.51 \\
P<.003\end{array}$ & $\begin{array}{l}2.45 \\
(.62)\end{array}$ & $\begin{array}{l}2.43 \\
(.59)\end{array}$ & $\begin{array}{l}2.07 \\
(.70)\end{array}$ & $\begin{array}{l}2.70 \\
(.48)\end{array}$ & $\begin{array}{l}2.62 \\
(.54)\end{array}$ & $\begin{array}{l}2.61 \\
(.58)\end{array}$ & $\begin{array}{l}2.60 \\
(.55)\end{array}$ & 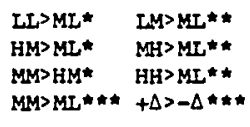 \\
\hline $\begin{array}{l}\text { Lack of Horry } \\
F(6,208)=2.83 \\
p<.01\end{array}$ & $\begin{array}{l}2.63 \\
(.77)\end{array}$ & $\begin{array}{l}2.59 \\
(.58)\end{array}$ & $\begin{array}{l}2.60 \\
(.80)\end{array}$ & $\begin{array}{l}2.83 \\
(.71)\end{array}$ & $\begin{array}{l}2.97 \\
(.65)\end{array}$ & $\begin{array}{l}3.09 \\
(.55)\end{array}$ & $\begin{array}{l}2.81 \\
(.63)\end{array}$ & $\begin{array}{l}M H>L L * \star \\
M H>H M \# * * \\
M H>M L * \\
+\Delta>-\Delta * * *\end{array}$ \\
\hline $\begin{array}{l}\text { Housing } \\
F(6,208)=3.29 \\
p<.004\end{array}$ & $\begin{array}{l}3.41 \\
(.54)\end{array}$ & $\begin{array}{l}3.44 \\
(.54)\end{array}$ & $\begin{array}{l}3.38 \\
(.63)\end{array}$ & $\begin{array}{l}3.37 \\
\{.67\}\end{array}$ & $\begin{array}{l}3.62 \\
(.54)\end{array}$ & $\begin{array}{l}3.77 \\
(.44)\end{array}$ & $\begin{array}{l}3.81 \\
(.30)\end{array}$ & $\begin{array}{ll}M H>L L * * & H H>H M^{* * *} \\
M H>H M * * & H H>M L^{*} \\
M H>M L * & H H>M M^{*} \\
M H>M M * * & +\Delta>-\Delta * * \\
H H>L L * * & \end{array}$ \\
\hline $\begin{array}{l}\text { Income } \\
E(6,208)=1.61 \\
p<.15\end{array}$ & $\begin{array}{l}2.56 \\
(.62)\end{array}$ & $\begin{array}{l}2.73 \\
(.56)\end{array}$ & $\begin{array}{l}2.61 \\
(.65)\end{array}$ & $\begin{array}{l}2.79 \\
(.48)\end{array}$ & $\begin{array}{l}2.69 \\
(.58)\end{array}$ & $\begin{array}{l}2.94 \\
(.47)\end{array}$ & $\begin{array}{l}2.78 \\
(.48)\end{array}$ & $\begin{array}{l}M H>L L * * \\
M H>M L *\end{array}$ \\
\hline
\end{tabular}

Note. Entries in the above table are means with standard deviations in parentheses.

$+\Delta=$ persons whose ISI scores changed in a positive direction.

$-\Delta=$ persons whose ISI scores changed in a negative direction.

$* p<.05$

** $\mathrm{p}<.01$

$\because+\frac{p}{p}<.001$ 
TABLE XXIV

A COMPARISON OF MEANS ON INDICATORS OF WELL-BEING

USING RESIDUALIZED CHANGE SCORES FOR

SEVEN LIFE SATISFACTION GROUPS

\begin{tabular}{|c|c|c|c|c|c|c|c|c|}
\hline \multirow[b]{2}{*}{ WBI $I^{a}$} & \multicolumn{8}{|c|}{ LIFE SATISFACTION GROUP } \\
\hline & $\underset{(n=30)}{L L}$ & $\underset{(n=44)}{\operatorname{HM}}$ & $\underset{(n=23)}{M L}$ & $\underset{(n=35)}{n M M}$ & $\underset{(n=31)}{L M}$ & $\underset{(n=33)}{\mathrm{MH}}$ & $\underset{(n=19)}{\text { нн }}$ & $\begin{array}{l}\text { Significant } \\
\text { Comparisons }\end{array}$ \\
\hline $\begin{array}{l}\text { Medical } \\
\text { Health } \\
\text { Status } \\
F(6,208)=4.657 \\
D<.0002\end{array}$ & $\begin{array}{l}+.120 \\
(.64)\end{array}$ & $\begin{array}{l}-.257 \\
(.76)\end{array}$ & $\begin{array}{l}-.631 \\
(.95)\end{array}$ & $\begin{array}{l}+.160 \\
(.86)\end{array}$ & $\begin{array}{l}+.133 \\
(.72)\end{array}$ & $\begin{array}{l}+.183 \\
(.76)\end{array}$ & $\begin{array}{l}+.341 \\
(.86)\end{array}$ & $\begin{aligned}+\Delta & >-\Delta * k \star \\
\text { stable } & >-\Delta * * *\end{aligned}$ \\
\hline $\begin{array}{l}\text { Lack of } \\
\text { Impairment } \\
F(6,208)=2.22 \\
p<.0424\end{array}$ & $\begin{array}{l}-.033 \\
(.86)\end{array}$ & $\begin{array}{l}-.113 \\
(.91)\end{array}$ & $\begin{array}{l}-.524 \\
(.91)\end{array}$ & $\begin{array}{l}+.197 \\
(.97)\end{array}$ & $\begin{array}{l}-.011 \\
(.91)\end{array}$ & $\begin{array}{l}+.203 \\
(.93)\end{array}$ & $\begin{array}{l}+.250 \\
(.73)\end{array}$ & $\begin{aligned}+\Delta & >-\Delta \star \\
\text { stable } & >-\Delta * *\end{aligned}$ \\
\hline $\begin{array}{l}\text { Cognitive } \\
\text { status } \\
F(6,208)=.901 \\
p<.495\end{array}$ & $\begin{array}{l}-.106 \\
(1.04)\end{array}$ & $\begin{array}{l}-.165 \\
(.95)\end{array}$ & $\begin{array}{r}-.156 \\
(.83)\end{array}$ & $\begin{array}{r}+.101 \\
(.99)\end{array}$ & $\begin{array}{r}+.038 \\
(.99)\end{array}$ & $\begin{array}{r}+.105 \\
(.74)\end{array}$ & $\begin{array}{l}+.306 \\
(.84)\end{array}$ & NDS \\
\hline $\begin{array}{l}\text { Social } \\
\text { Contacts } \\
F(6,208)=1.475 \\
D<.1913\end{array}$ & $\begin{array}{r}-.154 \\
(.75)\end{array}$ & $\begin{array}{r}-.054 \\
(.73)\end{array}$ & $\begin{array}{l}-.236 \\
(.84)\end{array}$ & $\begin{array}{l}+.061 \\
(.74)\end{array}$ & $\begin{array}{l}+.105 \\
(.78)\end{array}$ & $\begin{array}{l}+.009 \\
(.72)\end{array}$ & $\begin{array}{l}+.356 \\
(.75)\end{array}$ & $H H>L L *$ \\
\hline $\begin{array}{l}\text { Activities } \\
F(6,208)=4.128 \\
P<.0006\end{array}$ & $\begin{array}{l}-.099 \\
(.72)\end{array}$ & $\begin{array}{r}-.161 \\
(.71)\end{array}$ & $\begin{array}{l}-.457 \\
(.78)\end{array}$ & $\begin{array}{l}+.312 \\
(.54)\end{array}$ & $\begin{array}{l}+.180 \\
(.57)\end{array}$ & $\begin{array}{l}+.025 \\
(.69)\end{array}$ & $\begin{array}{r}+.169 \\
(.70)\end{array}$ & $\begin{aligned} \text { MM }>L L * \\
+\Delta>-\Delta * * \\
\text { stable }>-\Delta * * *\end{aligned}$ \\
\hline $\begin{array}{l}\text { Lack of Worry } \\
F(6,208)=2.025 \\
P<.0637\end{array}$ & $\begin{array}{l}-.053 \\
(.99)\end{array}$ & $\begin{array}{l}-.255 \\
(.74)\end{array}$ & $\begin{array}{l}-.193 \\
(.97)\end{array}$ & $\begin{array}{l}-.057 \\
(.96)\end{array}$ & $\begin{array}{l}+.244 \\
(.87)\end{array}$ & $\begin{array}{l}+.348 \\
(.88)\end{array}$ & $\begin{array}{l}+.011 \\
(.90)\end{array}$ & $\begin{array}{l}+\Delta>-\Delta * k * \\
+\Delta>\text { stable }\end{array}$ \\
\hline $\begin{array}{l}\text { Housing } \\
F(6,208)=2.257 \\
p<.0393\end{array}$ & $\begin{array}{l}-.227 \\
(.97)\end{array}$ & $\begin{array}{l}-.031 \\
(.83)\end{array}$ & $\begin{array}{l}-.166 \\
(.98)\end{array}$ & $\begin{array}{l}-.256 \\
(1.07)\end{array}$ & $\begin{array}{l}+.131 \\
(.79)\end{array}$ & $\begin{array}{l}+.327 \\
(.80)\end{array}$ & $\begin{array}{l}+.321 \\
(.55)\end{array}$ & $\begin{array}{l}\mathrm{HH}>\mathrm{LL}^{*} \\
\mathrm{HH}>\mathrm{MM}^{*} \\
+\Delta>-\Delta^{*}\end{array}$ \\
\hline $\begin{array}{l}\text { Income } \\
F(6,208)=.379 \\
F<.8916\end{array}$ & $\begin{array}{r}+.022 \\
(.78)\end{array}$ & $\begin{array}{l}-.040 \\
(.76)\end{array}$ & $\begin{array}{l}-.180 \\
(.74)\end{array}$ & $\ddot{(.001)}$ & $\begin{array}{l}+.032 \\
(.64)\end{array}$ & $\begin{array}{l}+.094 \\
(.58)\end{array}$ & $\begin{array}{l}+.063 \\
(1.02)\end{array}$ & NDS \\
\hline
\end{tabular}

Note. Entries in the above table are means with standard deviations in parentheses.

$+\Delta=$ persons whose ISI scores changed in a positive direction.

$-\Delta=$ persons whose ISI scores changed in a negative direction.

stable $x$ persons whose LSI scores remained stable.

a

* $p<.05$

$* p<.01$

$* * * p<.001$ 
APPENDIX C

RELIABILITY, STABILITY, AND VALIDITY OF THE WBIS AT TIMES 1, 2, AND 3 
TABLE XXV

INTERNAL CONSISTENCY RELIABILITY (COEEFICIENT ALPHA) FOR THE EIGHT WBIS

\begin{tabular}{lccc}
\hline \multicolumn{1}{c}{ WBI and LSI } & Time 1 & Time 2 & Time 3 \\
\hline PERSONAL STATUS AREAS: & & .2120 & .4963 \\
\hline Medical Health Status & .4632 & .5383 & .5616 \\
Lack of Impairment & .4397 & .4900 \\
Cognitive Status & .5575 & .7301 \\
SOCIAL STATUS AREAS: & & .5980 & .3844 \\
Social Contacts & .5792 & .6850 & .7932 \\
Activities & .7693 & & .6308 \\
ENVIRONMENTAL RESOURCES AREAS: & & .6836 & .7541 \\
Lack of Worry & .5453 & .8053 & .7336 \\
Housing & .4692 & .4848 & \\
Income & .6999 & & .8451 \\
PSYCHOLOGICAL WELL-BEING: & & & \\
Life Satisfaction Index & .5258 & & \\
\hline
\end{tabular}


TABLE XXVI

STABILITY COEFFICIENTS FOR THE EIGHT WELL-BEING INDICATORS

ACROSS TIME 1, TIME 2, AND TIME 3

Stability Coefficients

\begin{tabular}{lccc}
\hline Well-Being Indicators & Time $1-$ Time 2 & Time $2-$ Time 3 & Time $1-$ Time 3 \\
\hline Medical Health Status & .438 & .538 \\
Lack of Impairment & .468 & .454 & .565 \\
Cognitive Status & .279 & .395 & .402 \\
Social Contacts & .421 & .401 & $.319^{\mathrm{a}}$ \\
Activities & $.662^{\mathrm{a}}$ & .383 \\
Lack of Worry & .465 & .493 \\
Housing & .489 & .601 \\
Income & $.679^{\mathrm{b}}$ & $.745^{\mathrm{b}}$ \\
\hline
\end{tabular}

Note. All of the above Pearson correlations were computed for $\mathrm{N}=215$ with the exception of those designated "a" and " $\mathrm{b}$ ". All of the above correlations are significant at $p<.001$.

a Correlations based on $\mathrm{N}=214$

borrelations based on $\mathrm{N}=213$ 
TABLE XXVII

INTERCORRELATION MATRIX FOR EIGHT WELL-BEING INDICATORS

FOR TIME 1, TIME 2, AND TIME 3

\begin{tabular}{|c|c|c|c|c|c|c|c|c|}
\hline & & & & Well-Being & icators & & & \\
\hline & $\begin{array}{c}\text { Medical } \\
\text { Health Status }\end{array}$ & $\begin{array}{c}\text { Lack of } \\
\text { Impairment }\end{array}$ & $\begin{array}{l}\text { Cognitive } \\
\text { status }\end{array}$ & $\begin{array}{c}\text { Social } \\
\text { Contacts }\end{array}$ & Activities & $\begin{array}{l}\text { Lack of } \\
\text { Worry }\end{array}$ & Housing & Income \\
\hline $\begin{array}{c}\text { Medical } \\
\text { Health Status }\end{array}$ & $\begin{array}{ll}\text { T1 } & 1.00 \\
\text { T2 } & 1.00 \\
\text { T3 } & 1.00\end{array}$ & $\begin{array}{l}.466^{* * *} \\
.275^{* * *} \\
.371^{* * *}\end{array}$ & $\begin{array}{l}.140^{\star} \\
.150^{\star} \\
.145^{\star}\end{array}$ & $\begin{array}{l}.180 * * \\
.277 * * * \\
.132 *\end{array}$ & $\begin{array}{l}.337 * * * \\
.282 * * * \\
.420 * * *\end{array}$ & $\begin{array}{l}.217 * k \star k \\
.127 * \\
.168 * *\end{array}$ & $\begin{array}{l}.105 \\
.114 * \\
.042\end{array}$ & $\begin{array}{l}.233^{* * * *} \\
.211 * * * \\
.171 * *\end{array}$ \\
\hline $\begin{array}{c}\text { Lack of } \\
\text { Impairment }\end{array}$ & & $\begin{array}{ll}\text { T1 } & 1.00 \\
\text { T2 } & 1.00 \\
\text { T3 } & 1.00\end{array}$ & $\begin{array}{l}.092 \\
.174^{\star \star} \\
.039\end{array}$ & $\begin{array}{l}.103 \\
.365 * \star \star \\
.018\end{array}$ & $\begin{array}{l}.392 * \star \star \\
.367^{\star \star \star} \\
.164 * \star\end{array}$ & $\begin{array}{l}.152 \star \\
.050 \\
.152 \star\end{array}$ & $\begin{array}{l}.038 \\
.091 \\
.087\end{array}$ & $\begin{array}{l}.096 \\
.011 \\
.165 \text { \#k }\end{array}$ \\
\hline $\begin{array}{l}\text { Cognitive } \\
\text { Status }\end{array}$ & & & $\begin{array}{ll}\text { T1 } & 1.00 \\
\text { T2 } & 1.00 \\
\text { T3 } & 1.00\end{array}$ & $\begin{array}{l}.144^{\star} \\
.206^{\star * *} \\
.203^{* * *}\end{array}$ & $\begin{array}{l}.108 \\
.172^{\star \star} \\
.320^{* \star *}\end{array}$ & $\begin{array}{l}.009 \\
-.109 \\
-.158 * \star\end{array}$ & $\begin{array}{l}.236 * \star * \\
.158 * \star \\
.184 * \star\end{array}$ & $\begin{array}{l}.067 \\
.012 \\
.110\end{array}$ \\
\hline $\begin{array}{l}\text { Social } \\
\text { Contacts }\end{array}$ & & & & $\begin{array}{ll}\text { T1 } & 1.00 \\
\text { T2 } & 1.00 \\
\text { T3 } & 1.00\end{array}$ & $\begin{array}{l}.301 * * * \\
.325 * * * \\
.255 * \# *\end{array}$ & $\begin{array}{l}-.043 \\
.262 \text { \#* } \\
.005\end{array}$ & $\begin{array}{l}.247 * \cdots * \\
.321 * \ldots * \\
.276^{* * *}\end{array}$ & $\begin{array}{l}.126 * \\
.185 * \star \\
.178^{* *}\end{array}$ \\
\hline Activities & & & & & $\begin{array}{ll}\text { T1 } & 1.00 \\
\text { T2 } & 1.00 \\
\text { T3 } & 1.00\end{array}$ & $\begin{array}{r}.023 \\
-.003 \\
-.111\end{array}$ & $\begin{array}{l}.127 \star \\
.006 \\
.001\end{array}$ & $\begin{array}{r}.077 \\
-.028 \\
-.043\end{array}$ \\
\hline $\begin{array}{l}\text { Lack of } \\
\text { Horry }\end{array}$ & & & & & & $\begin{array}{ll}\text { T1 } & 1.00 \\
\text { T2 } & 1.00 \\
\text { T3 } & 1.00\end{array}$ & $\begin{array}{l}-.100 \\
.120^{\star} \\
.113^{\star}\end{array}$ & $\begin{array}{l}.277 * * * \\
.266 * * * \\
.264^{* *}\end{array}$ \\
\hline Housing & & & & & & & $\begin{array}{ll}\text { T1 } & 1.00 \\
\text { T2 } & 1.00 \\
\text { T3 } & 1.00\end{array}$ & $\begin{array}{l}.283 * \star * \\
.214 * \hbar * \\
.419 * * *\end{array}$ \\
\hline Income & & & & & & & & $\begin{array}{ll}\text { T1 } & 1.00 \\
\text { T2 } & 1.00 \\
\text { T3 } & 1.00\end{array}$ \\
\hline
\end{tabular}
Note. Each set of three correlations gives the Time 1 (T1), Time 2 (T2), and Time 3 (T3) correlations for the specified
-being indicators. All correlations were computed using $N=215$ with the exception of those involving the following WBIs: Activities at Time2 $(N=214)$ and Income at Time $2(N=213)$.

$\star p<.05$

$* *: p<.001$ 
APPENDIX D

CASE STUDIES 
TABLE OF CONTENTS

Page

I. Stable Life Satisfaction Groups. - . . . . . 157

Stable-High LS Group - Case No. 1 . . . . . 157

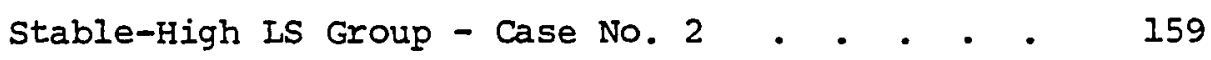

Stable-Middle LS Group - Case No. 3. . . . . 161

Stable-Middle LS Group - Case No. 4 . . . . 163

Stable-Low LS Group - Case No. 5 . . . . . 166

Stable-Low LS Group - Case No. 6. . . . . . 168

II. Positive Change Iife Satisfaction Groups . . . . 170

Low-Middle LS Group - Case No. 7 . . . . . . 170

Low-Middle LS Group - Case No. 8 . . . . . 172

Middle-High LS Group - Case No. 9 • • • • . 174

Middle-High LS Group - Case No. 10 . . . . . 177

III. Negative Change Life Satisfaction Groups . . . . 179

High-Middle LS Group - Case No. 11 . . . • . 179

High-Middle LS Group - Case No 12 . . . . . 181

Midale-Low LS Group - Case No. 13. . . . . . 183

Middle-Low LS Group - Case No. 14. . . . . . 185 


\section{STABLE IIFE SATISFACTION GROUPS}

STABLE-HIGH LS GROUP - CASE NO. 1

Mrs. Evans was 80 years old at the time of the first interview. She was raised by both parents on a large farm in Kansas. She had seven siblings, five of whom are still living. She completed one year of high school. Mrs. Evans was married for forty-one years however she had been widowed for the past thirteen years. She has two children and five grandchildren. She worked as a packer in a large hardware store and was a union member. She has lived in her present four room home which she owns free and clear, for the past forty-six years.

Interviewer Comments. Mrs. Evans' attitude is positive and cheerful. She seems very interested in things around her. She drives daily to a Senior Citizen's Center where she makes quilts and does other volunteer work. On Saturday she does the laundry for a number of older persons who are shut in. Her hobbies are numerous in addition to her volunteer work. She reads, sews and watches television when she is not working in her vegetable garden. She preserves much of the food from her garden.

RESPONSES AT TIME 1

\section{Personal Status Areas}

Medical Health Status. Mrs. Evans feels that her health is good for her age. During the past year she has not been hospitalized nor has she spent any days in bed at home due to illness during the past year. She has not had a visiting nurse. She has no illnesses or disabilities.

Lack of Impairment. She is able to get out alone and has no trouble crossing the streets with the traffic lights. She does not use a prosthesis nor does she have housework help, meals programs or physical therapy.

Cognitive Status. The interviewer reports that Mrs. Evans is very alert and cooperative and she shows no signs of confusion.

\section{Social Status Areas}

Social contacts. She has two children and five grandchilären whoin 
she sees at least monthly. She sees friends, neighbors and business people at least weekly and talks on the phone at least weekly. She has two confidants.

Activities. Mrs, Evans drives her own car and goes weekly to the grocery store and to the bank. She goes at least monthly to the post office and drug store and to a restaurant about every six months. She has not been to church for over one year.

Environmental Status Areas

Lack of Worry. Mrs. Evans reports being concerned about having enough money, about walking alone in her neighborhood and about the well-being of her friends and neighbors. She is not concerned about her health, the security of her home, the kind of people living in her neighborhood and the amount of traffic in the street.

Housing. Mrs. Evans lives in her own four room home which has a kitchen. She owns her home outright. The interviewer rates her home interior as excellent and the furnishings as good.

Income. Mrs. Evans' income is from four sources, social security benefits, a union pension, interest from a savings account and a yearly property tax refund. She does not receive SSI, welfare or food stamps. She reports always having some money left over each month and is able to add to her savings. She does not have to use her savings. She feels that her level of living is better than most people her age that she knows and that her level of living is about the same at it was ten years and one year ago.

RESPONSES AT TIME 2

All WBIs are the same except

Cognitive status. The interviewer reports that Mrs. Evans is very alert but not at all interested in the interview.

RESPONSES AT TIME 3 to the data.

All WBIs are the same as at time one. There are two alterations

Social Contacts. Mrs. Evans is a member of a Senior Citizen's Center and ts very satisfled with her social contacts.

Housing. Mrs. Evans is very satisfled with her housing. 
SUMMARY

Mrs. Evans experienced no change in indicators of well-being during the two and a half year data collection period. She has experienced a high level of well-being on all indicators. She is in good physical health, she has no physical impairments, she is alert with no signs of confusion. She is extremely active and in addition to caring for herself. she is involved in a number of activities involving assistance to others. She has a number of social supports including children, family and friends and she does not appear to be overly concerned with matters of health, money etc. Her home is in good condition. Her income is from several sources and she has adequate income with savings to use in case of emergency.

STABLE HIGH LS GROUP - CASE NO. 2

Mrs. Fisher was 73 years old at the time of the first interview. She was raised by both parents in a small town in North Dakota. Her father had a large wheat farm which he ran with the help of his twelve children, six of whom are still living. Mrs. Fisher completed the eighth grade. She worked as a nurse's aide. She was married for forty years and has been widowed for the past eleven years. She has five children and ten grandchildren. She has lived in Oregon in her present four room home for the past four years.

Interviewer Comments. Mrs. Fisher is a delightful person. She has a number of hobbies including song writing and ceramics. She is writing the genealogy of her family and has published a song for senior citizens. Her daughter provides a great deal of support and assistance to her. Mrs. Fisher takes in ironing and preserves much of her own food to help meet expenses.

RESPONSES AT TIME 1

Personal Status Areas

Medical Health Status. Mrs. Fisher feels that her health is good for her age. She has not been hospitalized during the past year but she did spend about two months in bed at home because of illness. She has not had a visiting nurse. The interviewer reports that she has bursitis and a chronic uterine inflammation.

Lack of Impairment. She is able to get out alone and has no difficulty crossing streets. She does not have a prosthesis nor has she had physical therapy. She does not use housework help or meals programs. 
Cognitive status. The interviewer reports that she is very alert and interested in the interview and shows no sign of confusion.

\section{Social Status Areas}

Social Contacts. Mrs. Fisher has five children and ten grandchildren. She reports seeing children, grandchildren, neighbors, friends and business persons at least weekly. She uses her phone at least weekly and reports having one confldant.

Activities. Mrs. Fisher usually relies on the bus for transportation. She is not confined to her home and goes to the grocery, bus stop and church at least weekly. She goes to the bank at least monthly and to a drugstore, post office and restaurant at least every six months.

Environmental Status Areas

Lack of Worry. Mrs. Fisher is concerned about having enough money, the well-being of neighbors and friends and about street traffic. She is not concerned about her health, security of her home or neighborhood or walking alone in her neighbornood.

Housing. Mrs. Fisher lives in a four room home which she rents. There is an adequate kitchen. The interviewer rates her home interior and furnishings as excellent.

Income. Mrs. Fisher has income from four sources, social security benefits, a small monthly income from taking in ironing, interest from a savings certificate, and a yearly renter tax rebate. She does not receive SSI, welfare or food stamps. She just manages to get by on her present income and is not able to save. She does not, however, have to use her savings. She thinks that her level of living is about the same as other people her age that she knows and she believes that she is better off now than she was ten years ago but about the same as one year ago.

RESPONSES AT TIME 2

\section{AIl WBIs were the same except}

Medical Health Status. Mrs. Fisher feels that her health is good for her age. During the past year she spent eight days in the hospital and fourteen days at home in bed because of illness. 
RESPONSES AT TIME 3

All WBIs were the same except

Medical Health Status. Mrs. Fisher was not hospitalized during the past year however she spent nine days in bed at home due to iliness.

Social Contacts. She reports seeing children, friends and nelghbors daily and other relatives monthly. She participates in senior center activities and is very satisfied with her social contacts.

Housing. Mrs. Fisher is very well satisfied with her home.

SUMMARY

Mrs. Fisher has fairly high levels of well-being on all

indicators. She has a chronic health problem however it does not confine her to her home nor does it limit her activities. She experiences fairly good health. She is alert with no signs of confusion. She is very active, carrying on her own hobbies and self maintenance. She has strong social supports and frequent contact with a number of people including children, friends and neighbors. She is not bothered by a number of concerns. Her housing is excellent and she is satisfied with it. Her income is adequate and she has a savings account to use in case of energency.

$$
\text { STABLE-MIDDLE LS GROUP - CASE NO. } 3
$$

Mrs. Close was 79 years old at the time of the first interview. She was raised by her mother in a small town in Texas where her mother was a seamstress for a local hospital. She has two siblings whom she lost track of twenty-five years ago. Mrs. Close completed two years of high school. She reports being divorced. She has one child and three grandchildren living in the Portland area. During her working years she did light housework and childcare. Mrs. Close has lived in her present one room apartment for the past eight years.

Interviewer Comments. Mrs. Close is jolly and laughs a lot. Mrs. Close reports having no friends or social contacts and likes it that way. She has no hobbies or activities except walking, reading and watching television. She says she pays no attention to her surroundings and that her only concern is that "things are all right. You don't need to be happy.". 
RESPONSES AT TIME 1

\section{Personal status Areas}

Medical Health Status. Mrs. Close feels that her health is good for her age. She has spent no days in bed sick at home nor has she been hospitalized during the past year. She does not use a visiting nurse and she has no physical disabilities.

Lack of Impairment. She is able to get out and has no problem crossing the street. She does not have a prosthesis nor does she receive physical therapy. She does not use meals programs or have housework help.

Cognitive status. The interviewer reports that Mrs. Close is very alert and cooperative and shows no signs of confusion.

\section{Social Status Areas}

Social Contacts. Mrs. Close has one child and three grandchildren whom she sees weekly. She sees friends, neighbors and business persons weekly. She has no confidants and it has been over a year since she has talked to someone on the telephone.

Activities. Mrs. Close is not confined to home and she usually walks to her destination. She goes at least weekly to the grocery store but has not been to a drugstore, post office, bank, restaurant or church in over a year.

\section{Environmental Status Areas}

Lack of Worry. Mrs. Close reports that she is concerned about street traffic, security of her home, walking alone in her neighborhood and having enough money. She is not concerned about her health, the kind of people living in her building and neighborhood or her friends and neighbors.

Housing. Mrs. Close lives in a one room apartment with kitchen appliances. The interviewer reports that the interior of the apartment and its furnishings are in fair condition but that there are holes and cracks in the walls and ceilings.

Income. Mrs. Close receives social security benefits, SSI, welfare, food stamps, and a yearly renter's tax rebate. She always has money left at the end of each month however she does not save it, nor does she have a savings account. She feels that her level of living is about the same as other old persons she knows and that she is about the same now as she was ten years ago however she is better off than she was one year ago. 
RESPONSES AT TIME 2

All WBIs are the same except

Lack of Worry. Mrs. Close reports that she does not worry about any of the items listed.

RESPONSES AT TIME 3

All responses were the same except

Lack of Impairment. Mrs. Close has used meals service three times a week for the past nine months.

SUMMARY

Mrs. Close's WBIs remained stable during the two and one half years of data collection. She is in good physical health, with no disabilities or health problems. She is alert with no signs of confusion. She is not confined to her home although her activities consist only of going to the grocery store. Her social contacts appear to be limited by her own choice and even though she sees children, friends and neighbors at least weekly, she does not like social contact and she has no confidants. She does not worry. Her housing is only fair but she is satisfied with her one room apartment. Mrs. Close's income is largely from a combination of government aid and she has no savings although she does have money left each month.

\section{STABLE-MIDDLE LS GROUP - CASE NO. 4}

Mr. Davis was 65 years old at the time of the first interview. He was one of the younger members of the sample studied. Mr. Davis lived with both parents in and around the Portland, Oregon area where his father was employed as a maintenance man. He has two siblings, both still living. Mr. Davis completed the eighth grade. He worked as a partner in a wholesale mean business and belonged to a union for only a short time. He was married for about thirty years and has been divorced for four years. He has two children and three grandchildren. Mr. Davis lived in a two-room apartment and later moved to another two-room apartment.

Interviewer Comments. Mr. Davis was angry and antagonistic at the first interview, refusing to answer many questions. He threatened to stop the interview several times during questions regarding his income. He is extremely dissatisfied with his living arrangements 
and wants to move to Eastern oregon. He is not happy with his activities which are limited to observing passersby and would like very much to work.

RESPONSES AT TIME 1

\section{Personal Status Areas}

Medical Health Status. Mr. Davis feels that his health is good for his age. He has a lame leg and is just recovering from a broken neck which kept him hospitalized for forty-two days during the past year. He has spent no time in bed at home due to illness during the past year and he does not have a visiting nurse.

Iack of Impairment. Mr. Davis gets out regularly and has no trouble crossing streets. He uses a neck brace but does not have physical therapy. His sister provides housework help for him.

Cognitive status. Mr. Davis is very alert and shows no signs of confusion. He is very antagonistic.

\section{Social Status Areas}

Social Contacts. He has two children, one living close to him. He talks to them at least monthly. He sees neighbors, friends and business people at least once a month and sees relatives at least once every 'six months. He reports having no confidants.

Activities. He is not confined to his home and his means of transportation are walking, taking a bus or driving his truck. He goes to the grocery, drugstore and bus stop at least once a week and to the bank and post office at least once a month. He has never been to church.

\section{Environmental Status Areas}

Lack of Worry. He reports being concerned about having enough money and his health. He is not concerned about security of his home, walking alone in his neighborhood, about the well-being of friends and neighbors, or about the kind of people in his neighborhood nor is he concerned about street traffic.

Housing. The interviewer reports that the interior and furnishings of this two-room apartment are good. It is not known how long Mr. Davis has been living there.

Income. The only income Mr. Davis reported is social security benefits and food stamps. He did not respond to any items about savings. He states that he just manages to get by each month. He feels 
that his level of living is about the same as other older people he knows. He feels that he is worse off now than he was ten years ago and about the same as one year ago.

\section{RESPONSES AT TIME 2}

\section{All indicators were the same except}

Medical Health Status. Mr. Davis had a health problem which caused him to be confined to a nursing home for seventy-four days during the past year.

Housing. He has recently moved to a new apartment which has two rooms. The interviewer rates the condition inside and out as good with an adequate kitchen.

\section{RESPONSES AT TIME 3}

\section{All inaicators are the same except}

Medical Health Status. Mr. Davis has had no days in the hospital or at home where he has been ill during the past year.

Cognitive Status. Interviewer rates Mr. Davis as being lethargic and not interested in the interview.

Social Contacts. Mr. Davis speaks to neighbors daily and sees his children less than once a year. He sees relatives about every six months and business persons weekly. He does not call people on the telephone and he does not have a confidant. He is not satisfied with his social relationships. He has gone to a senior Center but does not do so now.

\section{SUMMARY}

The WBIs for Mr. Davis have experienced some changes. His medical health status, although he perceives his health to be good, has fluctuated. During the first two years of the study he was recovering from a broken neck which necessitated hospitalization and he was later confined to a nursing home for about two months. At the last interview he had not experienced any new health problems. He had some impairment which included a lame leg however he was not confined to his home. His activities were limited to self maintenance and his involvements with those around him were minimal. His social contacts were limited and he expressed dissatisfaction with them. He reports being concerned only with his money and his health. He was dissatisfled with his 
housing and moved during the study to new housing. Both arrangements were described as good by interviewers. Mr. Davis' income was barely adequate, coming from social security and welfare. He was not happy with his income and wanted to work.

$$
\text { STABLE-IOW IS GROUP - CASE NO. } 5
$$

Mrs. Andrews was 74 years old at the time of the first interview. She was raised by both parents in a small town in Minnesota where her father operated a farm. She had seven siblings and only two are still. living. She was married for thlrty-nine years and has been widowed for the past four years. She worked as a waitress and was never a union member. She has had no children. Mrs. Andrews completed the sixth grade. She has lived in her two-room apartment for the past two years and has resided in oregon for fifty-six years.

Interviewer Comments. Mrs. Andrews talks frequently about not having much time to live left. She seems fairly isolated. During the interview at time 3 , she seemed hardly interested in responding and answered many questions with do not know.

RESPONSES AT TIME 1

Personal status Areas

Medical Health Status. Mrs. Andrews feels that her health is poor for her age. She was hospitalized for fifteen days during the past year however she has spent no days in bed at home due to illness. She has very poor vision and arthritis. She uses a visiting nurse regularly.

Iack of Impairment. Mrs. Andrews is confined to her home and must use a walker. She has physical therapy and uses housework help. She does not use meals programs.

Cognitive status. The interviewer reports that she is of average alertness however she is bored by the interview and shows some confusion when answering questions.

\section{Social Status Areas}

Social Contacts. Mrs. Andrews has no children. She has no confidants. She sees friends during the week and neighbors and relatives talk with her about once a month on the telephone. She uses her phone during the week.

Activities. She is confined to her home, going out only in a taxi or social service car. She has not been to a grocery store, 
drugstore for a month and it has been over a year since she has been to the post office, bank, restaurant or church.

Environmental Status Areas

Iack of Worry. Mrs. Andrews reports that she does not worry about anything.

Housing. Mrs. Andrews lives in a two-room apartment with a kitchenette as part of the living room. The apartment interior and furnishings are rated excellent by the interviewer.

Income. Mrs. Andrews receives income from social security and food stamps. She reports that she barely manages to get by and cannot save at the end of each month. She does not use money from her small savings account. She feels that her level of living is about the same as most older people she knows. She feels that she is worse off now than she was ten years ago but better off than one year ago.

RESPONSES AT TIME 2

All indicators the same except

Medical Health Status. Mrs. Andrews did not spend any time in the hospital during the past year.

Social Contacts. Mrs. Andrews reports having two confidants.

Activities. Mrs. Andrews has not been out of her house for over a year.

RESPONSES AT TIME 3

All indicators were the same. There were a large number of "do not know" responses.

SUMMARY

Mrs. Andrews has poor health and is almost completely confined to her home. She is moderately alert but shows some confusion and is not interested in the interview. Her social supports are minimal and she relles on social services and a few neighbors to assist her with her needs. Her housing is excellent. Her income is quite low allowing her to barely get by. She uses several service programs to assist with her daily maintenance. 
STABLE-IOW LS GROUP - CASE NO. 6

Mr. Black, aged 74 at the first interview, was raised by both parents in a small town in Idaho where his father operated a small farm. He was one of flve children, two of whom are deceased. Mr. Black attended two years of business college and did office work during his working years. He was never a union member. He was married twice. His second wife of thirty years died one year ago after a lengthy and expensive illness which took most of his savings. Mr. Black has lived in Oregon for fifty-four years. He moved into his three-room apartment one year ago.

Interviewer Comments. The interviewer reports that $\mathrm{Mr}$. Black was "grumpy" and very hard to get along with. He enjoys volunteer church work and spends as much time as his health permits, doing this. His other activities are reading and watching television.

\section{RESPONSES AT TIME 1}

\section{Personal Status Areas}

Medical Health Status. Mr. Black feels that his health is good for his age. He spent five days in the hospital during the past year recovering from eye surgery. He has not spent any days in bed at home due to illness, during the past year. He does not have a visiting nurse. He has very poor eyesight and a great deal of trouble walking.

Iack of Impairment. Mr. Black is able to get out alone but has trouble crossing the street. He does not have a prosthesis nor does he receive physical therapy. He does have housework help but does not use any meals programs.

Cognitive status. The interviewer reports that he is very alert and shows no signs of confusion. He is antagonistic about the interview.

\section{Social Status Areas}

Social Contacts. Mr. Black has no children. He reports having five confidants. He sees neighbors, fxiends, relatives and business persons at least weekly. He talks frequently on the telephone.

Activities. Mr. Black is not confined to his home and elther walks or uses the bus when he goes out. He goes at least weekly to the grocery store, drugstore, restaurant and church. He goes at least monthly to the bank and post office. 
Environmental Status Areas

Lack of Worry. Mr. Black reports being concerned about the security of his apartment and the people living in the bullding. He worries about having enough money and about the well-being of his neighbors and friends. He is not concerned about his health, traffic in the streets or the kinds of people living in his neighborhood or walking alone in his neighborhood.

Housing. The interviewer reports that $\mathrm{Mr}$. Black three-room apartment has an adequate kitchen and that the interior and furnishings of his home are excellent.

Income. Mr. Black receives social security benefits and has a small income saved from the past year. He does not receive SSI, welfare or food stamps. He just manages to get by and often has to use his savings. He feels that his level of living is about the same as other older persons he knows. He feels that he is better off now than he was ten years ago but he is worse off than one year ago.

RESPONSES AT TIME 2

\section{All indicators the same except}

Medical Health status. Mr. Black feels that his health is fair for his age. He had a health problem during the past year which caused him to be confined to a nursing home for two months. He has spent no time sick in bed at home during the past year. He now has a broken hip and shoulder which are mending.

Lack of Impairment. He can only get out of his house with help. He has a housekeeper and meals delivered daily.

Activities. Mr. Black's source of transportation is being driven by a friend or a social service agency. He gets out about once a month.

Income. Mr. Black has a hospital bill which he cannot pay.

RESPONSES AT TIME 3

All indicators are the same as at time 1 except

Medical Health Status. Ir. Black has not been hospitalized during the past year.

Iack of Impairment. Mr. Black is now able to get out alone however he still uses meals programs and a senior meal site. 
Social Contacts. He is visited daily by neighbors and sees friends weekly. He talks with relatives about every six months. He is somewhat satisfied with his social contacts.

Income. He is somewhat dissatisfied with his income.

Housing. He is very well satisfied with his home.

SUMMARY

At the initial interview $\mathrm{Mr}$. Black had experlenced several traumatic events, the death of his wife, depletion of savings, moving to a new residence, and eye surgery. He was confined to a convalescent home for two months after breaking $a$ hip and shoulder and finally at interview three, his health had stabilized. During the second year of the study, he was unable to get out of his home without assistance but at time 3 was once again able to get out alone, and to carry out his own activities without assistance. Mr. Black's social contacts are largely from friends and his church. His housing is rated excellent. His income is not supplemented by any federal aid and comes from social security benefits ans savings which he has to use regularly.

POSITIVE CHANGE LIFE SATISFACTION GROUPS

LOW-MIDDLE IS GROUP - CASE NO. 7

Mrs. Newgate was 78 years old at the first interview. She was raised on a farm in oregon by a male head of household other than her father. She has six siblings, three of whom are still living. She completed one year of college and worked as an accountant. She was married twice, to her second husband for sixteen years. She is newly widowed. She has no children. She has lived in her present four-room home for the past sixteen years and has resided in oregon for seventyfive years.

Interviewer Comments. Mrs. Newgate has just been very recently widowed and becomes very upset when answering questions about her husband.

RESPONSES AT TIME 1

Personal Status Areas

Medical Health Status. She feels that her health is good for her age. She has spent no time hospitalized or sick at home for the past 
year. She has not had a visiting nurse. She is presently unable to raise her left arm above her shoulder and she has a bad back which makes walking very difficult for her.

Lack of Impairment. Mrs. Newgate is able to get out alone and has no problem with crossing the streets. She does not have a prosthesis. She has physical therapy monthly. She does not have housework help or meals programs.

Cognitive status. The interviewer reports that Mrs. Newgate was alert and showed no signs of confusion however she was easily upset by the interview.

\section{Social Status Areas}

Social Contacts. Mrs. Newgate has no children. She sees neighbors, friends, relatives and others at least weekly. She reports having no confidants. She uses her phone regularly.

Activities. She is not confined to her home. Her main transportation is in a taxi or car driven by a friend. She sometimes walks. She goes at least weekly to the grocery store, church and restaurant and to the bank about every six months and drugstore about once a year.

\section{Environmental Status Areas}

Lack of Worry. Mrs. Newgate reports being concerned about her health, the welfare of friends and neighbors, about security of her home and walking alone in her neighborhood. She is not concerned about money, traffic or the kind of people living in her neighborhood.

Housing. Mrs. Newgate's four-room home is owned by her outright. There is an adequate kitchen. The interviewer rates the house and furnishings as good.

Income. Mrs. Newgate's income is from social security benefits, company pension, stocks and property tax rebate. She is able to save each month and does not take from her savings. She feels that her level of living is about the same as other older persons she knows. She reports that she is worse off now than she was ten years ago but about the same as one year ago.

RESPONSES AT TIME 2

\section{All indicators are the same except}

Medical Health Status. She spent two months in a convalescent home with a broken ankle during the past year. 
Cognitive status. The interviewer reports that she is not at all interested in the interview.

Income. She reports that she is just barely able to get by and is not able to save. She feels that she is worse off than she was one year ago.

RESPONSES AT TIME 3

All indicators the same except

Medical Health Status. She has spent no time in the hospital during the past year.

Soclal Contacts. Mrs. Newgate reports seeing friends and neighbors daily. She is active in a senior Citizens center. She is satisfied with her social contacts.

Income. She is very dissatisfied with her level of living and finds that her money situation is very uncomfortable.

Housing. The interviewer rated her housing, interior and exterior as excellent.

SUMMARY

Mrs. Newgate is in good physical health although she does have a bad back. During the study she broke her ankle which caused her to be hospitalized however at the third interview she was once again, doing well. She is alert and active. She has a number of social supports and she is able to carry on her own maintenance activities. She was newly widowed at the first interview but seemed to have adjusted well at the third interview. She became active in a senior Center during the study. Her income, at time one, was very adequate however by time three, she was very dissatisfied with her income. Her home is in good condition and she is satisfied with it.

LOW-MIDDLE LS GROUP - CASE NO. 8

Mrs. Monroe was 75 years old at the first interview. She has Ilved most of her life in Oregon. She was raised by her parents in a small town where her father was a railroad mechanic. She was one of ten chlldren, seven of whom are still living. Mrs. Monroe completed four years of high school after which she did clerical work for the railroad. She was twice married, to her last husband for four years. She is now widowed. She has two children and three grandchildren. Mrs. Monroe lives in a one-room apartment with a small alcove that 
serves as a kitchen. She has lived in this public housing unit for four years.

Interviewer Comments. Mrs. Monroe seems quite frail and is completely confined to a wheelchair.

RESPONSES AT TIME 1

Personal Status Areas

Medical Health Status. Mrs. Monroe feels that her health is good for her age. She has not been hospitalized or sick in bed at home during the past year. She does not have a visiting nurse. She is confined to a wheelchair.

Iack of Impairment. Mrs. Monroe is confined to her wheelchair and only gets out of her home with assistance. She does not have physical therapy. She uses meals programs and has housework help.

Cognitive status. The interviewer rates her as average alertness but showing no signs of confusion. She is bored with the interview.

\section{Social Status Areas}

Social Contacts. Mrs. Monroe has two children, one living close to her. She has seven confidants. She sees her child and neighbors at least weekly and friends about once a year. She sees relatives at least monthly. She uses her phone at least weekly.

Activities. She can only leave home with help. She travels in someone else's car or by taxi. She has not been to the grocery store, drugstore, post office, bank, restaurant or church in over a year.

\section{Environmental Status Areas}

her health.

Lack of Worry. Mrs. Monroe reports being concerned only about

Housing. Mrs. Monroe lives in a one-room apartment with kitchen appliances. The interviewer rates the interior and furnishings as excellent.

Income. Mrs. Monroe receives benefits from Social security, SSI, food stamps and a yearly renter's tax rebate. She manages to save money each month and never used her savings. She feels that her level of living is about the same as other people she knows. She feels that she 1s worse off now than she was ten years ago but about the same as she was one year ago. 
RESPONSES AT TIME 2

All indicators are the same.

RESPONSES AT TIME 3

All indicators are the same except

Social Contacts. She is very satisfled with her social contacts.

Activities. Mrs. Monroe is completely confined to her home.

Income. Mrs. Monroe's son has taken charge of Mrs. Monroe's money.

Housing. Mrs. Monroe is very satisfied with hei housing.

SUMMARY

Mrs. Monroe is confined to a wheelchair and during the study experienced increased confinement to her home and greater dependency upon neighbors and her son for her maintenance. At time 3, her son had taken charge of her finances. Her social supports are strong. She is maintained completely by her neighbor and son. She lives in public housing which is rated as excellent. She is very well satisfied with her living arrangements. She uses a number of services to assist her in her daily maintenance. Her income is adequate for her needs.

MIDDIE-HIGH IS GROUP - CASE NO. 9

iris. Kemp was 80 years old at the time of the fixst interview. She was raised on a farm in Oregon where she lived with her mother and four siblings, one of whom is still living. Mrs. Kemp completed one year of high school. She worked in an upholstery company and belonged to a union. She was married to her husband for fifty-three years and has been widowed for seven years. She has three children. Mrs. Kemp has lived in her present five-room home which she owns outright, for thirty-nine years.

Interviewer Comments. Mrs. Kemp is a very active lady who does volunteer work for her church, working with other older persons who need help in meal preparation and housework. She reads, watches television, sews, cleans, cooks and likes very much to go to movies and visit relatives. Her son provides her with a great deal of assistance. 
RESPONSES AT TIME 1

\section{Personal Status Areas}

Medical Health Status. Mrs. Kemp feels that her health is good for her age. She has not been hospitalized during the past year nor has she spent any sick days in bed at home. She does not have a visiting nurse. She has a "lame" shoulder, however this does not hinder her in any noticeable way.

Lack of Impairment. She gets out by herself and has no problems with traffic. She does not have a prosthesis nor does she receive physical therapy. She does not use meals programs or have housework help.

Cognitive status. The interviewer reports that she is very alert, not confused and very interested in the interview.

\section{Social Status Areas}

Social Contacts. Mrs. Kemp has two children living in the Portland area and one in another state. She has eight grandchildren and reports having three confidants. She sees children, neighbors, friends and others at least weekly and other relatives during the past six months. She uses her telephone frequently.

Activities. Mrs. Kemp gets out frequently, sometimes driving her own car however frequently she is driven in someone else's car or takes the bus. She goes at least weekly to the grocery store, church and bank. She goes to a drugstore and post office at least at least every six months and has not been to a restaurant for over a year.

\section{Environmental Status Areas}

Lack of Worry. She reports being concerned about her health, the welfare of friends, safety of her home and traffic in the streets. She is not conderned with having enough money, the kind of people in her neighborhood or walking alone at night in her neighborhood.

Housing. Mrs. Kemp's five-room home is owned outright. There is an adequate kitchen. The interviewer reports that the interior and furnishings are excellent.

Income. Mrs. Kemp's income is from social security benefits, union pension, and yearly property tax rebate. She saves money each month and never draws from her savings account. She feels that her level of living is better than most older persons she knows. She feels that she is better off now than she was ten years ago and 
about the same as she was one year ago.

RESPONSES AT TIME 2

All indicators are the same except

Medical Health Status. Interviewer reports that Mrs. Kemp has heart trouble and is hard of hearing.

RESPONSES AT TIME 3

All indicators are the same except

Medical Health Status. During the past year Mrs. Kemp was hospitalized for twelve days. She has cancer and heart trouble.

Lack of Impairment. She can now only get out with help. She no longer drives her car and relies on children and friends for transportation.

Social Contacts. Mrs. Kemp sees her children daily and friends, neighbors and relatives at least weekly. She is satisfied with her social contacts.

Activities. All activities are the same as at time I, however now she is driven by her child or a friend.

Housing. She is very satisfied with her housing.

\section{SUMMARY}

Mrs. Kemp's medical health status changed over the three year study from good health with no physical problems, to a diagnosis of cancer and heart trouble by the conclusion of the study. Initially she was not confined to her home however she became increasingly dependent upon children and friends to transport her. Her social supports are strong with friends, neighbors and children assisting her. She does not use social services. Her income is more than adequate with a savings to rely upon in case of need. Her home is in excellent condition. Her son provides assistance with repairs and other home maintenance.

Mrs. Kempp's overall status is very similar to those persons with stable high satisfaction. The exceptions are declining health and mobility. 
MIDDLE-HIGH LS GROUP - CASE NO. 10

Mrs. Levitt was 75 years old at the time of the first interview. She was raised by both parents in a small town in Germany, with her three siblings, all of whom are still living. Her father was a service worker. She has resided in oregon for the past twenty-six years. She completed two years of high school. She has worked as a household maid. She was married for twenty-two years and was widowed. She now has a male companion. She has five children and eleven grandchildren. She has lived in her present three-room row house for nine years.

Interviewer Comments. Mrs. Levitt has a number of activities but states that she particularly loves to dance and she does frequently at a Senior Citizens Center. She reads, watches television, crochets and cooks.

RESPONSES AT TIME 1

Personal Status Areas

Medical Health Status. Mrs. Levitt feels that her health is fair for her age. She has not been hospitalized during the past year but she did spend about one week in bed due to illness during the past year. She does not have a visiting nurse. She has periodic trouble with her legs and hip.

Lack of Impairment. She is able to get out alone and does not have any trouble with crossing the streets. She does not use a prosthesis, nor does she have physical therapy. She does not have meals programs or housework help.

Cognitive status. The interviewer reports that Mrs. Levitt was alert but seemed confused and slow at answering questions. She was interested moderately in the interview.

\section{Social Status Areas}

Social Contacts. Mrs. Levitt has five children and eleven grandchildren. One son is deceased. Two of her children live close to her. She sees children and neighbors at least weekly. She sees friends monthly and relatives about once a year. She talks regularly on the telephone.

Activities. She is not confined to her home and gets out regularly. She is driven in a car by her friend. She goes at least weekly to the grocery store and restaurant, monthly to the drugstore 
and post office and about every six months to a bank. It has been over a year since she has been to a church.

\section{Environmental Status Areas}

Lack of Worry. Mrs. Levitt reports being concerned about traffic and the security of her home as well as the welfare of her friends. She is not concerned about health, money or the kind of people in her neighborhood, nor is she concerned about walking alone in her neighborhood at night.

Housing. Her three-room row house has an adequate kitchen and is rated by the interviewer as good for the interior and excellent for furnishings.

Income. Mrs. Levitt's income is from social security benefits, interest on savings, veteran's pension, food stamps and renter's tax rebate. She has a savings account which she adds to each month but occasionally draws from. She feels that her level of living is about the same as other older persons she knows. She feels that her level of living is about the same now as it was both ten and one years ago.

RESPONSES AT TIME 2

\section{All indicators are the same except}

Medical Health Status. Mrs. Levitt had no days at home in bed due to illness.

RESPONSES AT TIME 3

\section{All indicators are the same except}

Social Contacts. Mrs. Levitt reports seeing neighbors and children daily. She participates in a Senior Center frequently. She is very satisfied with her social contacts.

Cognitive status. The interviewer reports that she is alert and interested in the interview and shows no signs of confusion.

Housing. Mrs. Levitt is very satisfied with her housing.

\section{SUMMARY}

Mrs. Levitt is in good health and able to carry out daily 
maintenance activities. She has strong social supports and is active socially. She participates in a number of senior Center activities. Her social supports are diverse, friends, neighbors and children are among her contacts. She has an adequate income with savings to rely upon. Her home is rated as good and she is very well satisfied with her living arrangements.

Mrs. Levitt resembles those persons with stable-high life satisfaction.

NEGATIVE CHANGE LIFE SATISFACTION GROUPS

HIGH-MIDDLE LS GROUP - CASE NO. 11

Mrs. Groves was 81 years old at the initial interview. She was born in Kansas but raised by both parents on timber land in central oregon. Her father was a farmer. She had two brothers neither of whom are still living. She was twice married. She and her second husband were married for twenty years and she has been widowed for seventeen years. She completed the seventh grade. She owned and operated a boarding house and then a small bakery. Mrs. Groves has five children and fourteen grandchildren. She has lived in her present four-room home for thirty three-years. She owns the home outright.

Interviewer Comments. Mrs. Groves is very cheerful and very positive although she appears to be very frail and in poor health.

RESPONSES AT TIME 1

Personal Status Areas

Medical Health Status. Mrs. Groves feels that her health is poor for her age. She spent four nights in the hospital during the past year but no days in bed at home due to illness. She does not have a visiting nurse. She is hard of hearing and is presently having radium treatments for cancer.

Lack of Impairment. Mrs. Groves is able to get out alone but cannot cross the street before the traffic light changes. She walks with a cane. She receives meals daily. She does not have physical therapy but receives housework help.

Cognitive status. The interviewer reports that she is very alert and shows no signs of confusion however she was not interested in the interview. 
Soclal Status Areas

Social Contacts. She sees children, neighbors, friends and others about once a week. She talks daily on her telephone. She has five children, one living close to her. She has fourteen grandchildren and two confidants.

Activities. Mrs. Groves only gets out of her house to walk to the mailbox about half a block away. She has not been to a grocery store, drugstore, bank, post office, church or restaurant for over a year. When she does go out it is in someone's car to her daughter's home.

Environmental Status Areas

Lack of Worry. Mrs. Groves reports that she is concerned about her health, security of her home and neighborhood and the welfare of her friends and neighbors. She is not concerned about having enough money, about traffic in the streets or walking alone at night.

Housing. Mrs. Groves owns her four-room home which has an adequate kitchen. The interviewer rates both the interior and furnishings as good.

Income. Mrs. Groves' income is from social security benefits, interest from savings and property tax refund. She has a small savings account which she does not have to use. However she is never able to save. She states that she just manages to get by. She feels that her level of living is about the same as other older persons she knows. She feels that she is better off now than she was ten years ago and about the same as she was one year ago.

RESPONSES AT TIME 2

All WBIs are the same except

Cognitive status. The interviewer rates her as very alert and very interested in the interview.

RESPONSES AT TIME 3

All indicators are the same except

Lack of Impairment. She is now completely confined to her home, leaving only when her daughter takes her. She receives daily meals but no longer has housework help because it is not avallable.

Social Contacts. She is very satisfied with her social contacts. 
Activities. She is completely confined to her home.

Housing. She is very satisfied with her housing.

\section{SUMMARY}

Mrs. Groves experienced a gradual health and mobility decline over the study period. Her daughter assists her with her needs and she has strong social supports from friends and neighbors. Her income is adequate and she has a small savings to fall back on.

\section{HIGH-MIDDLE LS GROUP - CASE NO. 12}

Mrs. Hughes was 87 years old at the time she was first interviewed. She was raised by both parents on a Kansas farm where her father raised livestock. She has two siblings; both are still living. She completed two years of college. Mrs. Hughes worked as a cloth cutter in a uniform company and was a union member. She was twice married. She was married to her second husband for twenty-seven years and has been widowed for twenty-six years. She has no children. She has lived in her five-room home for fifty-two years.

Interviewer Comments. Even though Mrs. Hughes is confined to her home she appears to be very active, keeping her home very clean, reading, watching television and doing handicrafts.

RESPONSES AT TIME 1

\section{Personal Status Areas}

Medical Health Status. Mrs. Hughes feels that her health is fair for her age. She has had no sick days during the past year in the hospital or at home. She does not have a visiting nurse. She has severe arthritis and it is very difficult for her to walk.

Lack of Impairment. Mrs. Hughes is confined to her home. She does not have a prosthesis and she does not have physical therapy. She does have housework help and meals service.

Cognitive status. The interviewer reports that Mrs. Hughes is very alert, not confused however is not particularly interested in the interview.

\section{Social Status Areas}

Social Contacts. Mrs. Hughes has no children. She has three 
confidants. She sees neighbors at least once a week and friends and relatives at least monthly. She sees other persons about every six months.

Activities. Although Mrs. Hughes cannot get out without help from a friend, she reports going to the grocery store about once a month, drugstore about every six months. It has been over a year since she has gone to the post office, bank, church or restaurant. Her friend provides transportation.

\section{Environmental Status Areas}

Lack of Worry. She reports that none of the items mentioned concern her. She does not worry.

Housing. Mrs. Hughes owns her five-room home outright. The interviewer reports that there is an adequate kitchen and that the interior and furnishings are in good condition.

Income. Mrs. Hughes' income is from social security benefits, property tax refund and interest from savings. She just manages to get by but never has to use her savings and she adds a little to it each month. She feels that her level of living is about the same as other older persons she knows and that she is as well off as she was ten and one years ago.

RESPONSES AT TIME 2

All indicators are the same.

RESPONSES AT TIME 3

All indicators are the same except

Medical Health Status. Mrs. Hughes spent fifty-seven nights in the hospital during the past year however she did not spend any time at home in bed because of illness. She now has visiting nurses. She feels that her health is good for her age.

Lack of Impairment. She is now completely confined to her home. She has physical therapy, housework help and meals programs.

Social Contacts. She is visited weekly by neighbors and friends and yearly by relatives. She talks on the phone daily to her neighbor, weekly to friends and during the year to relatives. She is satisfied with her social contacts but would like to see relatives more frequently. 
Activities. She now has special transportation provided in addition to being driven occasionally in the car of a friend. She has not been to a grocery store, drugstore, post office, bank or restaurant in over a year.

Housing. The interviewer rates the exterior, interior and furnishings as good to excellent but not very clean. Mrs. Hughes is not satisfied with her home because she feels that now it is too bigy for her.

Income. Mrs. Hughes is no longer able to save but she does not use her savings.

\section{SUMMARY}

Mrs. Hughes has had steadily declining health over the past two and one half years. At the third interview, she was completely confined to her home. She has no chilaren however her social supports from friends and neighbors are strong. She is completely dependent upon them to shop for her. She relies on social services to assist her with housekeeping and meals. Her housing is good although not at all satisfactory to her because her home is too large. Her income is adequate and she has a savings account to fall back on. She does not receive any supplemental federal income.

$$
\text { MIDDLE-LOW LS GROUP - CASE NO. } 13
$$

Mrs. Jacobs was 90 years old at the time of the first interview. She was raised by both parents in Chicago, Illinois, where her father was a steel worker. She has six siblings none of whom are still living. She completed the eight grade. During her working years she was a telephone operator. She was married for thirty-seven years and has been widowed for about thirty years. Hex husband owned and operated a garage. She has three children, two living close to her. She has a number of grandchildren. She has lived in her present oneroom apartment for six years and has been a resident of oregon for twenty-four years.

Interviewer Comments. Mrs. Jacobs is cheerful and very alert with an excellent memory. She is very frail and has difficulty getting around. Her activities are watching television, listening to the radio and reading as well as walking about her home. 
Personal Status Areas

Medical Health Status. Mrs. Jacobs feels that her health is good for her age. She spent nine days in the hospital during the past year and two days at home in bed due to illness. She does not have a visiting nurse. She does have severe arthritis.

Lack of Impairment. She can get out alone but is barely able to cross the street. She walks with a cane. She does not have physical therapy nor does she use meals programs or housework help.

Cognitive status. The interviewer reports Mrs. Jacobs to be very alert and cooperative. She has no confusion about remembering things.

\section{Social Status Areas}

Social Contacts. Mrs. Jacobs has three children and grandchildren. She has four confidants. She sees children, friends, neighbors and business persons weekly. She has access to her neighbor's phone and uses it regularly.

Activities. When she does get out she is usually driven by her son. She has been to a grocery store, drugstore, bank and post office during the past six months. She goes weekly to church but has not been in a restaurant for over a year.

\section{Environmental status Areas}

Lack of Worry. She is concerned about having enough money, about walking alone in her neighborhood and about the welfare of her friends. She is not concerned about her health, security of her home, the kind of people in her neighborhood and the amount of traffic in the streets.

Housing. Mrs. Jacobs lives in a one-room apartment with kitchen facilities. The interviewer rates the interior and furnishings as being in good condition but comments that the building is very old.

Income. Mrs. Jacobs receives social security benefits, SSI, food stamps and renter's tax rebate. She is able to save a little each month and does not use her savings. She believes her level of living is about the same as other old people she knows. She feels that she is better off now than she was ten and one years ago.

RESPONSES AT TIME 2

All indicators are the same except 
Medical Health Status. Mrs. Jacobs spent no sick days in the hospital or at home during the past year.

Lack of Impairment. She can now get out of her house only with help. Her neighbor cooks her evening meal and cleans house for her.

\section{RESPONSES AT TIME 3}

All indicators are the same except

Medical Health Status. Mrs. Jacobs spent twelve nights in the hospital during the past year.

Lack of Impairment. Mrs. Jacobs has moved to a home where all housekeeping chores are done for her, as well as meals prepared for her.

Social Contacts. She talks on the phone to children and friends weekly and sees them monthly. She is satisfied with this arrangement. She has no living relatives other than her children.

Activities. She is totally confined to home, getting out only monthly when her son takes her to church.

Housing. Mrs. Jacobs has recently moved into a home shared with five other women. Both the furniture, interior and exterior of the dwelling are rated as good by the interviewer. Mrs. Jacobs is satisfied with her housing.

Income. All money matters are now handled for her by her son.

\section{SUMMARY}

Mrs. Jacobs has experienced gradual decline of health, mobility, social contacts and activities of daily living during the course of the study. It is noteworthy that she was one of the oldest subjects in the study. During the last year of the study, she moved into a boarding home where she was completely cared for. She sees her children regularly.

MIDDLE-LOW IS GROUP - CASE NO. 14

Mr. Irving was 80 years old at the time of the first interview. He was born in a small town in Missouri where he was raised by his older, married sisters. He had eight siblings and he does not know if any are still living. He was never married and has no children. He completed 
the fourth grade and spent his working years as a coal miner, lumberjack and railroad fireman. He belonged to a union. He has been an oregon resident for fifty-one years and has been living in one room with only minimum kitchen facilities for four years. The room is located in an old hotel with no elevator.

Interviewer Comments. Mr. Irving seemed angry and hostile stating that he did not like "young punks". The second and third interviewers did not find him to be angry or hostile. He does not have a radio or television and spends most of his time in bed. His activities consist of walking, resting and reading. He is very frail. He has few friends and relies on the hotel manager when he needs assistance. He does not like his housing at all and wants to move into a nursing home or boarding home. His housing arrangement is particularly bad.

\section{RESPONSES AT TIME 1}

\section{Personal Status Areas}

Medical Health Status. Mr. Irving feels that his health is poor for his age. He has not been hospitalized during the past year. He states that he spends most of his time in bed. He has no observable physical disabilities. He does not have a visiting nurse.

Lack of Impairment. He is able to get out alone and is barely able to cross the street. He does not use a prosthesis nor has he had physical therapy. He has had housework help but he does not have meals programs.

Cognitive status. The interviewer reports that he is very alert, not confused but antagonistic.

\section{Social Status Areas}

Social Contacts. Mr. Irving has no children, was never married and lost contact with family years ago. He reports having no confidants. He has spoken to friends and neighbors during the past week and no one else for over a year.

Activities. Mr. Irving does get out alone and usually walks although occasionally he takes a taxi. He has been to a grocery store, post office and restaurant during the past week and to a drugstore during the past month. It has been more than a year since he has gone to a bank or church.

\section{Environmental Status Areas}

Lack of Worry. He states that he is concerned about his health, 
security of his home, traffic in the streets and walking alone in his neighborhood. He is not concerned about having enough money, the kinds of people living in his building or neighborhood or his friends and neighbors.

Housing. Mr. Irving lives in one room with kitchen appliances. The interviewer describes both the furnishings and interior as dilapidated with holes in the floor, wall and ceiling.

Income. Mr. Irving receives benefits from social security, SSI, welfare and food stamps as well as renter's rebate yearly. He has a small savings account which he never uses. He is not able to save and barely manages to get by. He feels taht his level of living is better than most older persons he knows. He feels that he is worse off now than he was ten years ago and about the same as he was one year ago.

\section{RESPONSES AT TIME 2}

All indicators the same except

Iack of Impairment. Mr. Irving uses a cane to assist with walking. He has meals delivered to his home twice a week.

Housing. The interviewer rated his housing as very poor. However he now has an elevator.

RESPONSES AT TIME 3

All indicators are the same except

Lack of Impairment. In addition to delivered meals, he now has housework help.

Social Contacts. He relies on his new landlord for help. He never hears from his family but sees friends weekly. He does not have a phone. He goes weekly to a Senior Citizen's Center. He is dissatisfied with his social contacts.

Housing. Mr. Irving has moved to a new rooming house. He now has two rooms which the interviewer rates as being in poor condition. Mr. Irving is not satisfied with his living arrangements.

\section{SUMMARY}

Mr. Irving experienced gradual decline in health, mobility, and increased confinement to home. He has limited social contacts, relying 
on his landlord to help him if necessary. He has increased his use of social services, relying upon them more frequently for meals, housekeeping and transportation. His housing was described as dilapidated during interview one, and poor when he moved to an apartment with more space. Mr. Irving, when compared with the rest of the sample, certainly is more isolated, lives in worse conditions, and has less financial resources. 